\title{
基于电化学方法构建碳一氮键的最新研究进展
}

\author{
蒙泽银 $a$ 冯承涛 $*, a$ 徐 坤 $*, b$ \\ ( ${ }^{a}$ 安徽理工大学化学工程学院 工业粉尘防控与职业安全健康教育部重点实验室 安徽淮南 232001) \\ ( ${ }^{b}$ 北京工业大学环境与生命学部 北京 100124)
}

\begin{abstract}
摘要 $\mathrm{C}-\mathrm{N}$ 键广泛存在于药物、天然产物以及功能材料中, 它的构建是有机合成化学的重要研究方向之一. 近年来, 随着有机电化学的深入发展, 以有机电化学作为绿色合成手段, 高效地构建 $\mathrm{C}-\mathrm{N}$ 键受到了合成化学家的广泛关注. 综 述了从 2015 年至今有机电化学在构建 $\mathrm{C}-\mathrm{N}$ 键领域所取得的研究进展, 对反应的条件和机理进行了总结, 并对该领域 所面临的挑战及发展方向进行了展望与探讨, 希望能对从事该领域研究的学者以及相关人员提供参考.
\end{abstract}

关键词 有机电化学; $\mathrm{C}-\mathrm{N}$ 键; 绿色化学

\section{Recent Advances in the Electrochemical Formation of Carbon-Nitrogen Bonds}

\author{
Meng, Zeyin ${ }^{a} \quad$ Feng, Chengtao ${ }^{*, a} \quad \mathrm{Xu}, \mathrm{Kun}^{*, b}$ \\ ( ${ }^{a}$ Key Laboratory of Industrial Dust Control and Occupational Health, Ministry of Education, School of Chemical \\ Engineering, Anhui University of Science and Technology, Huainan, Anhui 232001) \\ ( ${ }^{b}$ Faculty of Environment and Life, Beijing University of Technology, Beijing 100124)
}

\begin{abstract}
C}-\mathrm{N}$ bonds are widely existed in drugs, natural products, and functional materials. Thus, the construction of $\mathrm{C}-$ $\mathrm{N}$ bonds is one of the most important research areas in academia and industry. Recently, the renaissance in organic electrochemistry has promoted the electrochemical $\mathrm{C}-\mathrm{N}$ bond formations to be a special branch of organic synthesis. The most recent advances in the electrochemical $\mathrm{C}-\mathrm{N}$ bond formations since 2015 are summarized. The reaction mechanisms of these transformations are discussed, and the challenges and future directions of this important filed are included. We hope that this review can give references to the researchers, graduate students and other related people.

Keywords organic electrochemistry; carbon-nitrogen bond; green chemistry
\end{abstract}

$\mathrm{C}-\mathrm{N}$ 键作为一类重要的化学键广泛地存在于自然 界中，例如氨基酸、脱氧核糖核酸(DNA)碱基以及生物 碱中都含有 $\mathrm{C}-\mathrm{N}$ 键 ${ }^{[1]}$. 此外, $\mathrm{C}-\mathrm{N}$ 键也广泛分布于医 药和农药活性分子中. 在 2019 年食品药品监督管理局 (FDA)批准的新药中, 超过 $50 \%$ 的小分子药物中都含有 $\mathrm{C}-\mathrm{N}$ 键结构单元 ${ }^{[2]}$. 伯胺和仲胺结构单元可以作为氢 键受体或氢键供体, 与药物作用靶点形成氢键相互作 用, 进而有助于提高生物活性 ${ }^{[3]}$. 在材料科学中, $\mathrm{C}-\mathrm{N}$ 键结构单元也扮演着重要的角色. 含氮结构单元的引入 不仅可以增强分子间的相互作用, 也会影响最最高占据 分子轨道(HOMO) 和最低未占分子轨道( LUMO)的能极
差, 从而改变材料的理化性质 ${ }^{[4]}$. 鉴于 $\mathrm{C}-\mathrm{N}$ 键的重要 用途, $\mathrm{C}-\mathrm{N}$ 键的构建是有机合成化学的重要研究方向 之一. 除了传统的醛酮的还原胺化反应, 卤代烃与胺 (氨)之间的亲核胺化反应以外, 近些年发展起来的偶联 反应也是构建 $\mathrm{C}-\mathrm{N}$ 键的重要方法之一 ${ }^{[5]}$. 目前, 已有 大量优秀的文献综述对 $\mathrm{C}-\mathrm{N}$ 键的合成进行了归纳和总 结, 供感兴趣的读者参考学习 ${ }^{[6]}$. 虽然 $\mathrm{C}-\mathrm{N}$ 键的合成 已取得了巨大的进展，但是发展更加绿色和可持续的 $\mathrm{C}-\mathrm{N}$ 键合成方法学依然是有机科研工作者的重要任务 之一[]].

有机电化学合成直接利用洁净的电子作为氧化还

\footnotetext{
* Corresponding authors. E-mail: fengct@mail.ustc.edu.cn; kunxu@bjut.edu.cn

Received December 6, 2020; revised February 23, 2021; published online March 4, 2021.

Project supported by the Anhui Provincial Natural Science Foundation (No. 2008085MB50), the Beijing Education Committee Project (No. KM 202110005006) and the Graduate Innovation Foundation of Anhui University of Science and Technology (No. 2019CX2057).

安徽省自然科学基金(No. 2008085MB50)、北京市教委科研目(No. KM202110005006)、安徽理工大学研究生创新基金(No. 2019CX2057)资助项目.
} 
原试剂, 通过有机分子的直接电解(direct electrolysis)或 者经由催化媒介的间接电解(indirect electrolysis), 实现 有机分子的活化, 并经过后续的串联过程最终实现有机 分子的官能团化反应 ${ }^{[8]}$. 相对于传统的有机合成方法学, 有机电化学合成是通过反应物的直接电子得失实现氧 化还原过程, 可以避免化学氧化还原试剂的使用, 不但 减少了物质消耗, 还可大大降低环境污染; 电解反应中, 活性物种的生成数量与通入的电量成正比, 因此电解过 程中活性物种的生成是一个缓慢可控的过程, 有利于提 高反应的选择性，降低反应的副反应发生的几率[9]. 因 此, 有机电化学合成目前被公认为是一种绿色、高效的 有机合成方法 ${ }^{[10]}$. 鉴于 $\mathrm{C}-\mathrm{N}$ 键的重要用途以及电化学 有机合成的独特优势, 近年来利用电化学方法构建 $\mathrm{C}$ $\mathrm{N}$ 键逐渐成为有机合成的热点研究领域之一 ${ }^{[1]}$. 本文综 述了 2015 年至今有机电化学方法在 C-N 键的形成方 面所取得的代表性研究成果, 并对反应的特点和机理进 行了系统的总结和分析. 根据 $\mathrm{C}-\mathrm{N}$ 键的成键类型, 该 部分包括以下三个主要部分: $\mathrm{C}\left(\mathrm{sp}^{3}\right)-\mathrm{N}$ 键偶联反应、 $\mathrm{C}\left(\mathrm{sp}^{2}\right)$ - $\mathrm{N}$ 键偶联反应以及 $\mathrm{C}(\mathrm{sp})-\mathrm{N}$ 键偶联反应, 每部 分再根据分子内反应和分子间反应进行细分. 最后, 对 该领域面临的挑战及发展方向进行了展望与探讨.

\section{$1 \mathrm{C}\left(\mathrm{sp}^{3}\right)$ - $\mathrm{N}$ 键偶联反应}

\section{1 分子内 $\mathrm{C}\left(\mathrm{sp}^{3}\right)-\mathrm{N}$ 键偶联反应}

2017 年, 汪志勇课题组 ${ }^{[12]}$ 报道了一种基于间接电 氧化策略合成靛红的新方法 (Scheme 1). 该反应以 ${ }^{n} \mathrm{Bu}_{4} \mathrm{NI}$ 为电解质, $\mathrm{Pt}$ 片作为电极, 在单室电解池中以恒 电流模式电解, 邻氨基苯乙酮 1-1 发生分子内的氧化偶 联反应得到目标产物靛红 1-2. 该方法具有较好的底物 适应性，氮原子上含有烷基或芳基取代都可以用作反应 底物, 以较好的产率生成目标产物; 但是, 当 1-1 中的 氨基为芳伯胺基或形成酰胺后, 则不能得到目标产物.

基于电子顺磁共振(EPR)实验结果, 作者提出了经 由自由基过程的反应机理. 首先, 碘负离子发生阳极氧 化生成碘自由基, 随后㩲取底物 1-1 中的氢原子生成 C自由基中间体 1-3, 同时产生一分子的 HI. 接着, C-自由 基中间体被氧分子捕获形成中间体 1-4. 然后, 中间体 1-4 脱去羟基自由基生成相应的醛中间体 1-5. 中间体 1-5 中的胺基对醛基发生分子内亲核加成得到中间体 1-6. 最后, 中间体 1-6 经过进一步氧化得到目标产物靛 红 1-2.

2018 年, Muñiz 课题组 ${ }^{[13]}$ 利用阳极氧化脱氢偶联策 略, 开发了一种分子内苄基 $\mathrm{C}\left(\mathrm{sp}^{3}\right)-\mathrm{H}$ 键的胺化新方法 (Scheme 2). 该反应在室温条件下, 以四丁基四氟硼酸 铵 $\left(\mathrm{Bu}_{4} \mathrm{NBF}_{4}\right)$ 作为电解质, 六氟异丙醇(HFIP)为溶剂, 石

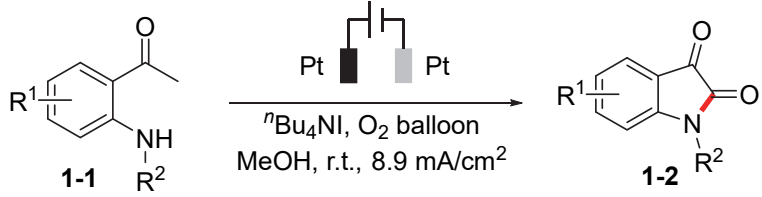

$$
\mathrm{R}^{1}=\mathrm{Br}, \mathrm{I}, \mathrm{Ph} \text {, alkynyl }
$$$$
\mathrm{R}^{2}=\text { alkyl, aryl }
$$

Anode:

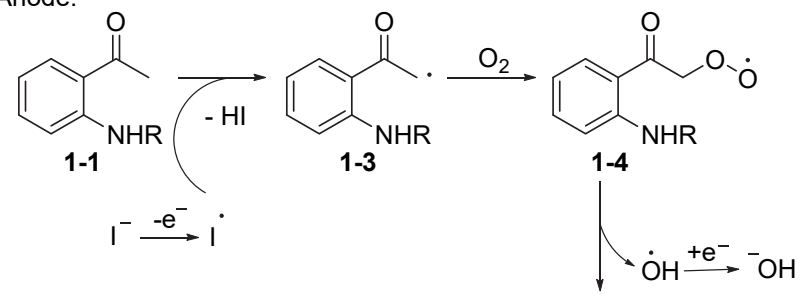<smiles>[R]Nc1ccc(C)cc1C(=O)C=O</smiles>

Cathode: $2 \mathrm{MeOH}+2 \mathrm{e}$

$2 \mathrm{MeO}^{-}+\mathrm{H}_{2}$

图式 12 -氨基苯乙酮的电化学分子内氧化环化反应 Scheme 1 Electrochemically oxidative intramolecular cyclization of 2'-amino-acetophenones

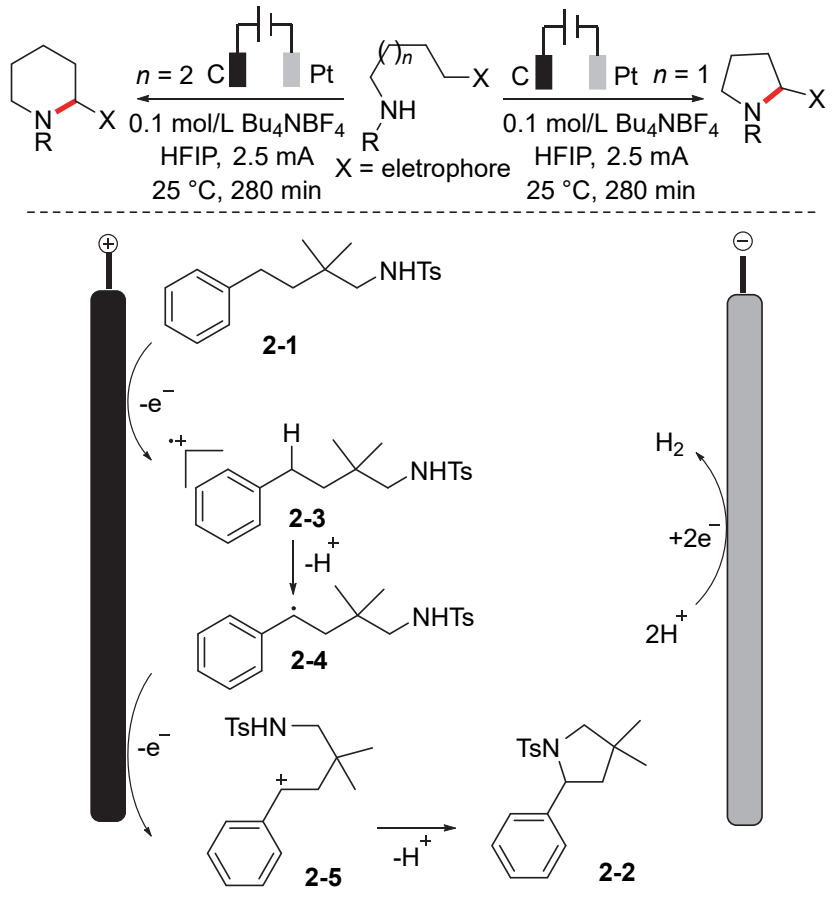

图式 2 电化学苄基 $\mathrm{C}\left(\mathrm{sp}^{3}\right)-\mathrm{H}$ 胺化反应

Scheme 2 Electrochemical benzylic $\mathrm{C}\left(\mathrm{sp}^{3}\right)-\mathrm{H}$ amination

墨棒为阳极, Pt 片电极为阴极, 在单室电解池中以恒电 流模式电解，得到一系列 2-位芳基取代的吡咯烷和哌啶 化合物。与传统的先产生 $\mathrm{N}$-自由基，再通过 1,5-或 1,6氢迁移产生 C-自由基而完成对 $\mathrm{C}-\mathrm{H}$ 键的活化不同，作 者认为他们的开发的方法不涉及 $\mathrm{N}$-自由基，而是首先 
在阳极发生一个单电子转移(SET)过程, 形成芳香自由 基阳离子 2-3. 由于芳基自由基阳离子的关系, 芐基氢 的酸性显著提高了几个数量级. 因此, 2-3 很容易脱质子 转化为苄基自由基 2-4. 自由基 2-4 再发生一次 SET 过 程, 生成亲电的苄基阳离子 2-5. 随后, 阳离子 2-5 被分 子内具有亲核性的氮原子捕获, 关环得到目标产物 2-2.

同年, 雷爱文课题组 ${ }^{[14]}$ 开发了一种电化学氧化类 型的 Hofmann-Löffler-Freytag (HLF)反应(Scheme 3). 该 反应在氮气氛围中, 以四丁基醋酸铵 $\left({ }^{n} \mathrm{Bu}_{4} \mathrm{NOAc}\right)$ 为电 解质, 1,2-二氯乙烷(DCE) 和 HFIP 作为混合溶剂, 碳棒 电极为阳极, Pt 电极为阴极, 在单室电解池中以恒电流 模式电解, 实现了分子内的远程惰性 $\mathrm{C}\left(\mathrm{sp}^{3}\right)-\mathrm{H}$ 键的胺 化反应. 该方法一方面可以避免金属催化剂、卤化试剂 和化学计量的氧化剂的使用; 另一方面, 该方法学还具 有较好的底物适应性, 能兼容伯、仲、叔碳上的 $\left(\mathrm{sp}^{3}\right)$ $\mathrm{H}$ 键，进而可获得多种功能化的含氮杂环化合物.

基于循环伏安实验和动力学同位素效应实验等实 验结果, 作者提出了一个可能的电化学氧化诱导的分子 内 $\mathrm{C}\left(\mathrm{sp}^{3}\right)-\mathrm{H}$ 胺化反应的反应机理. 首先底物胺 3-1 与 乙酸根负离子之间形成复合物 3-3; 接着发生阳极上的 单电子氧化生成 N-自由基中间体 3-4 (Path 1); 随后, 发 生 1,5-氢原子迁移过程, 由 $\mathrm{N}$-自由基㩲取 $\delta-\mathrm{C}-\mathrm{H}$ 键的 氢原子, 形成 C-自由基 3-5; C-自由基中间体 3-5 发生进 一步的阳极氧化, 得到碳正离子中间体 3-6; 亲核性的 氮原子对碳正离子发生分子内亲核进攻, 再消除一个质 子形成环化产物 3-2. 同时, 在反应过程中生成的质子 在阴极还原产生 $\mathrm{H}_{2}$. 此外, HFIP 可以在阴极上析氢并产 生烷氧负离子, 烷氧负离子作为碱使底物脱质子得到 $\mathrm{N}$-负离子中间体 3-7, 其可以在阳极上迅速氧化, 得到 $\mathrm{N}$-自由基中间体 3-4 (Path 2), 其后经历与 Path 1 相同的 路径得到目标产物 3-2.

最近, 徐坤课题组 ${ }^{[15]}$ 也报道了一例基于电化学氧 化脱氢偶联策略, 通过分子内 $\mathrm{C}\left(\mathrm{sp}^{3}\right)-\mathrm{H}$ 的胺化反应合 成反式-2,3-二取代氮杂环丙烷的新方法(Scheme 4). 该 反应在室温下, 以催化量的 $\mathrm{KI}$ 作为电解质, Pt 片为阴阳 极, $\mathrm{THF} / \mathrm{MeOH}$ 的混合液为溶剂, 在单室电解池中以恒 电流模式电解, 碳酸酯基保护的 $\beta$-氨基酮发生分子内的 氧化脱氢偶联反应生成氮杂环丙烷. 该方法具有较好的 原子经济性, 较好的立体选择性, 避免了过渡金属催化 剂、氧化剂和添加剂的使用, 因此是一种绿色、高效的 合成反式-2,3-二取代氮杂环丙烷的新方法.

控制实验表明该反应经历的是离子过程的反应机 理. 首先, 碘负离子在阳极被氧化成高价碘物种. 随后, 高价碘物种对底物 4-1 进行碘代生成 N-碘中间体 4-3. 阴极上产生甲氧基负离子夺取中间体 4-3 中酮 $\alpha$-位质子
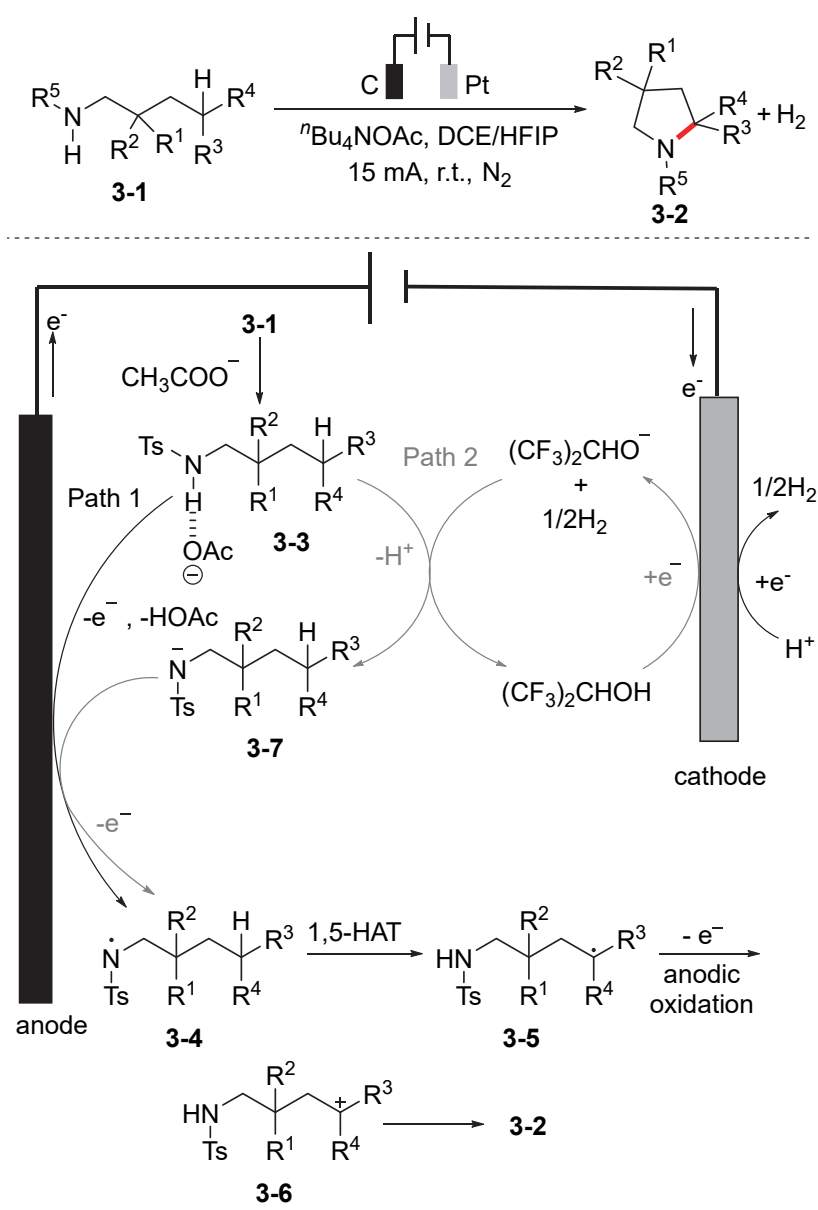

图式 3 电氧化诱导的分子内 $\mathrm{C}\left(\mathrm{sp}^{3}\right)-\mathrm{H}$ 胺化反应 Scheme 3 Electrochemically induced oxidative intramolecular $\mathrm{C}\left(\mathrm{sp}^{3}\right)-\mathrm{H}$ amination
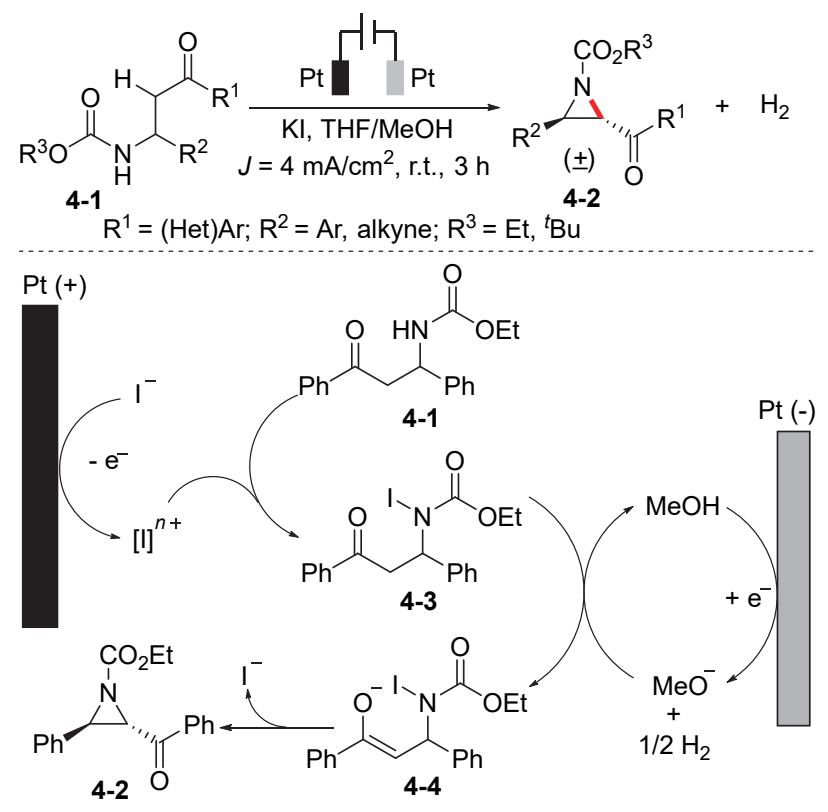

图式 4 电化学合成反式-2,3-二取代氮杂环丙烷

Scheme 4 Electrochemical synthesis of trans-2,3-disubstituted aziridines 
得到中间体 4-4. 最后，中间体 4-4 发生分子内亲核取代 反应生成目标产物氮杂环丙烷 4-2 和离去一个碘负离 子. 在阴极上, $\mathrm{MeOH}$ 被还原得到甲氧基负离子, 并析 出 $\mathrm{H}_{2}$.

\section{2 分子间 $\mathrm{C}\left(\mathrm{sp}^{3}\right)-\mathrm{N}$ 键偶联反应}

2015 年, 汪志勇课题组 ${ }^{[16]}$ 报道了一种阳极氧化合 成 $\beta$-烯胺酮的方法 (Scheme 5). 该反应在室温下, $\mathrm{O}_{2}$ 氛 围中, 以 $\mathrm{KI}$ 作为电解质, $\mathrm{Pt}$ 电极作为阴阳极, 三氟乙醇 (TFE) 作为添加剂, $\mathrm{MeOH}$ 为溶剂, 在单室电解池中以恒 电流模式电解, 硝基甲烷、甲基酮和仲胺三组分反应得 的 $\beta$-烯胺酩. 该反应的创新点是以硝基甲烷作为碳源, 为反式 $\beta$-烯胺酮的绿色合成提供了一种直接、高效的合 成方法学.

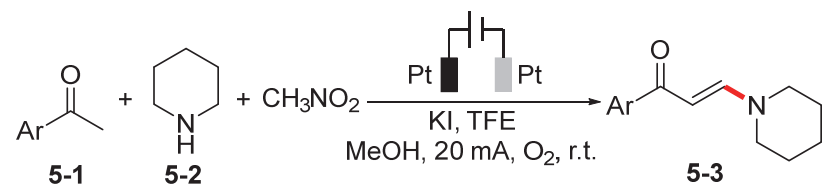<smiles>CC(=O)c1ccccc1</smiles>

5-1 5-4 5-5<smiles>O=C(C=[N+]1CCCCC1)c1ccccc1</smiles>

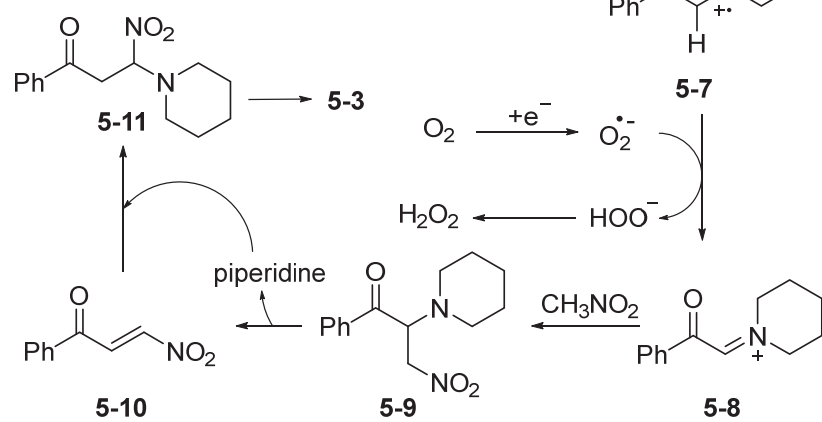

图式 5 电化学合成 $\beta$-烯胺酮

Scheme 5 Electrochemical synthesis of $\beta$-enaminones

根据控制实验和前期文献，作者提出了可能的反应 机理. 首先, 阳极产生的碘自由基篗取苯乙酮 5-1 中 $\alpha$ 碳上的氢原子产生 C-自由基 5-4, 伴随着释放一分子 $\mathrm{HI}$. $\mathrm{C}$-自由基和碘自由基进行自由基偶联生成 $\alpha$-碘代苯乙 酮 5-5. 接着, 哌啶与 $\alpha$-碘代苯乙酮发生亲核取代反应 得到 $\alpha$-胺基酮 5-6, 再经历阳极氧化后产生自由基阳离 子中间体 5-7. 同时, $\mathrm{O}_{2}$ 的电化学还原产生超氧自由基 阴离子, 然后再从中间体 5-7 中拔去一个质子生成亚胺 离子中间体 5-8. 硝基甲烷与中间体 5-8 发生亲核加成反 应生成中间体 5-9, 再消除一分子哌啶后得到硝基烯烃 5-10. 最后, 将哌啶与硝基烯烃发生 1,4-加成得到中间
体 5-11，该中间体随后经历 $\beta-\mathrm{H}$ 消除产生最终产物反式 $\beta$-烯胺酮 5-3.

2016 年, 汪志勇课题组 ${ }^{[17]}$ 在其电化学三组分反应 制备 $\beta$-烯胺酮的基础上，将硝基甲烷换成硝基乙酸乙 酯，开发了一种电化学三组分反应制备 $\alpha$-烯胺酮的新方 法(Scheme 6). 该反应在室温下, 以 $\mathrm{KI}$ 为电解质, $\mathrm{EtOH}$ 为溶剂, $\mathrm{Pt}$ 电极作为阴极和阳极, 在单室电解池中以恒 电流模式电解，硝基乙酸乙酯、甲基芳基酮和仲胺发生 三组分串联得到含硝基和酯基取代的 $\alpha$-烯胺酮. 该制备 $\alpha$-烯胺酮的方法对于五元或六元环状仲胺有较好的反 应效果，而以伯胺或者开链的仲胺为底物时则不能得到 目标产物.

机理研究表明，该反应可能经历了自由基反应历 程， $\alpha$-碘代苯乙酮和 $\alpha$-氨基苯乙酮是关键中间体. 该反 应和制备 $\beta$-烯胺䣶的反应有相似的反应历程，依次形成 C-自由基 6-5、 $\alpha$-碘代苯乙酮 6-6、 $\alpha$-氨基酮中间体 6-7 和亲电的亚胺阳离子中间体 6-8. 在碱性条件下，硝基 乙酸乙酯进攻缺电子的亚胺中间体 6-8, 生成中间体 6-9. 随后，中间体 6-9 被氧化成亚胺阳离子 6-10, 接着 失去一个质子后形成目标产物 $\alpha$-烯胺酮 6-4. 同时, $\mathrm{EtOH}$ 在阴极上被还原为乙氧基负离子，并伴随 $\mathrm{H}_{2}$ 的释 放.

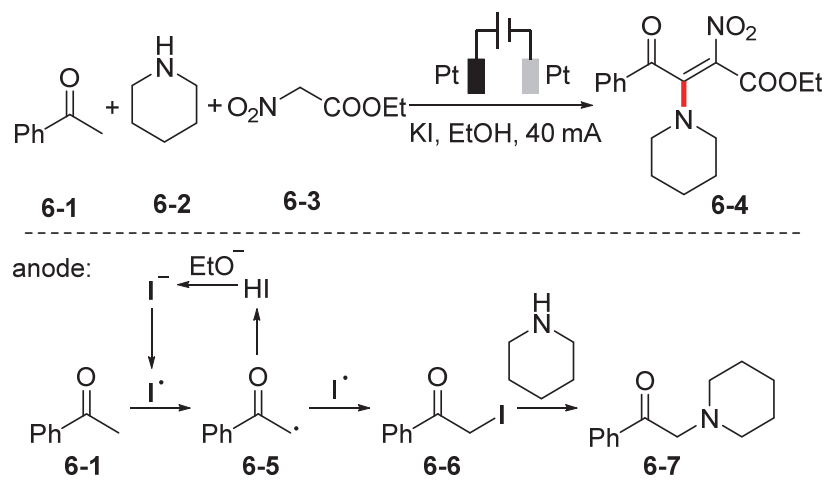<smiles>CCOC(=O)CO[N+](=O)C(=O)C(=O)C(C(=O)N1CCCCC1)N1CCCCC1</smiles><smiles>CCOC(=O)C(C(=O)OCC)=C(C(=O)[PH+]C[PH3+])C(=O)N1CCCCC1</smiles>

cathode: $2 \mathrm{EtOH}+2 \mathrm{e}^{-} \longrightarrow 2 \mathrm{EtO}^{-}+\mathrm{H}_{2}$

图式 6 电化学合成 $\alpha$-甲烯胺酮

Scheme 6 Electrochemical synthesis of $\alpha$-enaminones

基于分子间 $\mathrm{C}\left(\mathrm{sp}^{3}\right)-\mathrm{H} / \mathrm{N}-\mathrm{H}$ 的氧化脱氢偶联策略, 
2017 年, 雷爱文课题组 ${ }^{[18]}$ 报道了一种电化学氧化条件 下 $\mathrm{C}\left(\mathrm{sp}^{3}\right)-\mathrm{H}$ 杂环化的高效方法(Scheme 7). 该反应在 氮气氛围中, 以 $\mathrm{Pt}$ 片作为阳、阴极, ${ }^{n} \mathrm{Bu}_{4} \mathrm{NBF}_{4}$ 为电解质, $\mathrm{MeCN}$ 为溶剂, 在单室电解池中以恒电流模式电解, 与 氧、氮、硫等杂原子相邻的 $\mathrm{C}\left(\mathrm{sp}^{3}\right)-\mathrm{H}$ 类化合物 7-2 都 能与唑类杂环 7-1 反应生成相应的 $\mathrm{C}-\mathrm{N}$ 键偶联产物 7-3. 循环伏安实验表明, 在标准反应条件下只有唑可 以被氧化. 自由基抑制剂四甲基哌啶氧化物(TEMPO)的 加入能抑制反应的进行; 当自由基抑制剂 2,6-二叔丁 基-4-甲基苯酚(BHT)加入到反应体系, 能以 76\%的收率 分离出 BHT 与底物苯并三氮唑的加成物, 表明该反应 涉及自由基的反应历程. 动力学同位素效应实验表明 $\mathrm{C}\left(\mathrm{sp}^{3}\right)-\mathrm{H}$ 键的断裂不是反应的决速步骤.

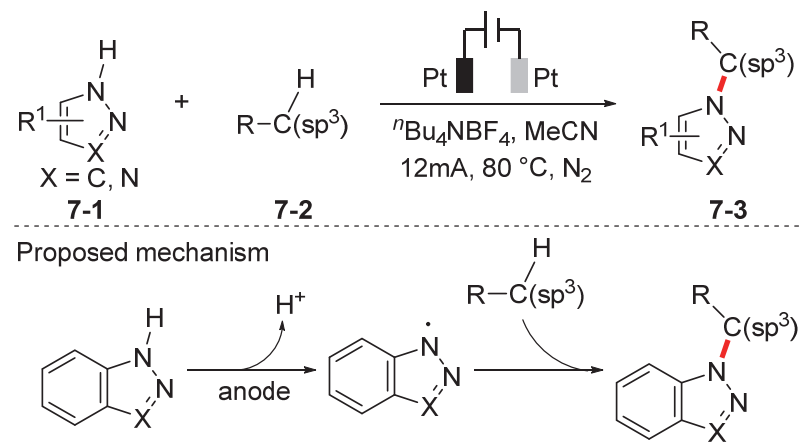

图式 7 电化学氧化条件下 $\mathrm{C}\left(\mathrm{sp}^{3}\right)-\mathrm{H}$ 与唑类化合物的胺化反 应

Scheme 7 Electro-oxidative $\mathrm{C}\left(\mathrm{sp}^{3}\right)-\mathrm{H}$ amination with azoles

基于上述电化学氧化诱导的脱氢交叉偶联策略, 2020 年, 雷爱文课题组 ${ }^{[19]}$ 将 $\mathrm{C}\left(\mathrm{sp}^{3}\right)-\mathrm{H}$ 化合物拓展到了 内酰胺 (Scheme 8). 该反应以碳布作为阳极, Pt 片作为阴 极, ${ }^{n} \mathrm{Bu}_{4} \mathrm{NBF}_{4}$ 作为电解质, $\mathrm{MeCN}$ 作为溶剂, 在单室电解 池中恒电流模式电解. 实验结果发现, 含 $\mathrm{N}-\mathrm{H}$ 键的唑 类化合物 8-1 可与内酰胺/酰胺 8-2 较好地进行脱氢偶联 反应. EPR 实验进一步证明了唑类底物在电解过程中可 以被氧化成 $\mathrm{N}$-自由基. 根据机理实验和已有文献报道, 作者提出了一种可能的反应机理. 首先, 具有较低氧化 电位的唑类底物 8-1 在阳极被氧化, 然后脱去氢离子生 成 $\mathrm{N}$-自由基 8-4. 紧接着, $\mathrm{N}$-自由基 8-4 和 1-甲基-2-吡咯 烷酮 8-2 进行分子间的氢转移生成 C-自由基 8-5 和底物 8-1. 随后, C-自由基 8-5 在阳极上被氧化生成亚胺阳离 子 8-6. 最后, 底物 8-1 再与 8-6 发生亲核加成反应生成 产物 8-3. 同时, 氢正离子在阴极被还原产生 $\mathrm{H}_{2}$.

2018 年, 曾程初课题组 ${ }^{200}$ 报道氧杂葱可与 $O$-烷基 异羟肜酸酯发生分子间电化学 $\mathrm{C}\left(\mathrm{sp}^{3}\right)-\mathrm{H} / \mathrm{N}-\mathrm{H}$ 交叉脱 氢偶联(Scheme 9). 该反应以二茂铁为催化剂, $\mathrm{Na}_{2} \mathrm{CO}_{3}$ 为添加剂, $\mathrm{LiClO}_{4}$ 为电解质, $\mathrm{MeCN} / \mathrm{CH}_{2} \mathrm{Cl}_{2}$ 为溶剂, 碳棒

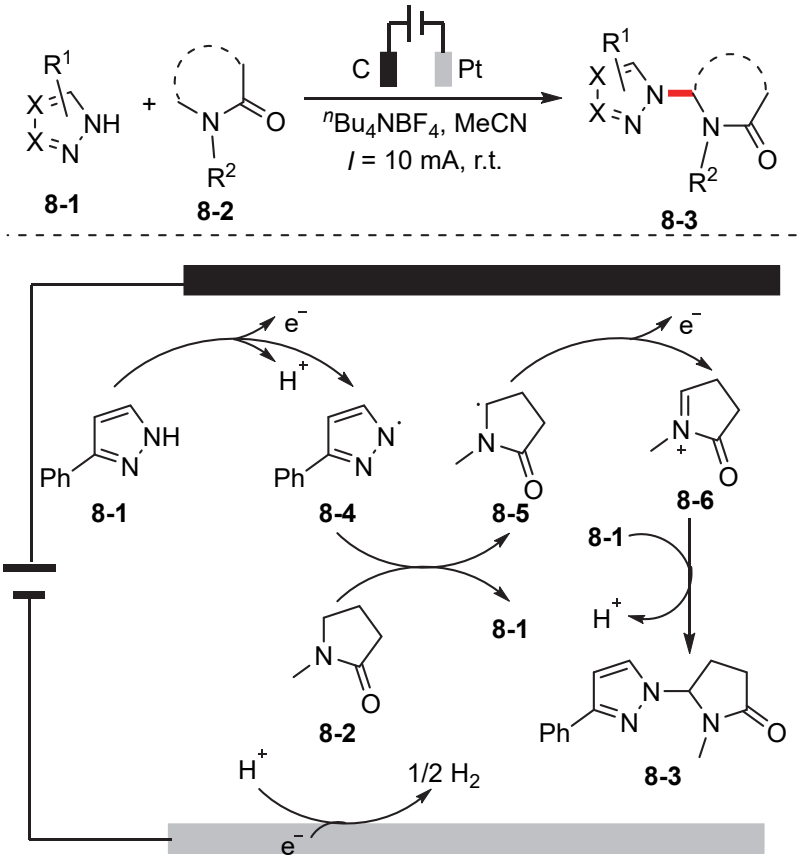

图式 8 内酰胺与唑的电化学脱氢偶联反应

Scheme 8 Electrochemical oxidative azolation of lactams

为阴阳极, 在单室电解池中以恒电流模式电解, 各种取 代的 $O$-烷基异羟弜酸酯与氧杂葱能以中等到好的产率 给出 $\mathrm{C}-\mathrm{N}$ 键偶联的产物. 然而, 在标准反应条件下, 异色烷、9,10-二氢葱、二苯甲烷和 1,2-亚甲基二氧苯不 能给出相应的目标产物. 此外, 澳化铵也可以作为催化 剂, 以 $51 \%$ 的产率得到 $\mathrm{C}-\mathrm{N}$ 键偶联的目标产物.

通过自由基抑制试验和循环伏安实验，作者提出了 基于自由基的反应机理. 首先, $\mathrm{Fc}(\mathrm{II})$ 在阳极被氧化为 $\mathrm{Fc}(\mathrm{III})$, 碱夺取 $O$-烷基异羟肟酸酯 9-1 氮上的质子生成 相应的氮负离子 9-4; 接着, $\mathrm{Fc}(\mathrm{III})$ 与 $O$-烷基异羟肟酸酯 氮负离子 9-4 发生单电子转移, 生成 $O$-烷基异羟肜酸酯 $\mathrm{N}$-自由基中间体 9-5 和 $\mathrm{Fc}(\mathrm{II})$, 从而完成 $\mathrm{Fc}$ 的催化循环; $\mathrm{N}$-自由基中间体 9-5 篗取氧杂葱中的一个苠基氢原子, 得到氧杂葱 C-自由基 9-6; 随后, C-自由基中间体 9-6 被 氧化失去一个电子生成碳正离子中间体 9-7; 最后, 亲 核性的 $O$-烷基异羟肜酸酯氮负离子 9-4 捕获碳正离子中 间体 9-7 得到目标产物 9-3. 同时, 质子的阴极还原产生 $\mathrm{H}_{2}$.

同年, 汪志勇课题组 ${ }^{[21]}$ 基于阳极间接电氧化策略, 开发了一种电化学分子间串联环化反应方法学, 并用于 咪唑并环类化合物的高效合成(Scheme 10). 该反应在 $100{ }^{\circ} \mathrm{C}$ 油浴中, 以 $\mathrm{NH}_{4} \mathrm{I}$ 作为电解质和催化剂, $\mathrm{Pt}$ 片电极 作为阴阳极, DMF 为溶剂, 在单室电解池中以恒电流模 式电解, 芐胺 10-2 与 2-甲基氮杂芳烃 10-1 反应生成咪 坐并 $N$-杂环类芳香氮杂环 10-3. 温度是该反应的一个 


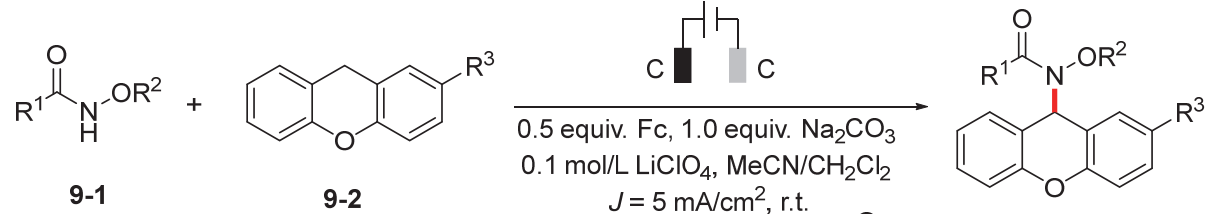

$9-1$

$9-2$ $J=5 \mathrm{~mA} / \mathrm{cm}^{2}$, r.t.
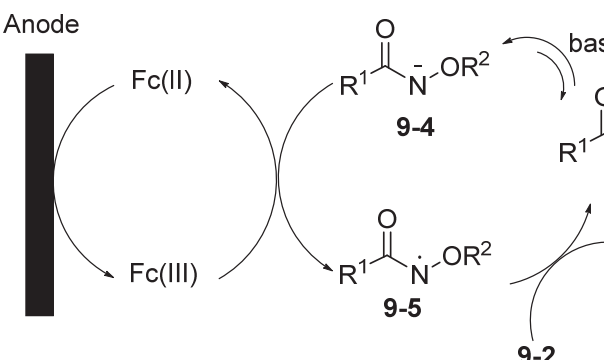

$\mathrm{R}^{1} \mathrm{~N}^{-} \mathrm{OR}^{2}$

9-3<smiles>CC1c2ccccc2Oc2ccc(F)cc21</smiles>

9-3 $9-4$ 9-1<smiles>[R]c1ccc2c(c1)Cc1ccccc1O2</smiles>

9-6

图式 9 黄嘌呤与氧杂葱与 $N$-烷氧基酰胺的分子间电化学 $\mathrm{C}\left(\mathrm{sp}^{3}\right)-\mathrm{H} / \mathrm{N}-\mathrm{H}$ 交叉偶联反应

Scheme 9 Electrochemically intermolecular $\mathrm{C}\left(\mathrm{sp}^{3}\right)-\mathrm{H} / \mathrm{N}-\mathrm{H}$ cross-coupling of xanthenes with $N$-alkoxyamide

重要的影响因素，降低反应温度，产率明显降低. 将苄 胺替换成氨基酸，该环化反应也可顺利进行.

该反应的可能机理如 Scheme 10 所示. 首先, 碘负 离子在阳极表面被氧化成 $\mathrm{I}_{2}$; 然后, $\mathrm{I}_{2}$ 与 2-甲基喹啉反应 生成 2-碘甲基喹啉 10-4; 茮胺 10-2 与中间体 10-4 发生 亲核取代反应形成第一个 $\mathrm{C}-\mathrm{N}$ 键, 得到中间体 10-5, 其再经历一系列碘介导的氧化反应, 得到亲电性的中间 体 10-7; 随后, 氮杂环中具有亲核性的氮原子进攻缺电
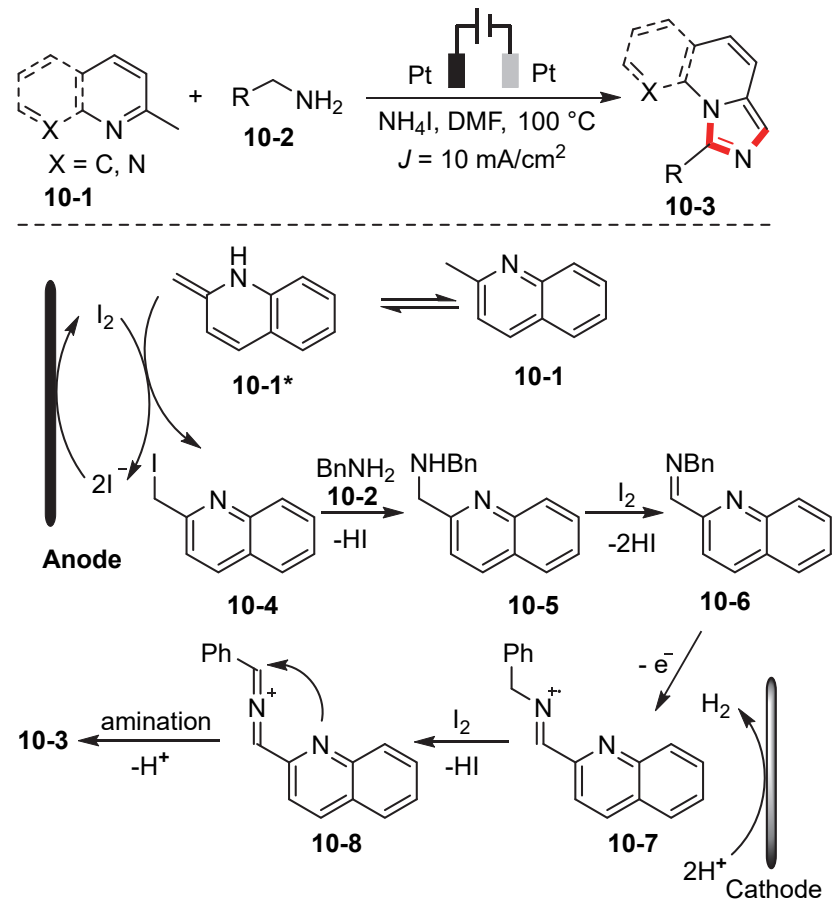

图式 10 甲基 $N$-杂芳烃与胺的电化学 $\mathrm{C}\left(\mathrm{sp}^{3}\right)-\mathrm{H} / \mathrm{N}-\mathrm{H}$ 偶联 反应

Scheme 10 Electrochemical intermolecular $\mathrm{C}\left(\mathrm{sp}^{3}\right)-\mathrm{H} / \mathrm{N}-\mathrm{H}$ coupling of methyl $\mathrm{N}$-heteroaromatics with amines
子的中间体 10-8, 发生分子内亲核加成反应形成第二个 $\mathrm{C}-\mathrm{N}$ 键而关环; 最后, 再经历氧化芳构化得到目标产 物咪唑并 $\mathrm{N}$-杂环 10-3. 在阴极表面, 质子被还原成 $\mathrm{H}_{2}$.

曾程初课题组 ${ }^{[22]}$ 报道了一种通过直接电解 $N$-甲基 苄胺制备偕二胺的反应方法学(Scheme 11). 该反应在 $40{ }^{\circ} \mathrm{C}$ 下, 以 $\mathrm{Bu}_{4} \mathrm{NClO}_{4}$ 作为电解质, $\mathrm{Pt}$ 片电极作为阴阳 极, $\mathrm{MeCN} / \mathrm{MeOH}$ 混合液为溶剂, 在单室电解池中以恒 电流模式电解, $N$-甲基取代苄胺 11-1 与邻苯二甲酰亚胺 11-2 发生氧化交叉脱氢偶联反应，以较好的产率得到邻 苯二甲酰亚胺保护的偕二胺. 三氮唑也能作为合适的底 物，与 $N$-甲基取代苄胺发生偶联形成 $\mathrm{C}-\mathrm{N}$ 键. 首先, $N$ 甲基取代苄胺 11-1 在阳极发生单电子转移, 得到 N-自 由基阳离子中间体 11-4, 其发生去质子化和进一步氧化 过程生成亚胺正离子中间体 11-5. 同时, $\mathrm{MeOH}$ 在阴极 上被还原得到甲氧基负离子和 $\mathrm{H}_{2}$. 甲氧基负离子可以 夺取邻苯二甲酰亚胺 11-2 氮原子上的质子, 得到氮负离 子中间体 11-6; 最后, 氮负离子中间体 11-6 与亚胺正离 子中间体 11-5 发生 Mannich 类型的加成反应, 生成目标 产物 11-3.

脱氢环化反应使用简单易得的原料一步构建两个 化学键, 这是一种较好的构筑环状化合物的方法. 然而, 传统的脱氢成键方法一般需使用过量的氧化剂, 且鲜有 该方法应用于饱和氮杂环的合成. 2018 年, 徐海超课题 组 ${ }^{[23]}$ 采用间接有机电化学合成策略, 实现了 1,3 -二羰基 化合物与 $N$-烯丙基酰胺的分子间脱氢环化反应(Scheme 12). 在氩气氛围中, 采用 $t-\mathrm{BuOMe} / \mathrm{MeCN} / \mathrm{H}_{2} \mathrm{O}$ 三元混 合溶剂, 以吩噻嗪衍生物为催化剂, ${ }^{n} \mathrm{Bu}_{4} \mathrm{NPF}_{6}$ 为电解质, $\mathrm{HCO}_{2} \mathrm{Na}$ 为添加剂, $\mathrm{RVC}$ 为阳极, $\mathrm{Pt}$ 片为阴极, $N$-烯丙基 酰胺 12-1 与丙二酸二甲酯 12-2 在恒电流模式下电解, 


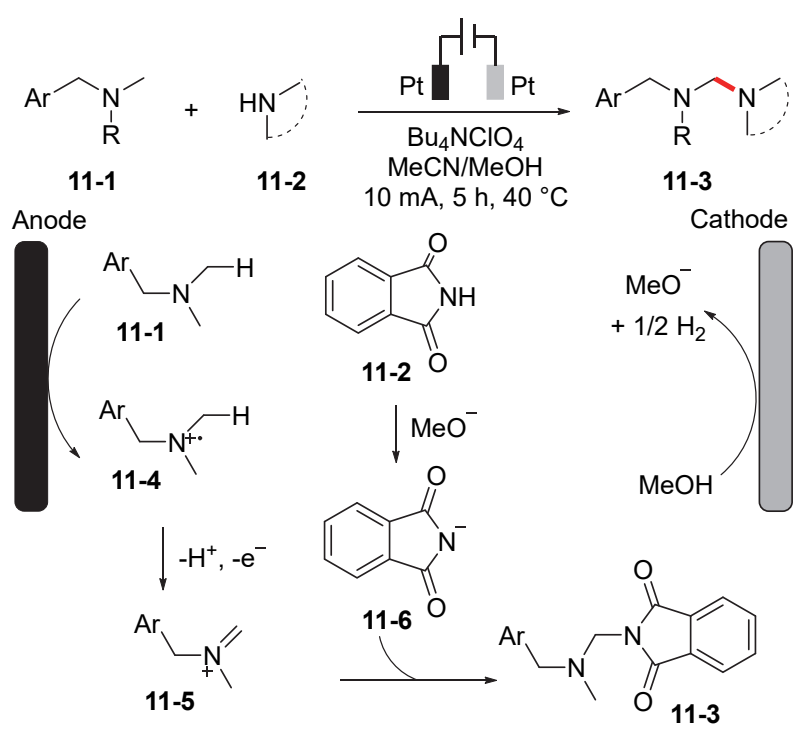

图式 11 电化学合成偕二胺

Scheme 11 Electrochemical synthesis of gem-diamines

发生 $[4+1]$ 环化反应生成吡咯烷 12-3, 或者与 $\beta$-酮酯发 生 $[4+2]$ 环化反应生成四氢吡啶衍生物 12-4. 该电合成 方法原料稳定、易得, 且副产物为 $\mathrm{H}_{2}$, 为吡咯烷和四氢 吡啶衍生物的合成提供了简便、高效、绿色的合成方法.

2019 年, 汪志勇课题组 ${ }^{[24]}$ 开发了一种碘盐为介质 的间接电解氧化方法, 用于制备 $\alpha$-烯胺酮(Scheme 13). 该反应在室温下, 以 $\mathrm{KI}$ 作为电解质, $\mathrm{Pt}$ 电极作为阴阳极,
在单室电解池中以恒电流模式电解, 苯胺 13-1 与环戊 酮 13-2 发生氧化脱氢 $\mathrm{C}-\mathrm{N}$ 键偶联生成 $\alpha$-烯胺酮 13-3. 该反应条件温和，避免使用金属催化剂和高温条件; 然 而，在标准反应条件下，环已酮、茚酮和非环状酮底物 的反应效果较差.

同大多数具有 $\alpha-\mathrm{H}$ 的酮在碘系电解质条件下的电 解反应类似, TEMPO、BHT 的加入会抑制反应的进行, $\alpha$-碘代酮为关键中间体，用 $\mathrm{I}_{2}$ 替代 $\mathrm{KI}$ 时无目标产物生 成. 作者认为碘离子在阳极中被氧化成碘自由基，然后 篗取环戊酮 13-2 中的 $\alpha$ 位氢原子, 生成 C-自由基 13-4, 并释放一分子 $\mathrm{HI}$; 接着, C-自由基 13-4 与碘自由基发生 自由基偶联生成 $\alpha$-碘代环戊酮 13-5; 随后，中间体 13-5 与苯胺 13-1 发生亲核取代反应形成 $\mathrm{C}-\mathrm{N}$ 键, 得到 2氨基取代的环戊酮 13-6; 中间体 13-6 再经历阳极氧化 后形成中间体 2-(苯基亚胺)-环戊酮 13-7; 最后，中间体 13-7 发生重排得到目标产物 $\alpha$-烯胺酮 13-3, 同时伴随着 $\mathrm{MeOH}$ 在阴极被还原，生成甲氧基负离子和 $\mathrm{H}_{2}$.

2019 年, 雷爱文课题组 ${ }^{[25]}$ 利用电化学氧化和布朗 斯特酸催化协同策略，通过[4+2]环化来合成吡嗪类化 合物(Scheme 14). 该反应在氮气氛围中, 反应温度为 $100{ }^{\circ} \mathrm{C}$, 以 $\mathrm{KI}$ 作为电解质, 对甲苯磺酸作为布朗斯特酸 催化剂, Pt 片作为阴极, 石墨棒作为阳极, DMA 作为溶 剂, 在单室电解池中以恒电流模式电解, 一系列简单酮 14-1 与邻二胺 14-2 反应得到吡嗪类化合物 14-3. 机理研

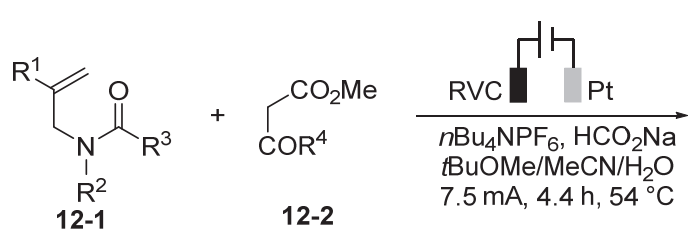

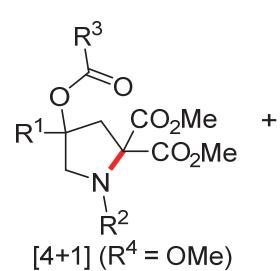

12-3

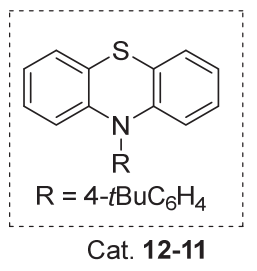

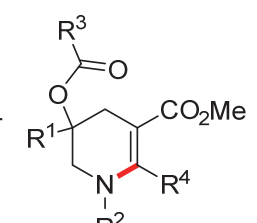

$\mathrm{R}^{2}$

[4+2] $\left(\mathrm{R}^{4}=\right.$ alkyl $)$

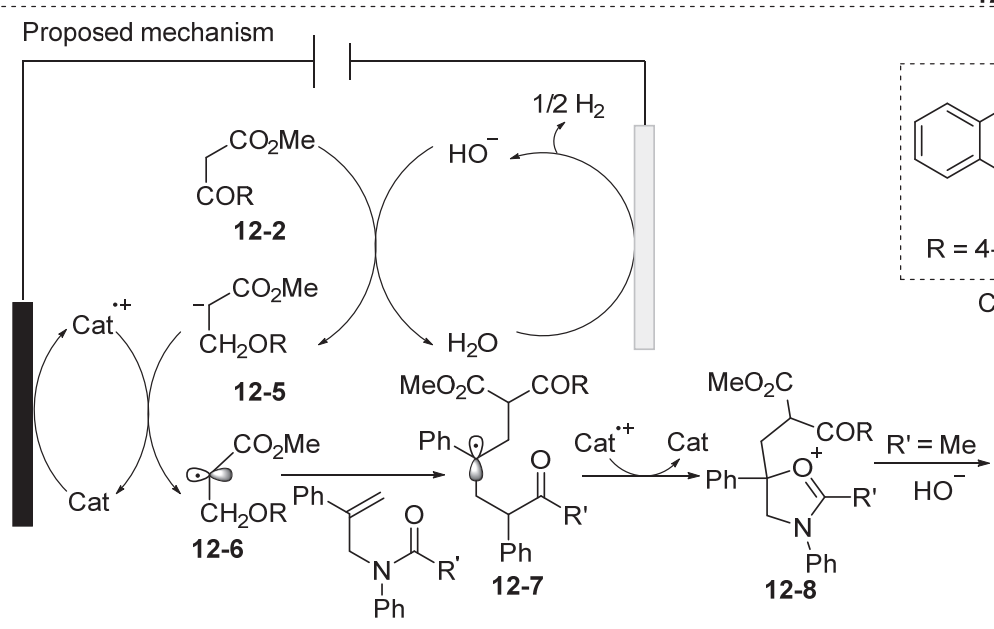



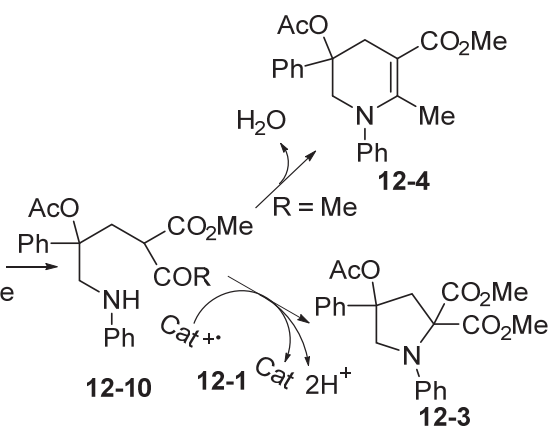

图式 $12 N$-烯丙基酰胺与 1,3-二羰基化合物的电化学氧化环化反应

Scheme 12 Electrooxidative annulation of $N$-allyl amides with 1,3-dicarbonyl compounds 

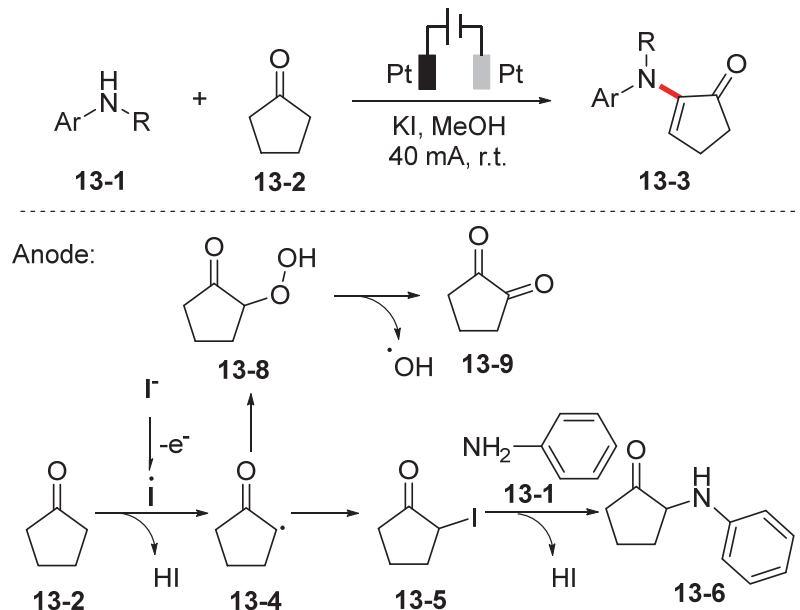

[O]

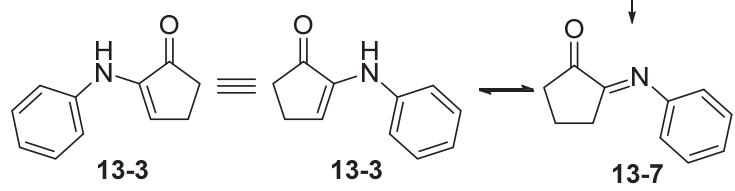

Cathode:

$\mathrm{MeOH}+e^{-} \longrightarrow \mathrm{MeO}^{-}+1 / 2 \mathrm{H}_{2}$

图式 13 电化学诱导的环状酮的 $\alpha-\mathrm{C}-\mathrm{H}$ 胺化反应

Scheme 13 Electrochemically induced cyclic ketones $\alpha-\mathrm{C}-\mathrm{H}$ aminations
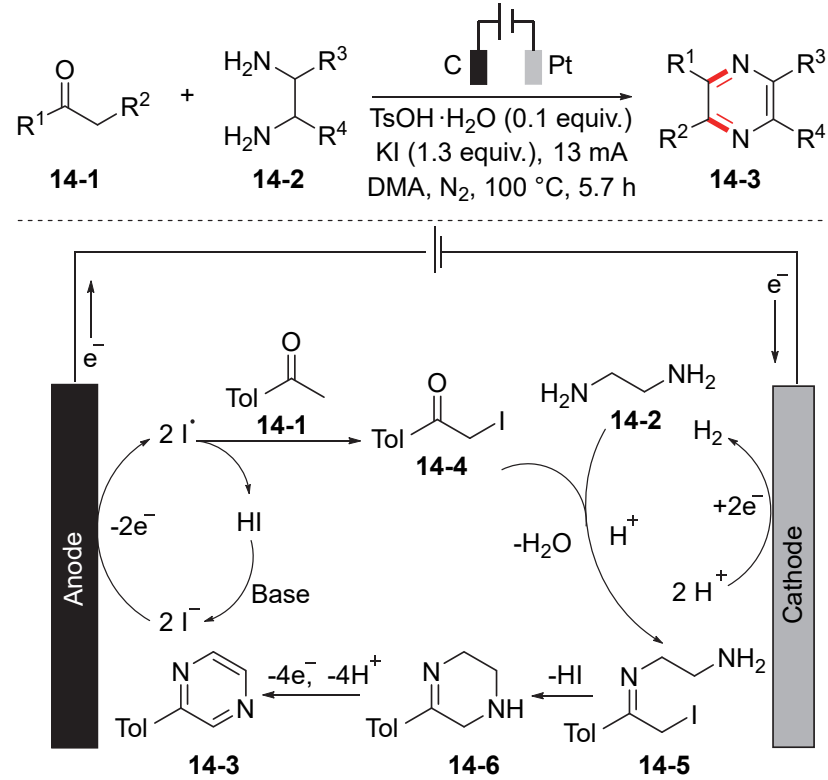

图式 14 电化学氧化诱导的 $[4+2]$ 环化合成吡嗪

Scheme 14 Electrooxidation induced [4+2] annulation for the synthesis of pyrazines

究表明该反应涉及自由基过程， $\alpha$-碘代酮为关键中间体. 首先，碘负离子在阳极被氧化成碘自由基，碘自由基与 酮 14-1 反应得到 $\alpha$-碘代酮 14-4; 然后, Brønsted 酸催化 下, 邻二胺 14-2 和 $\alpha$-碘代酮 14-4 发生缩合反应生成亚 胺中间体 14-5; 随后，亚胺中间体发生分子内的亲核取
代反应形成环状中间体 14-6; 最后，通过阳极氧化，生 成芳构化的吡嗪产物 14-3. 同时质子在阴极被还原, 生 成 $\mathrm{H}_{2}$.

同年，陈善勇、余孝其课题组 ${ }^{[26]}$ 报道一例基于碘化 物介导的间接电氧化来构建 $\mathrm{C}-\mathrm{N}$ 键的反应(Scheme 15). 该反应以 ${ }^{n} \mathrm{Bu}_{4} \mathrm{NBF}_{4}$ 为电解质, $\mathrm{HI}$ 为催化剂, 碳片为 阳极, Pt 为阴极, 在单室电解池中以恒电位模式电解, 苯乙酮 15-1 与 2-氨基吡啶 15-2 发生基于 $\mathrm{C}-\mathrm{N}$ 键偶联 的串联环化反应，得到一系列咪唑并 $[1,2-a]$ 吡啶. 在标 准反应条件下，向反应体系中加入二硫醚或二硒醚，可 以中等收率得到 3-統基或硒基取代的咪唑并 $[1,2-a]$ 吡 啶. 首先, 氢碘酸在阳极氧化生成 $I_{2}, I_{2}$ 与酮 15-1 反应生 成 $\alpha$-碘酮 15-4; 随后, 2-氨基吡啶 15-2 和中间体 15-4 发 生亲核取代反应生成中间体 15-5; 接着，中间体 15-5 进 行分子内缩合反应，关环生成中间体 15-6; 最后，中间 体 15-6 脱氢芳构化生成目标产物 15-3.

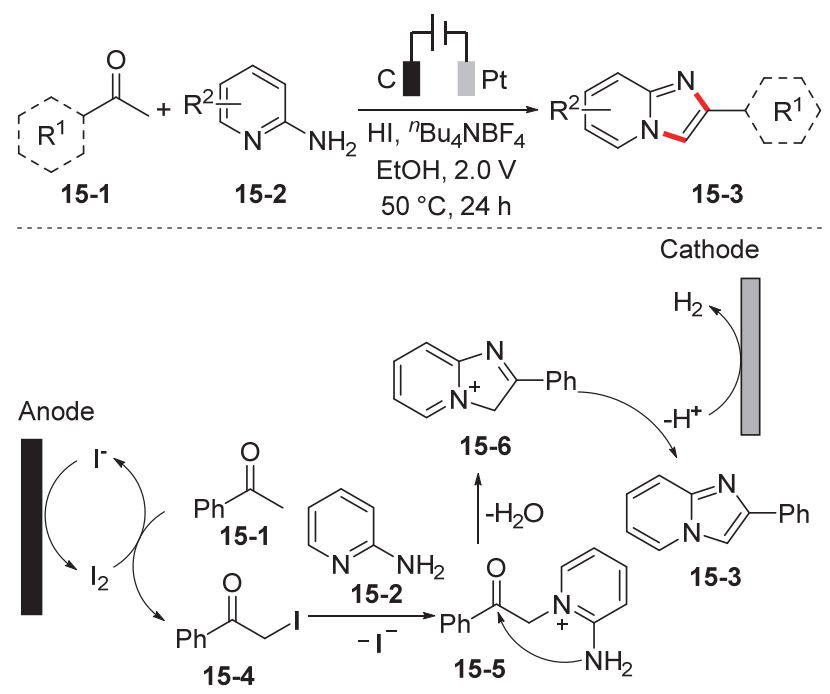

图式 15 电化学引发的酮与 2-氨基吡啶分子间环化反应 Scheme 15 Electrochemically initiated intermolecular cyclization of ketones with 2-aminopyridines

2019 年，曾程初和孙宝国课题组 ${ }^{[27]}$ 报道了一种利 用有机电化学方法合成烯丙胺类化合物的新方法, 与传 统方法相比，该反法避免了过渡金属催化剂和碱的使用 (Scheme 16). 该反应在 $30{ }^{\circ} \mathrm{C}$ 下, 以 $\mathrm{Pt}$ 片为电极, $\mathrm{NaI}$ 为 电解质, DCE 与 $\mathrm{MeCN}$ 的混合溶液为溶剂, 在单室电解 池中以恒电流模式电解, 磺酰胺或酰亚胺 16-1 与烯丙 基砜 16-2 反应得到烯丙胺类化合物 16-3. 当离去基团 LG 为溴或酯基时, 也能获得目标产物, 但产率相对较 低.

向反应体系中加入 BHT，反应被完全抑制，以 $70 \%$ 的产率得到底物磺酰胺与 BHT 的加成产物, 表明 N-自 由基是该反应的关键中间体. 如果不电解，但向反应体 系中加入 $\mathrm{I}_{2}$ 并不能驱动该反应的发生. 作者认为磺胺 
16-1 与原位生成的高价碘反应生成 N-碘中间体 16-4. 随后，中间体 16-4 的还原裂解产生 N-自由基 16-5, 该自 由基与烯丙基化合物 16-2 经历加成一消除反应, 生成目 标产物烯丙胺 16-3.

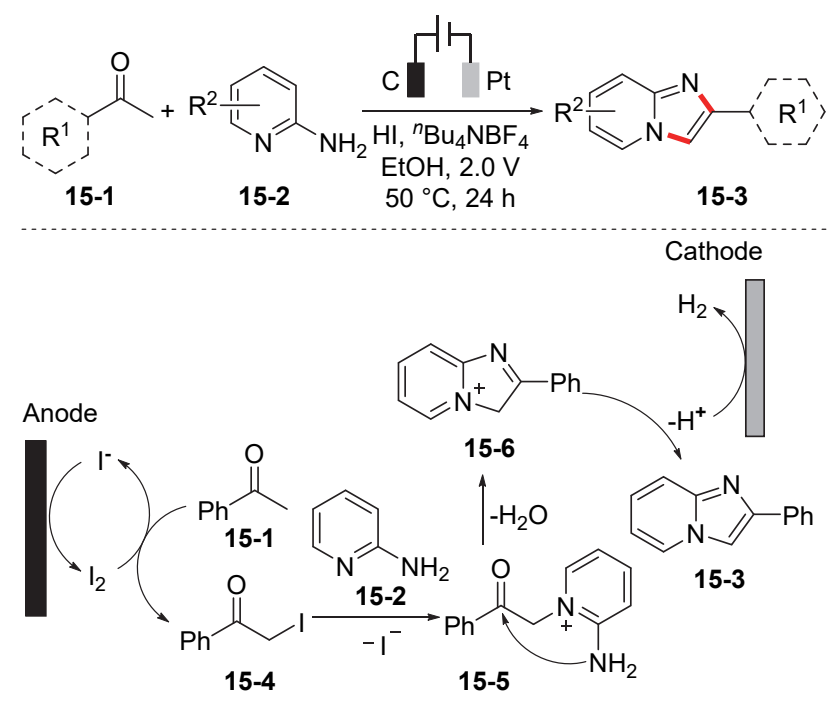

图式 16 电化学合成烯丙胺

Scheme 16 Electrochemical synthesis of allylamines

对于苠基 $\mathrm{C}-\mathrm{H}$ 键的电化学氧化胺化反应, 由于胺 基化的产物与苄基 $\mathrm{C}-\mathrm{H}$ 键具有相似的氧化电位, 因此, 防止胺化产物的过度氧化是一个具有挑战性的难题. 2017 年, Yoshida 课题组 ${ }^{[28]}$ 以对甲苯磺酰联苯硫亚胺为 对甲苯磺酰胺基来源, 在电化学条件下通过一锅两步法 的方式, 实现了对茮基 $\mathrm{C}-\mathrm{H}$ 键的胺化(Scheme 17). 首 先, 底物 17-1 中的苄基通过阳极氧化生成苠基碳正离 子 17-4; 然后, 联苯硫亚胺中的氮原子进攻苠基碳正离 子, 得到茮胺基硫鎓离子中间体 17-5; 最后, 在非电解 条件下, 中间体 17-5 与四丁基碘化铵反应, 脱去二苯硫 醚, 生成对甲苯磺酰化的苄胺衍生物 17-3. 该反应是在 一个配有碳纤维布为阳极和 Pt 片为阴极的 $\mathrm{H}$ 型隔膜双 室电解池中进行, 在阳极室中放置有含苄基的底物 17-1、对甲苯磺酰联苯硫亚胺 17-2、 $\mathrm{Bu}_{4} \mathrm{NB}\left(\mathrm{C}_{6} \mathrm{~F}_{5}\right)_{4}$ (电解 质), 在阴极室中放置有 $\mathrm{TfOH}$ (添加剂)、 $\mathrm{Bu}_{4} \mathrm{NB}-$ $\left(\mathrm{C}_{6} \mathrm{~F}_{5}\right)_{4}$ (电解质)及 $\mathrm{CH}_{2} \mathrm{Cl}_{2}$. 在 $25{ }^{\circ} \mathrm{C}$, 以恒电流模式电解 该反应液, 得到中间体芐胺基硫鎓离子 17-5. 接着, 向 阳极室和阴极室中加入 $\mathrm{Bu}_{4} \mathrm{NI}$ 和 $\mathrm{CH}_{2} \mathrm{Cl}_{2}$, 在非电解条件 下继续搅拌反应 $1 \mathrm{~h}$, 便可得到目标产物. 该方法可以 避免胺化产物的过度氧化, 也不需使用过量的苠基底 物, 且具有较好的底物适用范围.

虽然上述方法较好地解决了电氧化条件下的茮位 $\mathrm{C}-\mathrm{H}$ 键胺化反应所存在的问题, 但是该方法需要使用 较难获得的对甲苯磺酰联苯硫亚胺为胺基化试剂, 且需 要消除一个大分子的二苯硫醚作为废弃物，限制了该方

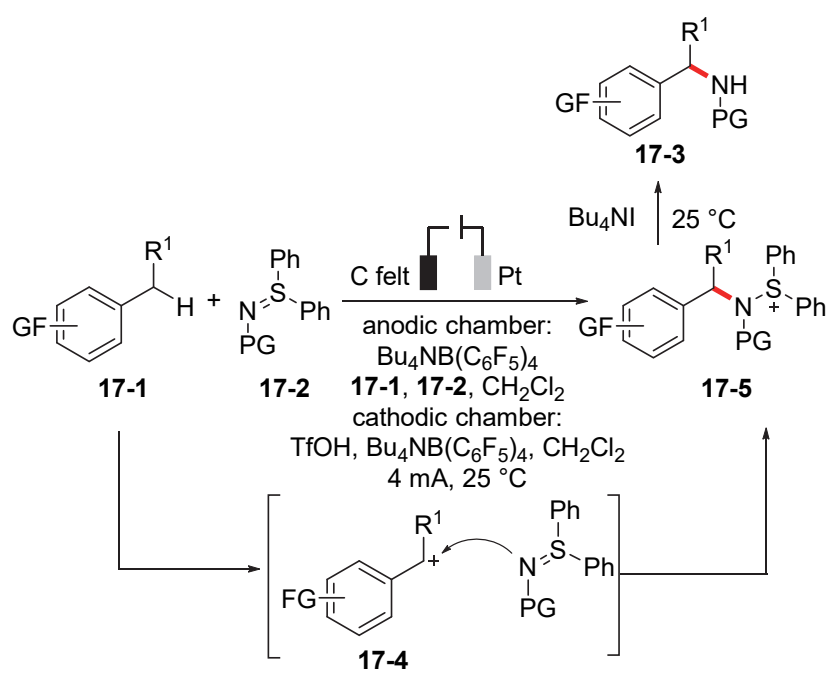

图式 17 电化学苠位 $\mathrm{C}-\mathrm{H}$ 键胺化反应

Scheme 17 Electrochemical benzylic $\mathrm{C}-\mathrm{H}$ amination reaction

法的应用. 2020 年, 徐海超课题组 ${ }^{[29]}$ 利用交叉脱氢偶联 策略, 使用廉价易得的磺酰胺作为胺基化试剂, 实现了 将茮基 $\mathrm{C}-\mathrm{H}$ 键转化为 $\mathrm{C}-\mathrm{N}$ 键的位点选择性电化学胺 化反应(Scheme 18). 该方法最优反应条件为: 在配有 $\mathrm{RVC}$ 阳极和 $\mathrm{Pt}$ 片阴极的单室电解池中, 以 ${ }^{n} \mathrm{Bu}_{4} \mathrm{NBF}_{4}$ 为 电解质, 室温下在 HFIP/DCE 的混合溶剂中恒电流模式 电解. 该方法不仅可以应用于贲胺的高效合成，其它类 型的亲核试剂如醋酸和醇也能兼容. 反应过程涉及茮基 $\mathrm{C}-\mathrm{H}$ 键的阳极氧化形成碳正离子中间体 18-4, 然后其 被亲核试剂捕获构建 $\mathrm{C}-\mathrm{N}$ 或 $\mathrm{C}-\mathrm{O}$ 键.

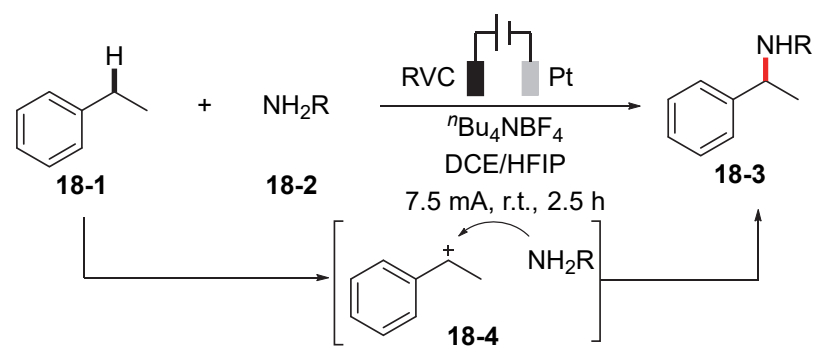

图式 18 位点选择性的电化学苄基 $\mathrm{C}-\mathrm{H}$ 键胺化反应 Scheme 18 Site-selective electrochemical benzylic C-H amination reaction

$\mathrm{C}\left(\mathrm{sp}^{3}\right)-\mathrm{H}$ 键的选择性氧化叠氮化在药物合成和生 物研究方面具有重要的应用价值. 亲核性叠氮化试剂用 于烷基叠氮的合成, 通常需要加入化学计量的氧化剂. 通过协同锰催化、电有机合成以及可见光催化的策略, 雷爱文课题组 ${ }^{[30]}$ 实现了无外加化学计量氧化剂条件下 $\mathrm{C}\left(\mathrm{sp}^{3}\right)-\mathrm{H}$ 键的氧化叠氮化(Scheme 19). 在蓝光照射和 恒电流电解协同作用下, 以 $\mathrm{MnF}_{2}$ 为催化剂、1,10-菲咯 啉为配体、9-芴酮为光催化剂、 $\mathrm{KBr}$ 和三氟乙酸(TFA) 为添加剂、 $\mathrm{LiClO}_{4}$ 为电解质, 使用叠氮化钠 19-2 为叠氮 
化试剂, 可以有效地向苄基 $\mathrm{C}-\mathrm{H}$ 以及简单的烷烃 $\mathrm{C}-$ $\mathrm{H}$ 引入叠氮基团. 该方法借助电化学氧化叠氮负离子生 成的叠氮自由基 19-5 和激发态的光催化剂 19-7 来箱取 $\mathrm{C}\left(\mathrm{sp}^{3}\right)$ - $\mathrm{H}$, 生成 $\mathrm{C}\left(\mathrm{sp}^{3}\right)$-自由基 19-4. 最后, $\mathrm{Mn}(\mathrm{III})-\mathrm{N}_{3}$ 对生成的 C-自由基 19-4 进行叠氮转移, 生成目标产物 19-3.
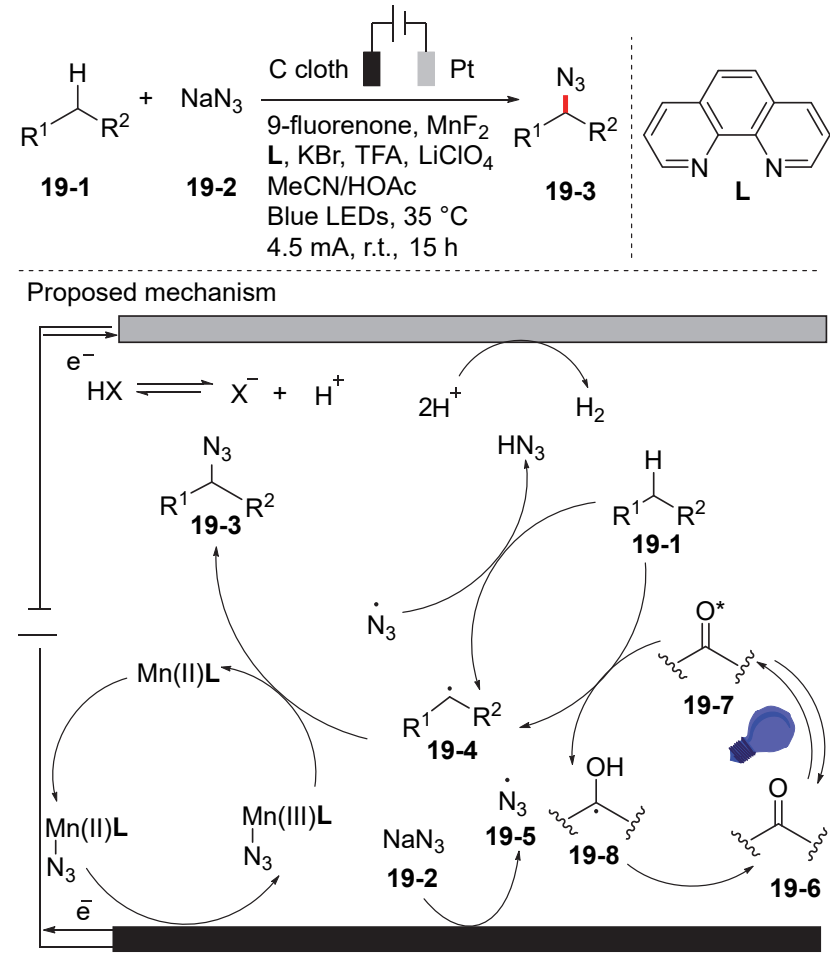

图式 19 锰催化的 $\mathrm{C}\left(\mathrm{sp}^{3}\right)-\mathrm{H}$ 键的光电协同叠氮化反应 Scheme 19 Manganese-catalyzed electrophotochemical azidation of $\mathrm{C}\left(\mathrm{sp}^{3}\right)-\mathrm{H}$ bonds

\section{$2 \mathrm{C}\left(\mathrm{sp}^{2}\right)-\mathrm{N}$ 键偶联反应}

\section{1 分子内 $\mathrm{C}\left(\mathrm{sp}^{2}\right)-\mathrm{N}$ 键偶联反应}

酰胺 N-自由基在有机合成中具有重要的应用价值, 但是产生酰胺 N-自由基的绿色合成方法学较少, 这限 制了酰胺 N-自由基在有机合成中的广泛应用. 徐海超 课题组 ${ }^{[31]}$ 发现利用廉价、易得的二茂铁为电催化剂, 以 电作为 “氧化剂” 氧化酰胺 $\mathrm{N}-\mathrm{H}$ 键可高效得到酰胺 $\mathrm{N}$-自由基. 2016 年, 该课题组利用电催化条件下形成的 酰胺 N-自由基和未活化烯烃发生分子内加成反应, 发 展了具有高选择性的烯烃氢胺化反应(Scheme 20). 以 二茂铁 $(\mathrm{Fc})$ 为催化剂, ${ }^{n} \mathrm{Bu}_{4} \mathrm{BF}_{4}$ 作为电解质, $\mathrm{THF}$ 和 $\mathrm{MeOH}$ 的混合溶剂, $\mathrm{Na}_{2} \mathrm{CO}_{3}$ 为添加剂, 碳棒为阳极, $\mathrm{Pt}$ 片为阴极, 回流条件下, 在单室电解池中恒电流模式电 解, 含有烯基侧链的酰胺发生分子内的烯烃氢胺化反 应, 得到一系列含氮杂环化合物.

首先, $\mathrm{Fc}$ 在阳极氧化为 $\mathrm{Fc}^{+}, \mathrm{MeOH}$ 阴极还原为 $\mathrm{H}_{2}$ 和甲氧负离子; 然后, 甲氧负离子夺去底物酰胺 $\mathrm{N}-\mathrm{H}$

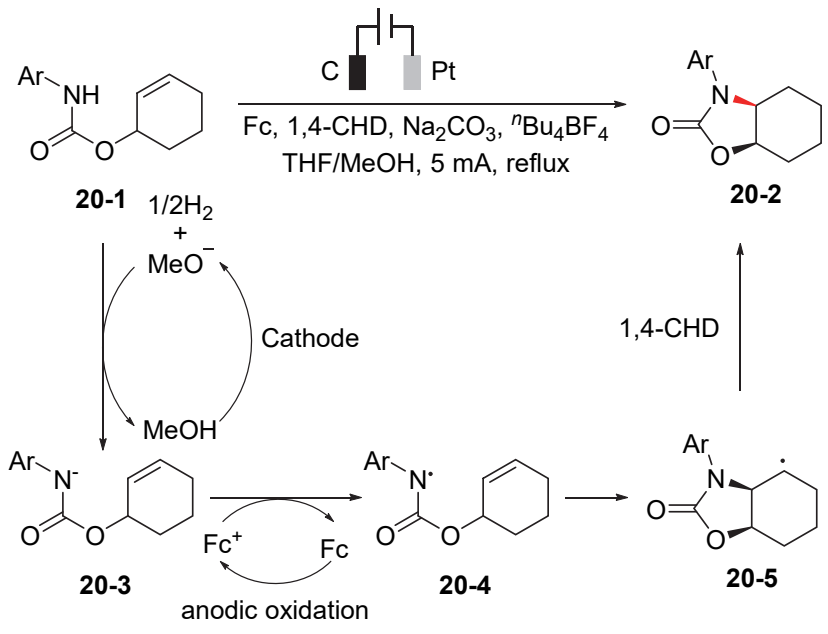

图式 20 电氧化诱导的分子内烯烃氢酰胺化反应

Scheme 20 Electrooxidation induced intramolecular olefin hydroamidation reaction

上的氢原子形成酰胺氮负离子 20-3; 通过单电子转移, 酰胺氮负离子被 $\mathrm{Fc}^{+}$氧化生成关键的酰胺 $\mathrm{N}$-自由基 20-4, 并完成 $\mathrm{Fc}$ 的再生; 随后, 酰胺 $\mathrm{N}$-自由基进攻烯烃, 形成 $\mathrm{C}-\mathrm{N}$ 键而关环; 最后, $\mathrm{C}$-自由基中间体擢取 1,4CHD 或溶剂分子中的氢原子, 生成烯烃的氢胺化产物. 基于相同的间接阳极氧化产生 $\mathrm{N}$-自由基策略, 2017 年 Wirth 课题组 ${ }^{[32]}$ 设计了一种改进型电化学流动微反应装 置, 通过氨基甲酸酯类化合物的分子内自由基环化反 应，实现了异吲哚啉酮产物的高效制备.

徐海超课题组 ${ }^{[33]}$ 利用电化学氧化作为绿色合成手 段, 实现了具挑战性三取代或四取代烯烃的分子内氧化 胺化反应(Scheme 21). 该反应以 $\mathrm{RVC}$ 电极为阳极, $\mathrm{Pt}$ 电 极为阴极, $\mathrm{Et}_{4} \mathrm{NPF}_{6}$ 为电解质, $\mathrm{DMA}$ 和 $\mathrm{AcOH}$ 的混合液为 溶剂, 在氩气氛围下, 在单室电解池中, $110{ }^{\circ} \mathrm{C}$ 下以恒 电流模式电解, 含酰胺基团的烯烃可以发生分子内氧化 胺化反应，生成一系列烯基取代的含氮杂环. 该反应底 物适用范围较广，三取代或四取代烯烃均可兼容此反 应，反应也能很好地放大到克级规模. 对于反应历程, 作者认为底物 21-1 酰胺基 $\mathrm{N}-\mathrm{H}$ 键的阳极活化生成 $\mathrm{N}-$ 自由基中间体 21-3, 该中间体随后对烯基加成实现基于 $\mathrm{C}-\mathrm{N}$ 键形成的分子内环化, 并产生 C-自由基 21-4. C自由基经历进一步的阳极氧化形成碳正离子中间体 21-5, 最后 $\beta-\mathrm{H}$ 消除得到烯基取代的含氮杂环化合物 21-2.

2018 年, 徐海超课题组 ${ }^{[34]}$ 报道了利用电化学氧化 产生的含 $\mathrm{N}$-自由基, 实现了分子内的脱氢 $[3+2]$ 环化反 应, 并用于功能化 (氮杂) 吲哚啉类化合物的合成 (Scheme 22). 该电合成法以廉价易得的 $\mathrm{Cp}_{2} \mathrm{Fe}$ 为电催化 剂, ${ }^{n} \mathrm{Bu}_{4} \mathrm{NBF}_{4}$ 为电解质, 在以 $\mathrm{NaOAc}$ 为碱的 $\mathrm{MeOH} / \mathrm{THF}$ 

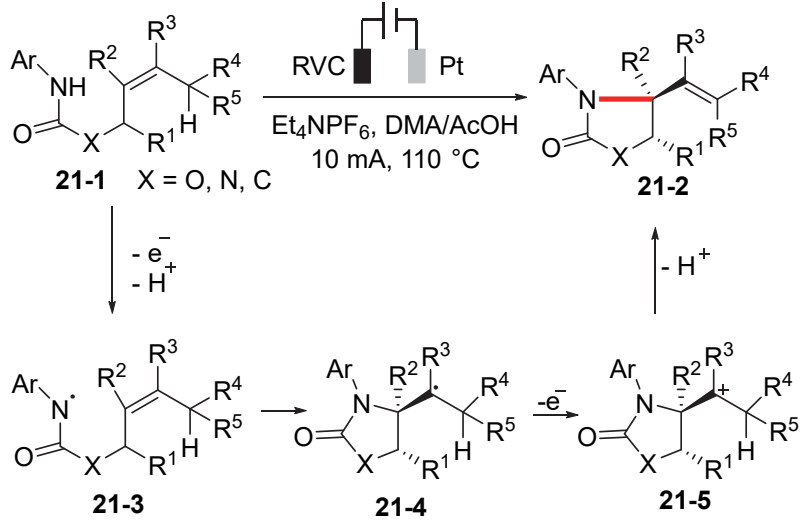

图式 21 多取代烯烃的电化学分子内氧化胺化反应

Scheme 21 Electrochemical oxidative intramolecular amination of multisubstituted alkenes

混合溶剂中, RVC 作为阳极、Pt 片作为阴极, 含烯基侧 链的二芳基嫝 22-1 在恒电流的条件下电解, 能以高收 率获得吲哚并喹唑啉酮类氮杂环 22-2. 当腿氮的取代基 为含氮杂环时, 在标准条件下效果较差; 作者对碱的种 类和用量又重新进行了优化, 发现 $\mathrm{K}_{2} \mathrm{CO}_{3}$ 作为碱时, 对 此类含氮杂芳环的底物效果最好. 利用这个电合成法为 关键步骤, 用市售原料经 12 步全合成了海洋生物碱 (土)-Hinckdentine A. 循环伏安实验表明电化学生成的 $\mathrm{Cp}_{2} \mathrm{Fe}^{+}$有效地氧化了底物的共轭碱. 结合先前的工作, 该反应机理与上一篇报道机理类似, $\mathrm{Cp}_{2} \mathrm{Fe}^{+}$有效地氧化 底物的共轭碱产生 N-中心自由基 22-3, 其加成到烯烃 发生环化反应，同时产生 C-中心自由基 22-4, 其进攻芳 烃完成第二次关环生成目标产物 22-2.

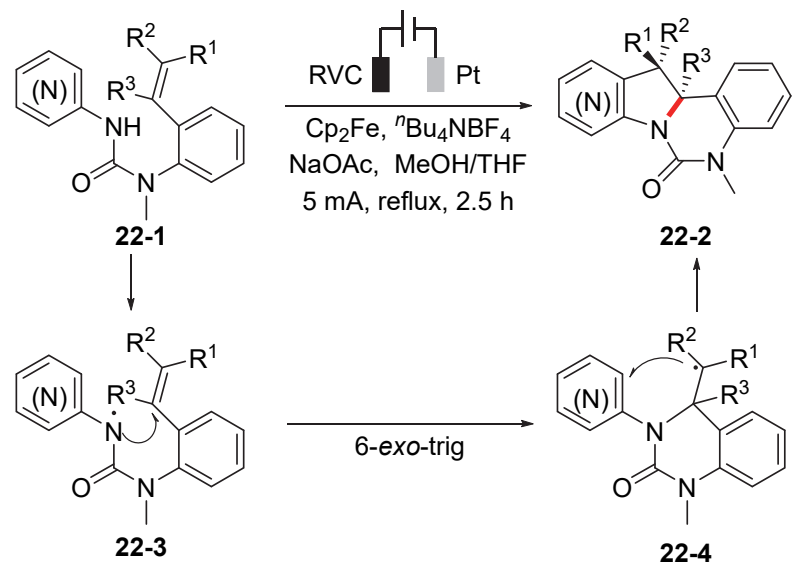

图式 22 脱氢 $[3+2]$ 环化电化学合成(氮杂)吲哚啉类化合物

Scheme 22 Electrochemical synthesis of (aza)indolines via dehydrogenative $[3+2]$ annulation

同年, 将 C-中心自由基受体由芳烃替换为烯烃，徐 海超课题组 ${ }^{[35]}$ 报道了一种电化学合成功能化七元碳环 化合物的新方法(Scheme 23). 该反应采用 RVC 为阳极, $\mathrm{Pt}$ 电极为阴极, ${ }^{n} \mathrm{Bu}_{4} \mathrm{NBF}_{4}$ 为电解质, $\mathrm{Cp}_{2} \mathrm{Fe}$ 为催化剂,
$\mathrm{Na}_{2} \mathrm{CO}_{3}$ 为碱, 1,4-环已二烯(1,4-CHD)为还原剂, $\mathrm{MeOH} /$ THF 混合液为溶剂, 氩气保护下回流, 在单室电解池中 以恒电流模式电解, 含有一个二取代的顺式烯基和一个 末端烯基的氨基甲酸酯发生 5-exo-trig/7-endo-trig 自由 基串联环化反应，得到一系列并合七元环的噁唑烷酮类 化合物. 当底物分子中的两个烯基均为内烯烃的时候, 只发生 5-exo-trig 关环反应并形成一个五元环, 没有七 元碳环的生成. 与该课题组前期涉及氨基甲酸酯底物的 工作类似，该反应也涉及 $\mathrm{N}$-自由基为关键中间体. 阴极 产生的碱使得底物 23-1 中 N-H 断裂得到氮负离子中间 体, 其被 $\mathrm{Cp}_{2} \mathrm{Fe}^{+}$氧化为 $\mathrm{N}$-中心自由基 23-3. N-中心自由 基经过立体选择性的 5-exo-trig 环化反应形成 C-中心自 由基 23-4. C-中心自由基对分子中的末端烯基进行 7-endo-trig 自由基加成环化反应, 再通过氢原子转移得 到双环目标化合物 23-2.

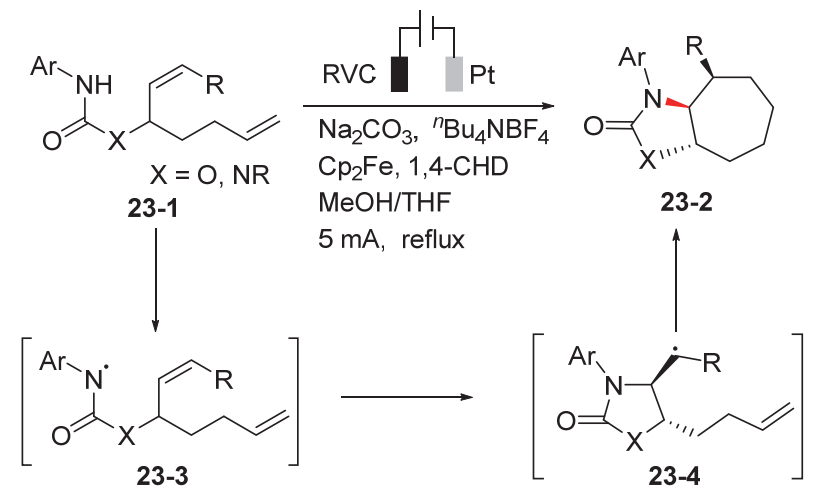

图式 23 电化学条件下自由基串联环化在 7 元碳环化合物合 成中的应用

Scheme 23 Electrochemical synthesis of 7-membered carbocycles via tandem radical cyclization

2017 年, 徐海超课题组 ${ }^{[36]}$ 将酰胺 N-自由基换为脒 基 $\mathrm{N}$-自由基, $\mathrm{N}$-自由基受体由烯基替换为芳烃，实现了 脒基与芳环的分子内电化学交叉脱氢偶联反应，并合成 得到了一系列功能化的含氮稠杂环化合物(Scheme 24). 该反应利用 $\mathrm{Et}_{4} \mathrm{NPF}_{6}$ 为电解质, $\mathrm{RVC}$ 为阳极, $\mathrm{Pt}$ 片为阴 极, $\mathrm{MeOH}$ 为溶剂, 氩气保护下回流, 以恒电流模式在 单电解池中电解, 底物 24-1 中的榺基 $\mathrm{N}-\mathrm{H}$ 键在阳极氧 化形成脒基 $\mathrm{N}$-自由基 24-2, 随后 $\mathrm{N}$-自由基加成到分子 内的芳环形成 $\mathrm{C}-\mathrm{N}$ 键, 完成关环, 最后经历氧化芳构 化过程得到目标产物 24-3. 传统形成亚胺 N-自由基中 间体的方法通常涉及氮杂键的断裂，徐海超课题组开发 的基于 $\mathrm{N}-\mathrm{H}$ 断裂的亚胺 $\mathrm{N}$-自由基形成提供了一种新 型的亚胺 $\mathrm{N}$-自由基的生成方法, 该方法无需添加过渡 金属催化剂和氧化剂, 具有较广的底物适用范围和较高 原子经济性, 为基于亚胺 $\mathrm{N}$-自由基的杂环合成开辟了 新的途径. 通过反应的机理研究, 作者证实了脒基自由 
基中间体的存在.

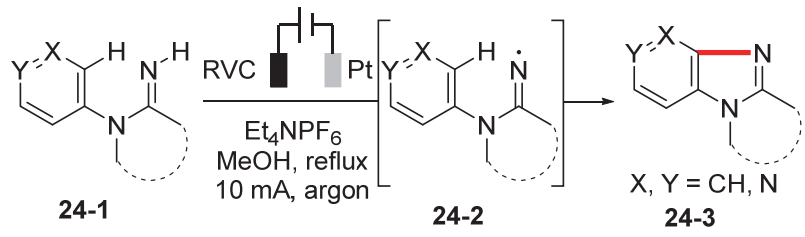

图式 24 脒基自由基的电化学形成及其在 $\mathrm{C}-\mathrm{H}$ 官能团化反 应中的应用

Scheme 24 Amidinyl radical formation via anodic oxidation and its application in aromatic $\mathrm{C}-\mathrm{H}$ bond functionalization

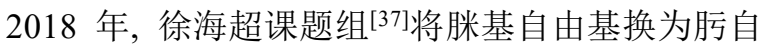
由基，通过电氧化酮肜形成肜自由基与芳环发生分子内 交叉偶联反应，采用不同的阴极材料选择性合成 $\mathrm{N}$-杂 环芳烃的氮氧化物和脱氧的 $N$-杂芳烃(Scheme 25). 当 使用 $\mathrm{Pt}$ 片为阴极，二芳基酮肜的电解会发生脱氢环化， 生成基于 $N$-杂芳烃的氮氧化物 25-2; 当使用 $\mathrm{Pb}$ 为阴极 时，会发生顺序脱氢环合/阴极脱氧，从而形成脱氧的 $N$-杂芳烃化合物 25-3.

自由基捕获实验证实了肜自由基中间体的参与. 结 合先前的报道，作者提出了二芳基酮肜的电化学环化机 理. 首先, TEMPO 在阳极上氧化为 $\mathrm{TEMPO}^{+}$, 然后与 25-1 反应得到肜自由基 25-4. 肜自由基对苯环的自由
基环化，进一步芳构化得到氮氧化物 25-2. 当采用 $\mathrm{Pt}$ 片 作阴极时, $\mathrm{H}_{2} \mathrm{O}$ 被阴极还原生成 $\mathrm{H}_{2}$ 和 $\mathrm{HO}^{-}$. 然而, 当使 用 $\mathrm{Pb}$ 作阴极时, $\mathrm{H}_{2}$ 的析出需要更高的电势, 这时更有利 于 25-2 的 $\mathrm{N}-\mathrm{O}$ 键还原断裂, 利于产物 25-3 的形成.

同年，与徐海超课题组已报道的产生 $\mathrm{N}$-中心自由 基的路径不同，徐坤、曾程初等 $\left.{ }^{[3]}\right]$ 报道通过内层电子转 移过程，通过 $\mathrm{N}-\mathrm{Br}$ 键均裂生成 $N$-酰氧基酰胺自由基, 区域选择性和化学选择性地实现 $\mathrm{C}\left(\mathrm{sp}^{2}\right)-\mathrm{H}$ 和 $\mathrm{C}\left(\mathrm{sp}^{3}\right)$ $\mathrm{H}$ 键的胺化反应, 并获得内酰胺类产物(Scheme 26). 为 了有效地生成 $N$-酰胺基自由基, 在单室电解池、恒电流 模式下, 以 $\mathrm{NaBr}$ 为催化剂和电解质, $\mathrm{Pt}$ 片为阴阳极, $\mathrm{MeCN} / \mathrm{H}_{2} \mathrm{O}$ 为溶剂, 作者研究了不同保护基的酰胺化合 物, 发现新戊酰氧基(OPiv)是合成内酰胺的最佳保护基 团. 利用发展的电化学合成方法学, 作者实现了化合物 PRAP 抑制剂 PJ34 和天然产物 Phenaglaydon 的合成，证 实了该合成方法学的实用性.

通过循环伏安实验分析，作者观察到了催化电流的 产生，基于此作者证实了 $\mathrm{NaBr}$ 在反应过程中起到了催 化作用. 该反应历程如下: 首先, 底物 26-1 中酰胺 N$\mathrm{H}$ 被阴极产生的甲氧负离子拔取质子生成氮负离子中 间体 26-4, 随后发生溴代反应生成 26-5; 然后, $\mathrm{N}-\mathrm{Br}$ 的均裂产生澳自由基和 $\mathrm{N}$-中心自由基 26-6; 随后, $\mathrm{N}$-自

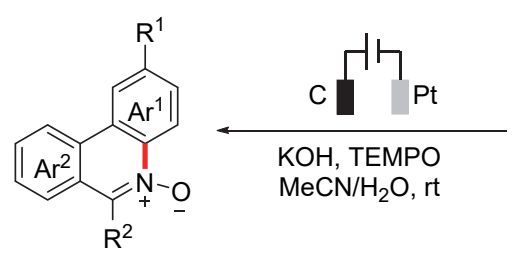

25-2

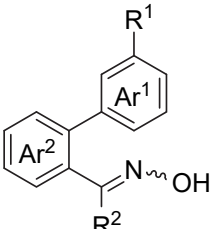

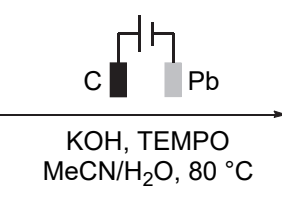
$\mathrm{KOH}, \mathrm{TEMPO}$
$\mathrm{MeCN} / \mathrm{H}_{2} \mathrm{O}, 80^{\circ} \mathrm{C}$

$\mathrm{R}^{2}$

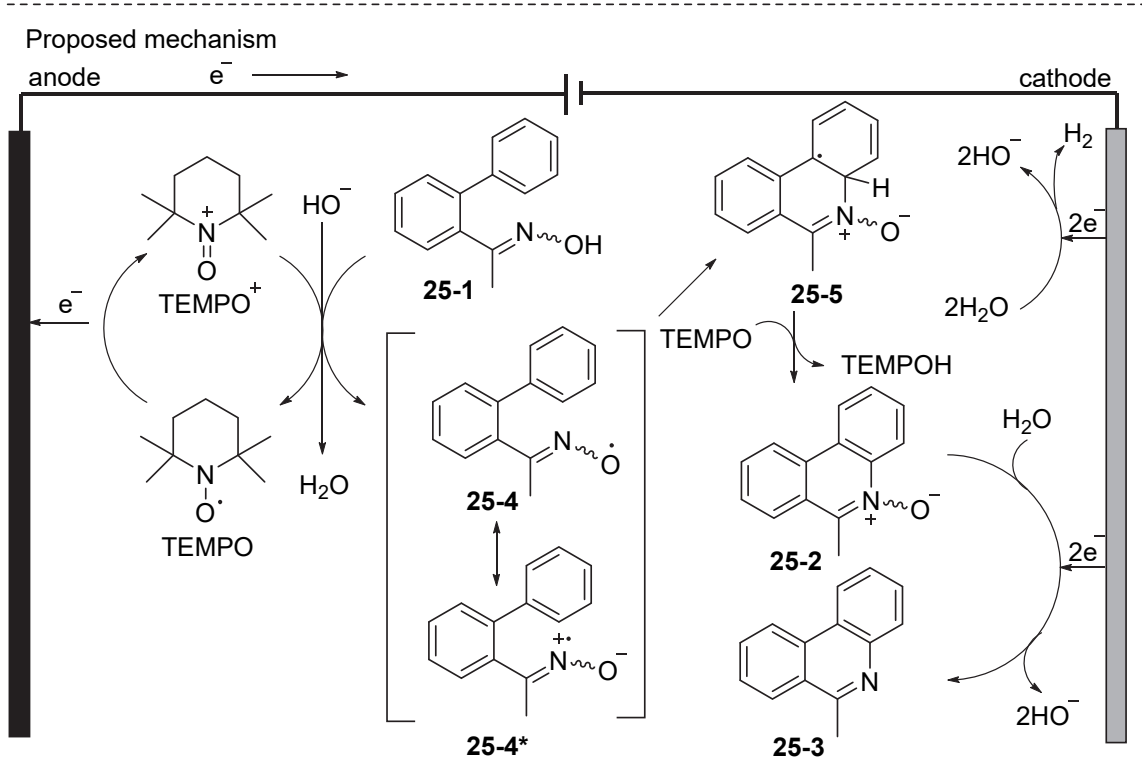

图式 25 阴极材料决定的二芳基酮肟电化学 $\mathrm{C}-\mathrm{H}$ 官能团化反应

Scheme 25 Cathode material determined product selectivity for electrochemical C-H functionalization of biaryl ketoximes 


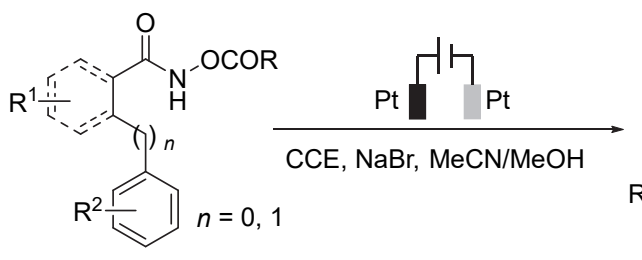

26-1

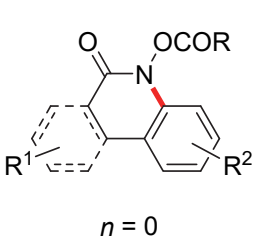

26-2

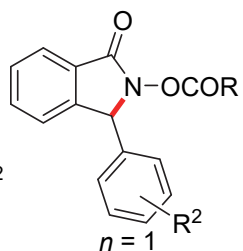

26-3

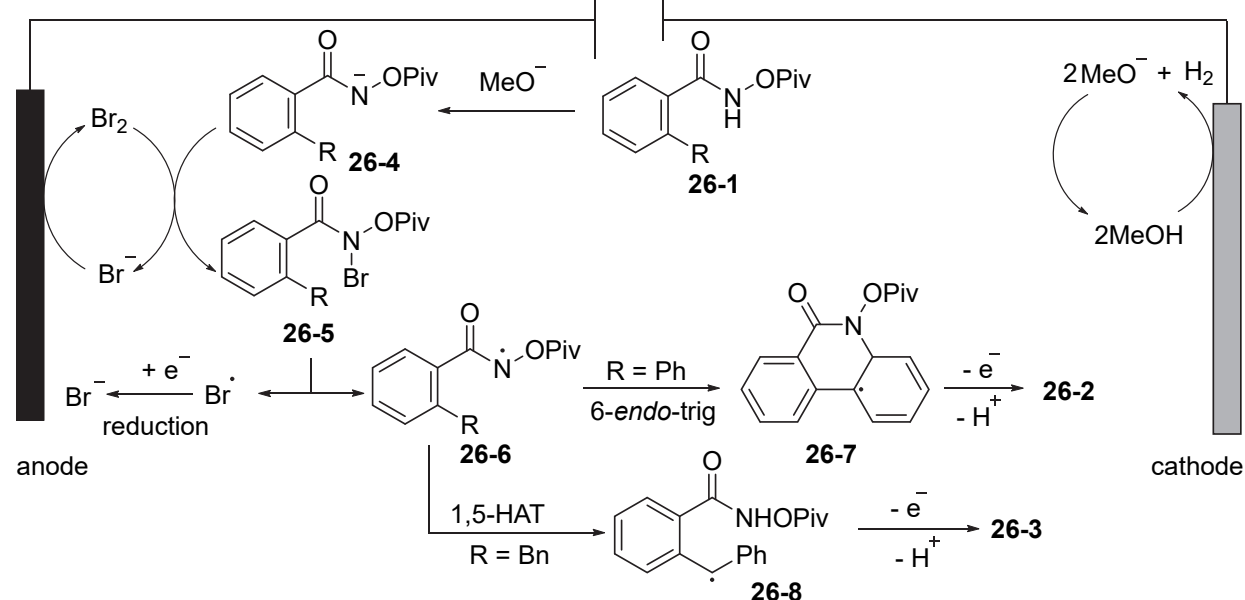

图式 $26 \mathrm{C}\left(\mathrm{sp}^{2} / \mathrm{sp}^{3}\right)-\mathrm{H}$ 键的区域选择性内酰胺化反应

Scheme 26 Regioselective intramolecular amidation of $\mathrm{C}\left(\mathrm{sp}^{2} / \mathrm{sp}^{3}\right)-\mathrm{H}$ bonds

由基通过 6-endo-trig 环化反应生成 $\mathrm{C}$-自由基中间体 26-7; 最后, 中间体 26-7 进一步氧化脱氢转化为产物 26-2. 对于 $\mathrm{C}\left(\mathrm{sp}^{3}\right)-\mathrm{H}$ 胺化反应, 分子内的 1,5-氢原子转 移得到苄基自由基 26-8, 其进一步氧化/分子内环化得 到内酰胺产物 26-3.

最近, 郭凯课题组 ${ }^{[39]}$ 利用有机电催化剂, 在无外部 氧化剂与无金属的条件下，经由 $\mathrm{N}$-自由基诱导的芳基 迁移过程, 用于 $\mathrm{C}-\mathrm{N}$ 键的高效构建(Scheme 27). 含芳 烃或杂芳烃的邻氨基茮醇被选作模型底物, 使用 $\mathrm{MeCN} / \mathrm{TFE}$ 为溶剂, ${ }^{n} \mathrm{Bu}_{4} \mathrm{NBF}_{4}$ 为电解质, 在 $70{ }^{\circ} \mathrm{C} 、 8 \mathrm{~mA}$ 恒电流下, 在配备有碳毡为阳极和 $\mathrm{Pt}$ 片为阴极的单室 电解池中电解, 当反应消耗 $1.990 \mathrm{~F} / \mathrm{mol}$ 的电荷时, 能以 优异的产率生成所需的迁移产物. 控制实验证实了吩噻 嗪催化剂和电流是该反应必不可少的两个要素. 基于机 理实验和先前报道, 作者提出了该反应的可能反应过 程: 首先, 阴极还原产生的 TFE 负离子作为碱算取底物 的氢离子生成 N-负离子中间体, 其被 Cat. ${ }^{+}$氧化得到相 应的 N-自由基中间体 27-3, 随后其对分子内的芳基加 成转化为螺环自由基中间体. 最后, 通过 $\mathrm{C}\left(\mathrm{sp}^{3}\right)-\mathrm{C}\left(\mathrm{sp}^{2}\right)$ 裂解和 $\mathrm{C}-\mathrm{N}$ 杂芳基迁移形成 $\mathrm{C}$-自由基中间体 27-4, 并 被 Cat. ${ }^{+}$氧化生成最终产物 27-2.

除了利用 $\mathrm{N}$-自由基构建 $\mathrm{C}-\mathrm{N}$ 键, 2015 年 Yoshida 课 题组 ${ }^{[40]}$ 报道了一种电化学分子内 $\mathrm{C}-\mathrm{H}$ 键胺化新方法 (Scheme 28), 该方法以 2-嘧啶氧基苯或 2-嘧啶硫基苯为

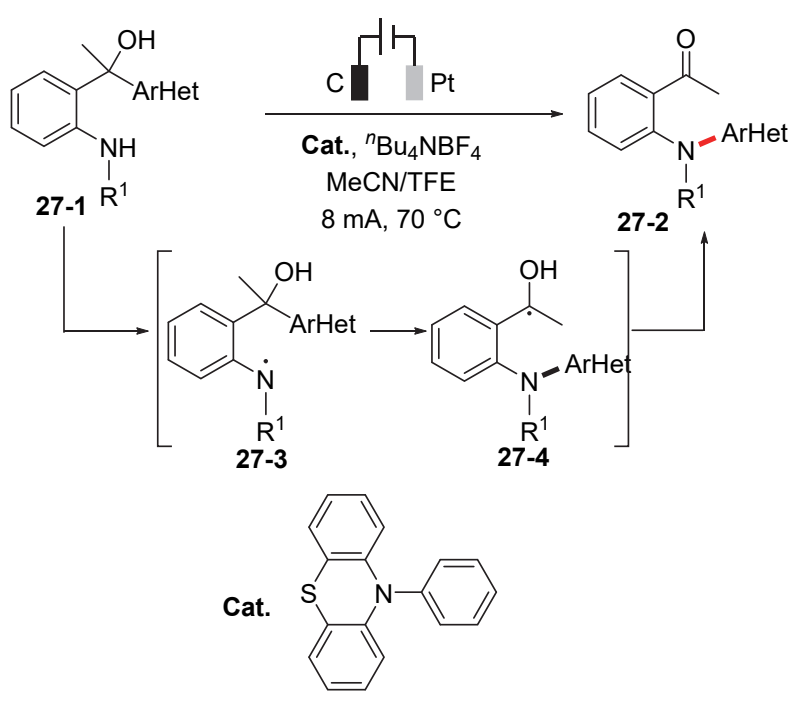

图式 $27 \mathrm{~N}$-自由基引发的芳基远程迁移反应

Scheme 27 Nitrogen-centered radical induced aryl migration reaction

底物, 以电化学氧化芳烃获得的芳烃自由基阳离子作为 关键中间体. 在配有碳毡阳极和 $\mathrm{Pt}$ 片阴极的 $\mathrm{H}$ 型隔膜电 解池中, 向阳极室中加入 2-嘧啶氧基苯或 2-嘧啶硫基 苯、 $\mathrm{K}_{2} \mathrm{CO}_{3}$ 及 $\mathrm{LiClO}_{4}$ 的 $\mathrm{MeCN}$ 溶液, 阴极室中加入 $\mathrm{CF}_{3} \mathrm{SO}_{3} \mathrm{H} 、 \mathrm{LiClO}_{4}$ 的 $\mathrm{MeCN}$ 溶液, 2-嘧啶氧基苯或 2-嘧 啶硫基苯 28-1 首先以恒电流模式电解，经由分子内碳 氢键胺化反应得到三环阳离子化合物 28-2. 然后, 该阳 离子化合物在哌啶中加热反应, 可以在非电解条件下转 
化为 2-氨基苯并噻唑或 2-氨基苯并呋喃 28-3.

2017 年, 徐海超课题组 ${ }^{[41]}$ 利用 $\mathrm{NH}_{3}$ 与邻芳基取代 的芳甲醛原位生成的亚胺为关键中间体, 也实现了电化 学介导的 $\mathrm{C}-\mathrm{H} / \mathrm{N}-\mathrm{H}$ 交叉脱氢偶联反应(Scheme 29). 该反应在室温下氩气氛围中, 以 $\mathrm{RVC}$ 为阳极, $\mathrm{Pt}$ 片为阴 极, $\mathrm{HFIP} / \mathrm{MeOH}$ 的混合液为溶剂, 在单室电解池中以恒 电流模式电解, 邻位芳基取代的芳香甲醛与 $\mathrm{NH}_{3}$ 发生串 联环化反应, 得到一系列菲啶类含氮稠杂环. 该方法无 需额外添加电解质, 反应条件温和, 且具有较好的底物 范围和区域选择性. 根据密度泛函理论(DFT)计算结果 和已有文献报道, 作者认为该方法涉及芳基自由基阳离 子中间体. 首先, 醛基和 $\mathrm{NH}_{3}$ 之间的缩合产生醛亚胺中 间体 29-3, 其在阳极上被氧化转化为芳基自由基阳离子 29-4. 随后, 亚胺进攻芳基阳离子形成 $\mathrm{C}-\mathrm{N}$ 键, 从而实
现了分子内关环; 最后，中间体 29-5 再失去一个电子和 两个质子，生成菲啶类目标产物 29-2.

通过烯烃的官能团化来构建 $\mathrm{C}-\mathrm{N}$ 键, 经由三元环 状碘鎓离子中间体是一种常用的策略. 2020 年, 汪志勇 课题组 ${ }^{[42]}$ 采用碘盐为介质的间接电解方式，在无金属 条件下通过阳极氧化来选择性合成吲哚和吲哚啉的方 法(Scheme 30). 该反应以 $\mathrm{Me}_{4} \mathrm{NI}$ 为电解质, $\mathrm{MeCN} / \mathrm{H}_{2} \mathrm{O}$ 的混合液为溶剂, $\mathrm{KSCN}$ 为添加剂, $\mathrm{Pt}$ 片电极为阴阳极, 反应温度为 $80{ }^{\circ} \mathrm{C}$, 在单室电解池中以恒电流模式电解, $N$-磺酰基保护的 2-乙烯基苯胺衍生物 30-1 发生分子内 $\mathrm{C}\left(\mathrm{sp}^{2}\right)-\mathrm{H}$ 胺化反应，生成 $\mathrm{N}$-磺酰基吲哚 30-3. 然而，以 $\mathrm{Me}_{4} \mathrm{NI}$ 为催化剂, $\mathrm{NH}_{4} \mathrm{PF}_{6}$ 为电解质, $\mathrm{CH}_{3} \mathrm{CN} / \mathrm{H}_{2} \mathrm{O}$ 的混合 液为溶剂, $\mathrm{Pt}$ 片电极为阴阳极, 室温下在单室电解池中 以恒电流模式电解, N-磺酰基保护的 2-乙烯基苯胺衍生<smiles>[X]c1ccccc1I</smiles>

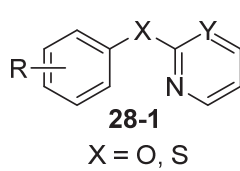
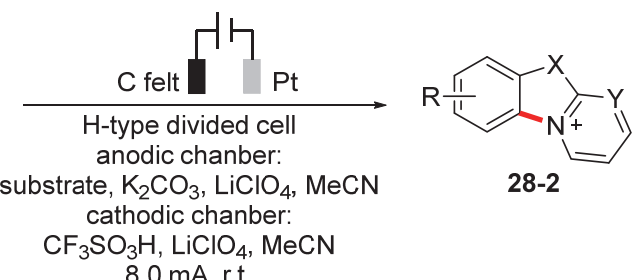

piperidine

$\mathrm{X}=\mathrm{O}, \mathrm{S}$ $\mathrm{Y}=\mathrm{CH}, \mathrm{N}$

$\mathrm{CF}_{3} \mathrm{SO}_{3} \mathrm{H}, \mathrm{LiClO}_{4}, \mathrm{MeCN}$

28-2

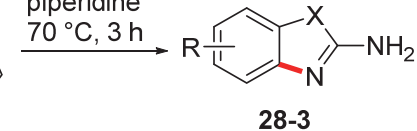

$8.0 \mathrm{~mA}$, r.t.

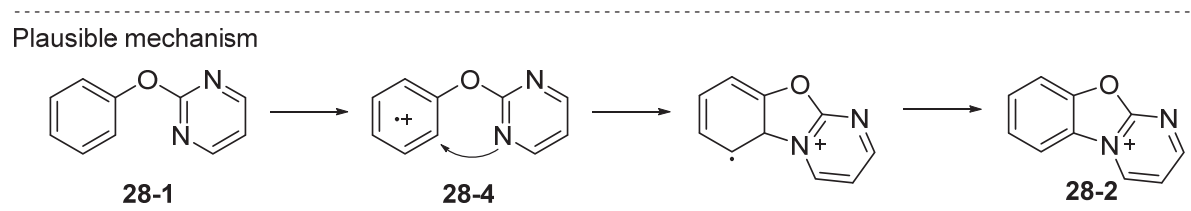

图式 28 电化学诱导的分子内 $\mathrm{C}-\mathrm{H}$ 胺化

Scheme 28 Electrochemical induced intramolecular $\mathrm{C}-\mathrm{H}$ amination
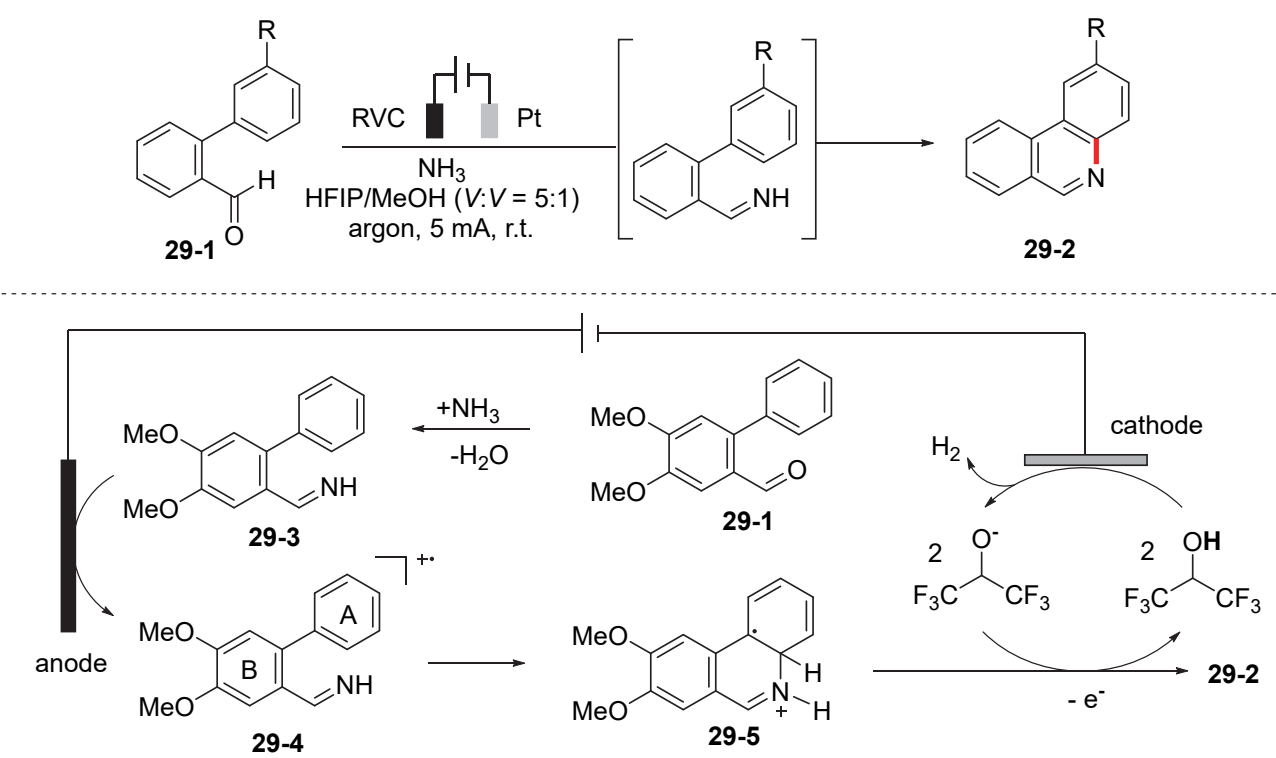

图式 29 二芳醛与 $\mathrm{NH}_{3}$ 区域选择性合成 $N$-杂芳烃

Scheme 29 Regioselective synthesis of $N$-heteroaromatics from biaryl aldehydes and $\mathrm{NH}_{3}$ 

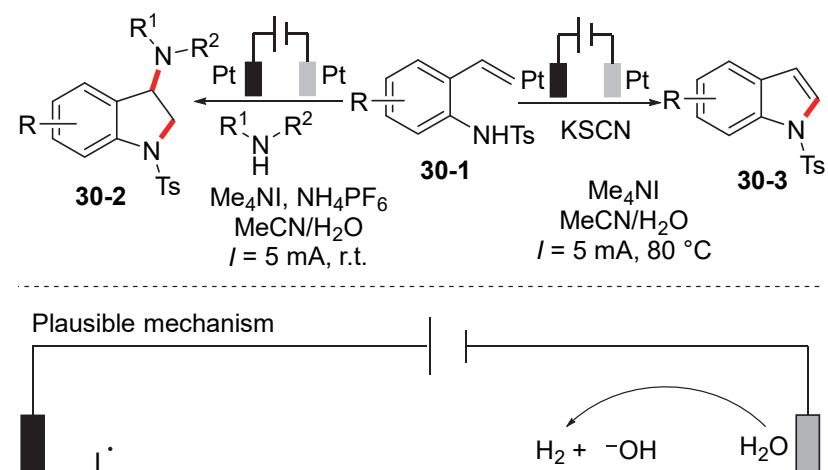

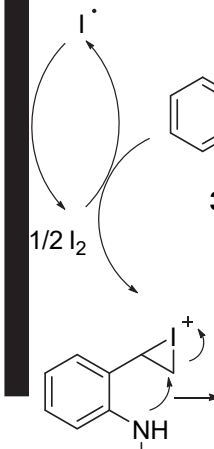

Ts

$30-4$

图式 30 碘盐介导的电化学合成吲哚啉和吲哚

Scheme 30 Iodide-mediated electrosynthesis of indolines and indoles

物可与 $\mathrm{N}-\mathrm{H}$ 的苯胺发生串联环化反应, 生成 3-位苯胺 基取代的二氢吲哚化合物 30-2.

自由基抑制剂 TEMPO 或 BHT 的加入并不能抑制 反应的进行; 采用含环丙基的底物进行自由基钟实验, 得到了环丙基保留的产物. 这些实验结果表明该反应不 涉及自由基机理, 可能是离子型反应机理. 首先, 碘负 离子在阳极被氧化成 $I_{2}, I_{2}$ 与底物 30-1 反应得到三元环 状碘鎓离子中间体 30-4; 随后, 底物中氮原子对碘鎓离 子的分子内亲核加成得到中间体 30-5, 并进一步脱质子 化生成 3-碘代的二氢吲哚 30-6; 最后, 30-6 与 $\mathrm{PhNH}_{2}$ 发 生亲核取代反应生成 3-苯胺基取代的二氢吲哚 30-2; 当 反应体系中存在硫氰酸钾时, 硫氰基可取代碘生成 3-硫 氰基取代的二氢吲哚 30-7, 随后在碱的作用下发生消除 反应生成吲哚 30-3.

基于三元环状碘鎓离子中间体形成 $\mathrm{C}-\mathrm{N}$ 键的策 略, 汪志勇课题组 ${ }^{[43]}$ 将亲核试剂由苯胺换为叠氮化钠, 开发了电化学条件下一锅构建两个 $\mathrm{C}-\mathrm{N}$ 键的串联环化 反应，并用于合成 3-叠氮基取代的吲哚啉(Scheme 31). 该反应以 $\mathrm{Me}_{4} \mathrm{NI}$ 为电解质, $\mathrm{HOAc}$ 为添加剂, $\mathrm{MeCN} / \mathrm{H}_{2} \mathrm{O}$ 为溶剂, 阴极和阳极均为石墨棒, 室温下, 在单室电解 池中以恒电流模式电解, $N$-磺酰基保护的 2-乙烯基苯胺 衍生物 31-1 与叠氮化钠反应, 以较高的收率得到一系 列 3-叠氮基取代的吲哚啉类化合物 31-2.

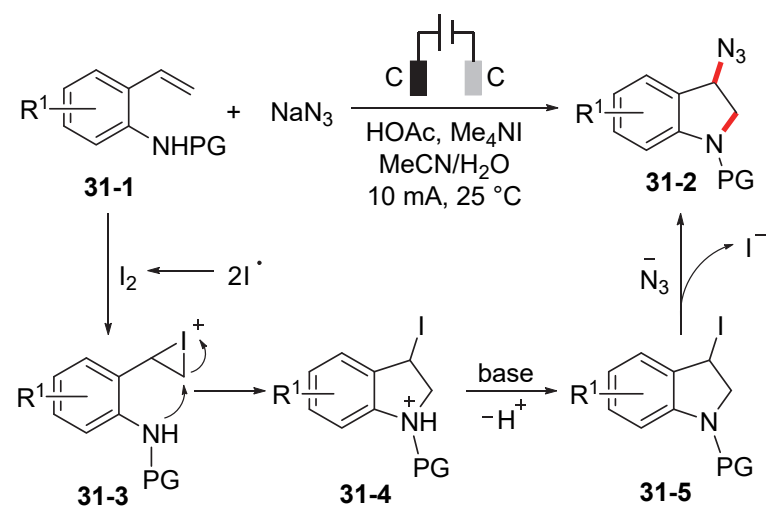

图式 31 电化学合成 3-叠氮基吲哚啉

Scheme 31 Electrochemical synthesis of 3-azido-indolines

\section{2 分子间 $\mathrm{C}\left(\mathrm{sp}^{2}\right)-\mathrm{N}$ 键偶联反应}

2015 年，曾程初和 Little 等 ${ }^{[44]}$ 基于光电协同的策略, 实现了 $N$-杂环丙烷 32-3 的电化学绿色合成(Scheme 32). 该反应以 $N$-氨基邻苯二甲酰亚胺作为氮源, TFE 作为溶 剂, ${ }^{n} \mathrm{Bu}_{4} \mathrm{NI}$ 作为催化剂, 在碳棒作为阳极, 铁片作为阴 极的单室电解池中以电流密度为 $4 \mathrm{~mA} / \mathrm{cm}^{2}$ 的条件下电 解, 能够获得多种取代基类型的氮杂环丙烷.

基于控制实验及密度泛函计算结果, ${ }^{n} \mathrm{Bu}_{4} \mathrm{NI}$ 介导的 电化学氮杂环丙烷化反应机理被提出. 首先, 碘负离子 在阳极氧化生成 $\mathrm{I}_{2}$, 然后与 ${ }^{n} \mathrm{Bu}_{4} \mathrm{NI}$ 反应生成 ${ }^{n} \mathrm{Bu}_{4} \mathrm{NI}_{3}$, 其 在可见光的激发下生成 $\mathrm{I}^{\bullet}$ 和 $\mathrm{I}_{2}{ }^{--}$. 随后, $\mathrm{I}^{\bullet}$ 篗取 $N$-氨基邻 苯二甲酰亚胺 32-1 的氢原子生成氮基自由基 32-4, 而后 被烯烃 32-2 捕获形成 C-自由基 32-5. 最后, 含 C-自由 基发生进一步的氧化和分子内的环化得到氮杂环丙烷 化合物.

3-氨基喹啉酮骨架广泛存在于抗菌、抗病毒、抗癌、 抗糖尿病和抗炎等生物活性化合物中，对此进行结构修 饰有利于发现性能更好的化合物, 因此开发喹喔啉酮的 胺化反应具有重要的研究意义. 2019 年, 曾程初与孙宝 国课题组 ${ }^{[45]}$ 开发了电氧化条件下的喹喔啉酮的 $\mathrm{C}-\mathrm{H}$ 胺 化反应，脂肪胺和唑类都可作为氮源(Scheme 33). 该反 应发生以石墨作阳极, Pt 片作阴极, HOAc 为添加剂, $\mathrm{LiClO}_{4}$ 为电解质, $\mathrm{DMF}$ 为溶剂, 在单室电解池中采用恒 电流电解模式. 但是, 该方法不适用于伯胺类化合物.

根据先前文献报道和循环伏安实验，作者认为该反 应涉及自由基机理历程. 首先, 胺 33-2 经历阳极氧化生 成 $\mathrm{N}$-自由基 33-4; 随后该自由基被质子化的喹喔啉酮 33-5 捕获，生成自由基阳离子中间体 33-6; 最后自由基 阳离子发生进一步的阳极氧化和去质子化过程, 得到目 标产物 33-3.

基于电化学氧化诱导分子间芳基 $\mathrm{C}-\mathrm{H}$ 键与 $\mathrm{N}-\mathrm{H}$ 键的交叉脱氢偶联策略, 2019 年, 雷爱文课题组 ${ }^{[46]}$ 以二 

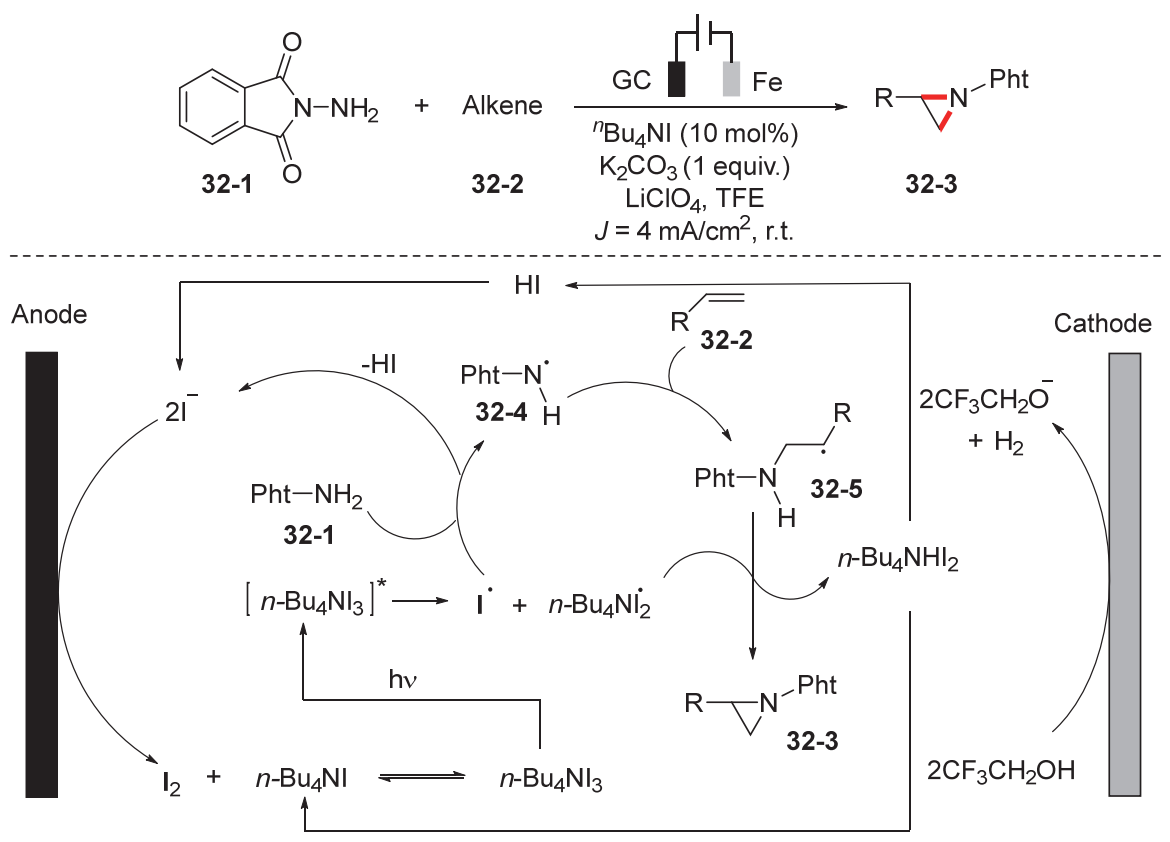

图式 32 电化学条件下烯烃的氮杂环丙烷化反应

Scheme 32 Electrochemical aziridination of alkenes

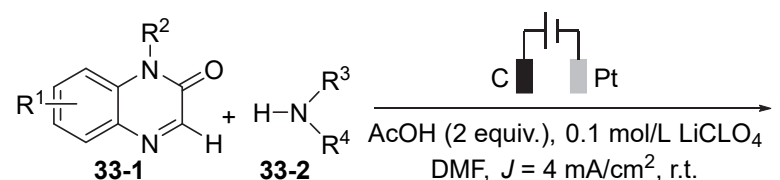<smiles>[R]N([R])c1nc2cc[R1]cc2n([R])c1=O</smiles>

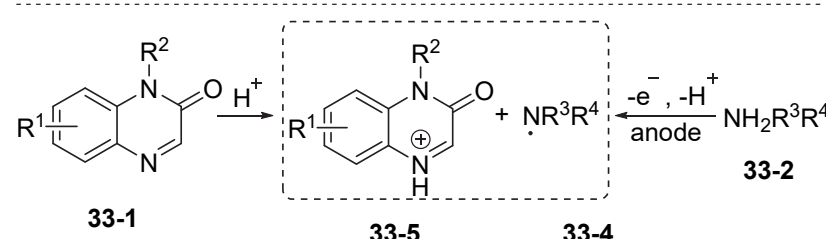<smiles>[R]N1C(=O)C(N([R])[R])Nc2cc[R1]([H])cc21</smiles>

图式 33 电氧化条件下喹喔啉酮的 C-H 胺化反应

Scheme 33 Electrooxidative $\mathrm{C}-\mathrm{H}$ amination of quinoxalin$2(1 H)$-ones

磺酰亚胺为胺源, 在无催化剂和外加氧化剂条件下, 实 现了一系列芳基 C-H 键的胺化反应(Scheme 34). 该反 应在氮气氛围中, 以 ${ }^{n} \mathrm{Bu}_{4} \mathrm{NOAc}$ 作为电解质, 使用 $\mathrm{DCM} / \mathrm{MeCN} / \mathrm{HFIP}$ 三元混合溶剂, 碳棒为阳极, Pt 片为 阴极，室温下，芳烃、杂芳烃、烯烃 34-1 与磺酰胺 34-2

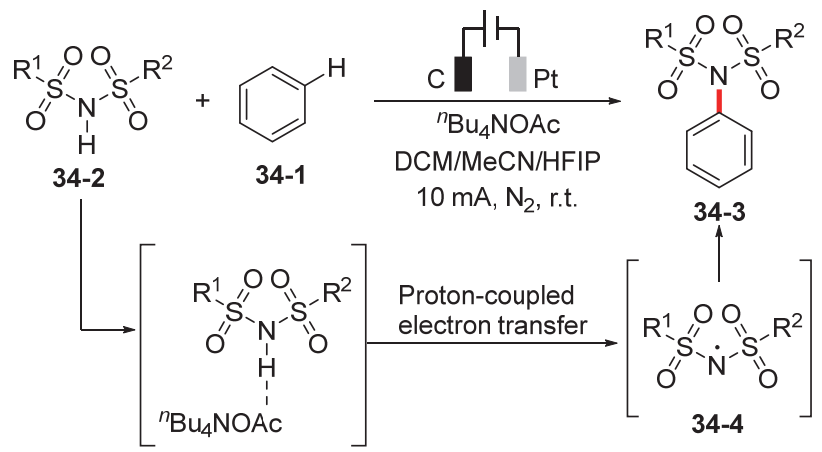

图式 34 电化学氧化诱导的分子间芳香族 $\mathrm{C}-\mathrm{H}$ 酰亚胺化反 应

Scheme 34 Electrooxidation induced intermolecular aromatic $\mathrm{C}-\mathrm{H}$ imidation

在单室电解池中以恒电流模式电解, 进而发生氧化脱氢 偶联反应得到一系列 $\mathrm{C}-\mathrm{N}$ 键偶联的产物 34-3. 自由基 捕捉实验和自由基钟实验表明反应中涉及二磺酰亚胺 自由基 34-4. 动力学同位素效应实验表明二磺酰亚胺自 由基加成到芳烃上是反应的决速步骤。循环伏安实验表 明 $\mathrm{N}$-亚胺自由基中间体的产生涉及电化学阳极氧化和 氢键相互作用 $\left({ }^{n} \mathrm{Bu}_{4} \mathrm{NOAc}\right.$ 与二磺酰亚胺 $)$ 协同的质子耦 合电子转移过程.

与已报道的烯胺或乙烯基苯胺的分子内电氧化环 化制备吡咯烷或吲哚相比，分子间的电化学氧化环化反 应研究较少. 2020 年, 雷爱文课题组 ${ }^{[47]}$ 报道了 DDQ 催 化的苯胺与烯烃的分子间电氧化环化反应(Scheme 35). 该反应以 ${ }^{n} \mathrm{Bu}_{4} \mathrm{NBF}_{4}$ 为电解质, 石墨棒为阳极, $\mathrm{Pt}$ 片为阴 
极, DDQ 为催化剂, $\mathrm{HOAc} / \mathrm{MeCN} / \mathrm{DCE}$ 为反应溶剂, $N$-(4-甲氧基苯基)-4-甲基苯磺酰胺 35-1 与 $\alpha$-甲基苯乙烯 35-2 在单室电解池中恒电流 $(10 \mathrm{~mA})$ 电解 $2 \mathrm{~h}$, 能以优异 的产率获得目标产物 35-3. 在最优条件下, 带有不同官 能团的烯烃与苯胺均具有很好的耐受性. 此外, 该反应 可以在流动电解池中进行, 不需要添加电解质, 因此具 有潜在的应用价值.

自由基捕捉实验和 EPR 结果表明该反应经历了 C自由基中间体. 此外, 循环伏安实验还表明, DDQ 与 35-1 之间无法直接发生反应. 动力学实验证实了 35-1 的 阳极氧化可能是关键步骤. 根据上述实验结果, 作者提 出了如下的反应机理: 首先, 苯胺 35-1 在阳极氧化并脱 去一分子质子生成 $\mathrm{N}$-自由基 35-4, 该自由基发生共振 可生成 C-自由基 35-5. 随后 35-5 对烯烃 35-2 的自由基 加成生成中间体 35-6. 中间体 35-6 可被 DDQ 或阳极氧 化, 然后发生分子 $\mathrm{C}-\mathrm{N}$ 键偶联生成目标分子 35-3, $\mathrm{DDQH}_{2}$ 在阳极氧化生成 DDQ, 完成催化循环. 同时, 醋酸在阴极还原释放出 $\mathrm{H}_{2}$.

三唑吡啶及其相关的三唑聚合体(杂)芳香结构是许 多生物活性分子和功能材料的核心骨架. 2018 年, 张逢 质课题组 ${ }^{[48]}$ 报道了在无金属和无氧化剂的条件下，通 过 $\mathrm{N}$-自由基对 $\mathrm{C}-\mathrm{N}$ 双键的加成反应，一锅法合成多种 功能化的三唑类化合物(Scheme 36). 该反应需要分步 进行: 第一步, 底物 36-1 和 36-2 在 $\mathrm{MeCN}$ 溶剂中进行
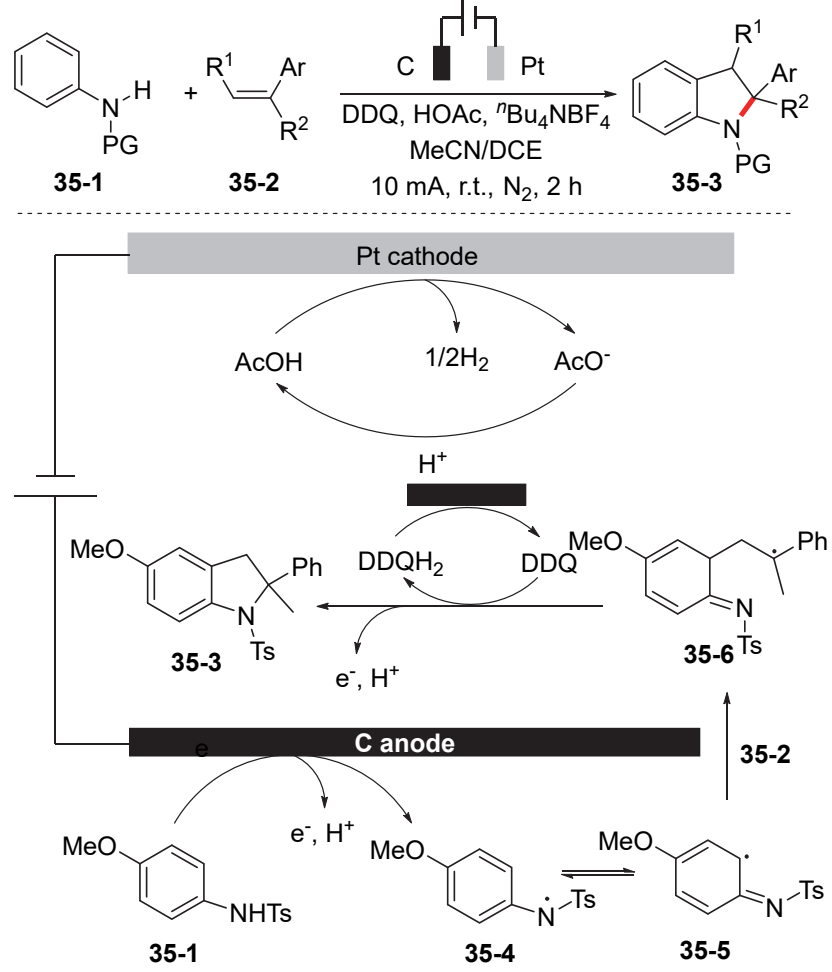

图式 35 电化学氧化诱导的 $[3+2]$ 环化反应制备吲哚啉类化 合物

Scheme 35 Electrooxidation induced [3+2] annulation for the preparation of indolines
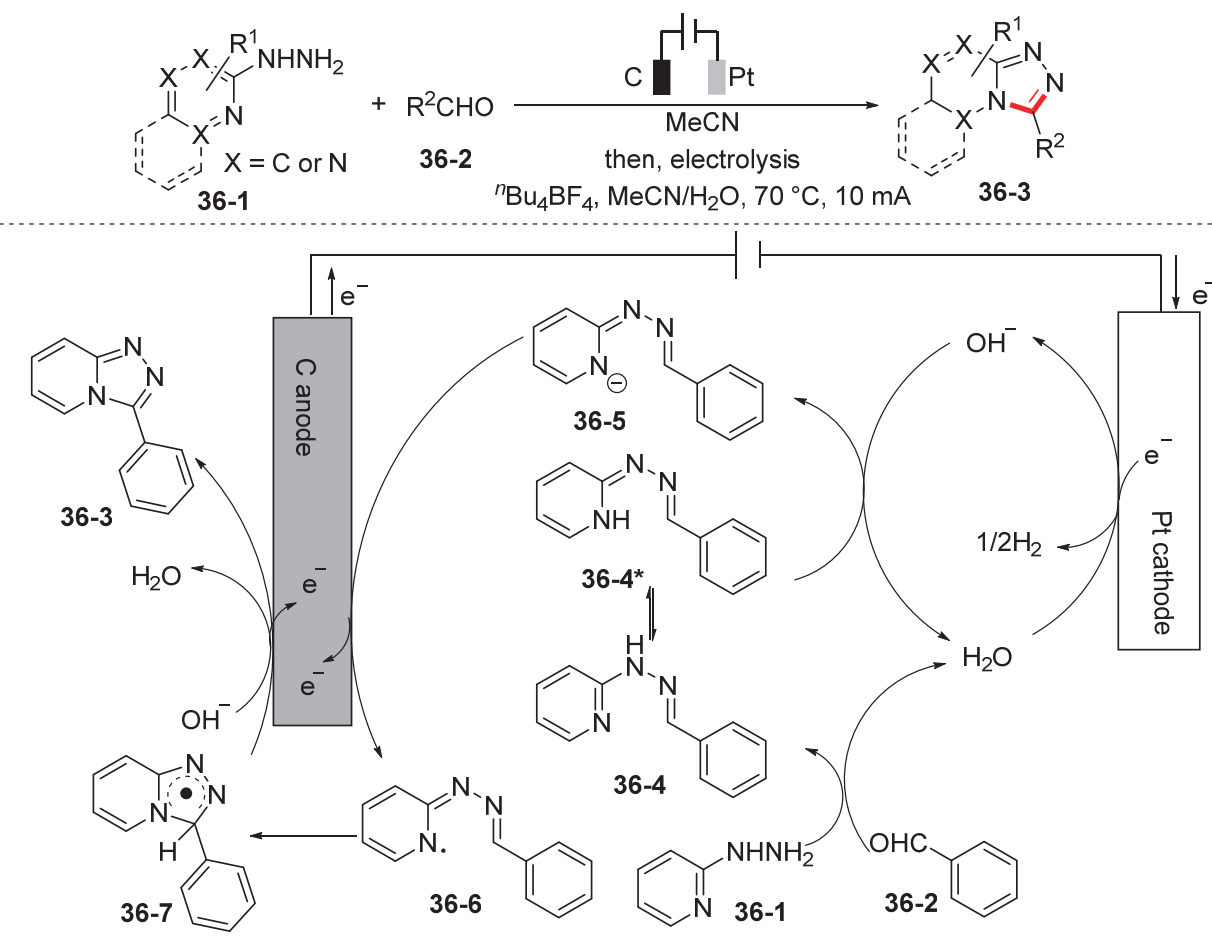

图式 36 电化学合成 $1,2,4$-三唑杂环

Scheme 36 Electrochemical synthesis of 1,2,4-triazole-fused heterocycles 
缩合; 第二步, 以 ${ }^{n} \mathrm{Bu}_{4} \mathrm{NBF}_{4}$ 为电解质, $\mathrm{MeCN} / \mathrm{H}_{2} \mathrm{O}$ 为溶 剂, 石墨棒作阳极, Pt 片作阴极, 缩合产物在单室电解 池中以恒电流模式进行电解, 能以优良的产率获得环化 产物 36-3. 在最优条件下, 芳香族醛、杂芳香族醛、脂 肪族醛和不饱和醛都具有较好的兼容性.

为了验证反应机理，作者向反应中加入自由基捕捉 剂(BHT 和 TEMPO), 发现产率大大降低, 这些实验表明 了该反应可能涉及自由基中间体. 作者提出的反应机理 如下: 首先, 2-肼吡啶 36-1 与苯甲醛 36-2 的缩合反应得 到腙 36-4, 其为 36-4*的互变异构体; 随后, 由阴极还原 产生的氢氧化物使得 36-4*脱质子生成氮负离子中间体 36-5; 36-5 在阳极进一步单电子氧化生成 $\mathrm{N}$-自由基中间 体 36-6; 最后, $N$-自由基中间体发生分子内的自由基加 成、阳极氧化和去质子化, 生成最终产物 36-3.

以自由基阳离子为关键中间体, 2018 年, 雷爱文课 题组 ${ }^{[49]}$ 开发了酚的电化学氧化 $\mathrm{C}-\mathrm{H}$ 胺化反应, 以较好 的官能团耐受性获得了三芳胺衍生物, 该方法既不需要 金属催化剂也不需要化学氧化剂 (Scheme 37). 以 ${ }^{n} \mathrm{Bu}_{4} \mathrm{NBF}_{4}$ 为电解质, $\mathrm{MeCN} / \mathrm{MeOH}$ 为溶剂, 石墨棒为阳 极, 镍片为阴极, 对甲氧基苯酚 37-1 与吩噻嗪 37-2 在单 电解池中以恒电流模式电解 $100 \mathrm{~min}$, 以优异的分离产 率获得偶联产物. 但是, 对位含有较强吸电子基团的酚 类化合物以较低的收率获得胺化产物. 含卤素、给电子 或吸电子取代基的吩噻嗪类化合物均能以好到高的收 率得到胺化产物. 通过循环伏安实验, 作者认为 37-2 首 先在阳极氧化生成自由基阳离子中间体 37-4. 然后, 自 由基阳离子中间体 37-4 与酚类 37-1 进行亲电加成得到 C-自由基中间体 37-5. 随后, 37-5 经历阳极氧化和去质 子过程得到目标产物 37-3. 同时, 原位生成的质子在阴 极被还原释放出 $\mathrm{H}_{2}$.

酪氨酸作为一种重要的天然氨基酸, 存在于多种多 肽和蛋白质中, 如酪氨酸蛋白激酶、吻素和肌红蛋白等. 由于酪氨酸在天然蛋白质中的丰度较低, 它可用于标记 生物分子. 2019 年, 雷爱文课题组 ${ }^{[50]}$ 利用直接电化学氧 化策略, 较简便地实现了酪氨酸与吩噻嗪 38-2 的偶联 (Scheme 38). 酪氨酸与吩噻嗪在单室电解池中, 以石墨 棒作阳极, 镍片作阴极, $\mathrm{Na}_{2} \mathrm{SO}_{4}$ 为电解质, $\mathrm{MeCN} / \mathrm{H}_{2} \mathrm{O}$ 为溶剂, 室温下以恒电流模式电解 $75 \mathrm{~min}$, 以优良产率 获得目标产物 38-3. 在最优条件下, 带卤素原子、硫醚 基、三氟甲基、乙酰基、氰基及叠氮化合物的吩噻嗪都 能与酪氨酸偶联, 并以中等的产率获得相应的产物. 含 酪氨酸的各种二肽与吩噻嗪也能顺利偶联, 但含 $\mathrm{Cys}$ (半 胱氨酸)的二肽只能获得微量的相应产物. 作者成功地 将各种未受保护的肽(从 5 肽到 29 肽)与吩噻嗪偶联, 获 得了很好的转化率. 通过控制实验, 作者还证明该方法

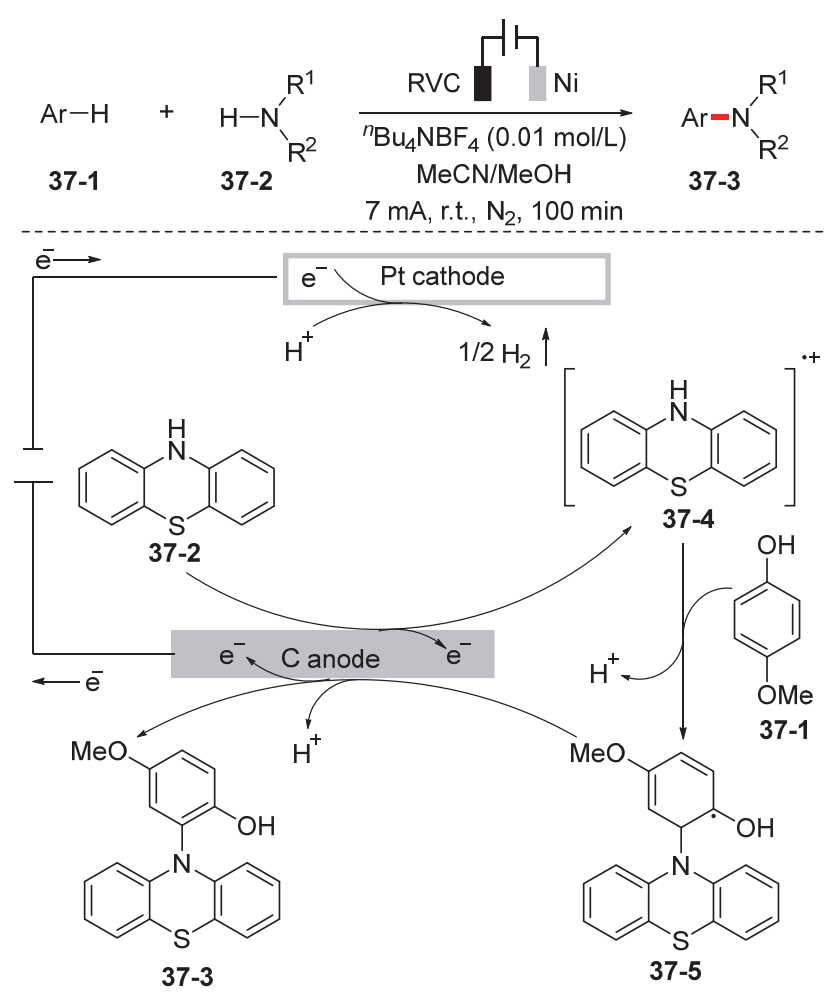

图式 37 酚类的电化学氧化 $\mathrm{C}-\mathrm{H}$ 胺化反应

Scheme 37 Electrochemical oxidative $\mathrm{C}-\mathrm{H}$ amination of phenols

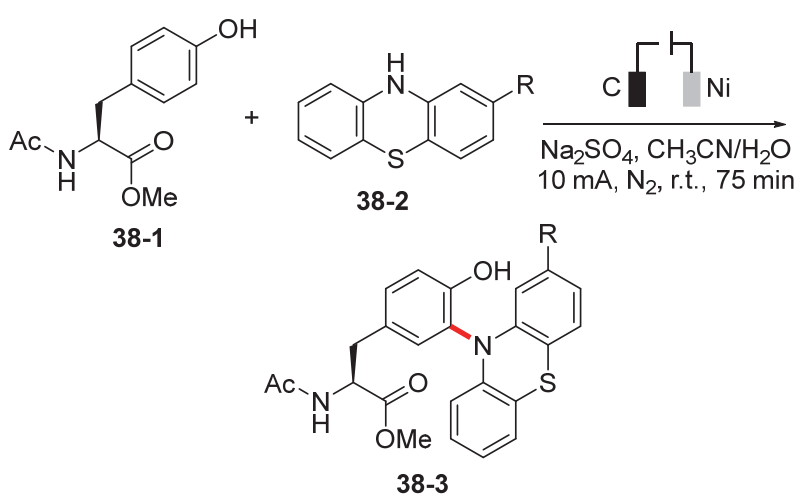

图式 38 电化学氧化诱导的酪氨酸选择性修饰反应

Scheme 38 Electrochemical oxidation induced selective modification of biomolecules with tyrosine

能够在生物分子上特异性标记酪氨酸残基, 该方法具有 良好的位点和化学选择性.

经由亲核性含氮化合物对原位生成的芳基自由基 阳离子的加成反应是一种构建 $\mathrm{C}-\mathrm{N}$ 键的重要策略. 2017 年, Waldvogel 课题组 ${ }^{[51]}$ 用吡啶作氮源, 通过电化 学阳极氧化实现了对苯氧基乙酸酯的芳基 $\mathrm{C}-\mathrm{H}$ 键胺化 反应(Scheme 39). 该反应以石墨电极作为阳极, 在以多 孔玻璃料(P4)作为隔膜的双室电解池中恒电流模式室温 下电解. 阳极室中含有底物、吡啶、 $\mathrm{Bu}_{4} \mathrm{NBF}_{4}$ 及 $\mathrm{MeCN}$ (溶 剂), 阴极室含有 $\mathrm{Bu}_{4} \mathrm{NBF}_{4} 、 \mathrm{CF}_{3} \mathrm{SO}_{3} \mathrm{H} 、 \mathrm{MeCN}$. 

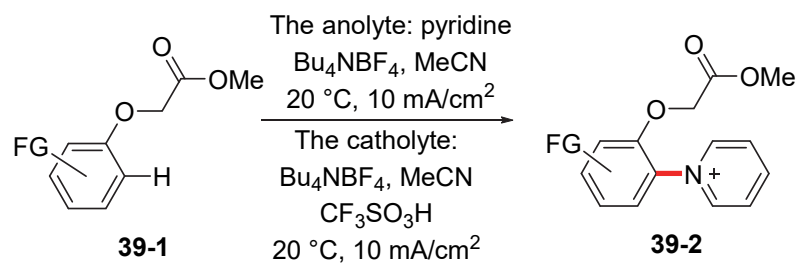

39-2

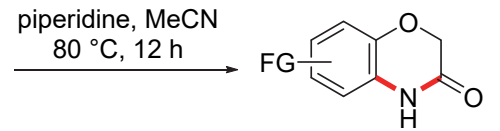

39-3

图式 39 电化学合成噁嗪酮类化合物

Scheme 39 Electrochemical synthesis of oxazinones

苯氧基乙酸甲酯 39-1 首先经历电化学阳极氧化生成芳 基自由基阳离子, 吡啶氮原子亲核进攻芳基自由基阳离 子形成 $\mathrm{C}-\mathrm{N}$ 键, 由于 $\mathrm{C}-\mathrm{N}$ 键偶联产物 39-2 为氧化电 位高的阳离子, 从而避免了芳基 $\mathrm{C}-\mathrm{H}$ 与胺直接电化学 氧化胺基化所伴随的产物过度氧化问题. 在非电解条件 下，该吡啶盐中间体 39-2 可以在哌啶的作用下开环裂 解释放出氨基, 随后发生分子内酯的胺解而关环, 得到 目标产物 1,4-苯并噁嗪-3-酮 39-3.

利用间接电解产生的芳基自由基阳离子为关键中 间体，2019 年，唐海涛、潘英明课题组 ${ }^{[52]}$ 报道了电氧化
条件下 $\mathrm{N}-\mathrm{H}$ 吲哚选择性地完成了 $\mathrm{C}(2)$-肼化和 $\mathrm{C}(3)$-磺 酰化的反应 (Scheme 40). 在氩气氛围中, 以 $\mathrm{NH}_{4} \mathrm{Br}$ 为催 化剂和电解质, $\mathrm{MeOH}$ 为溶剂, $\mathrm{Pt}$ 片为阳极, $\mathrm{RVC}$ 为阴极, 吲哚 40-1 在单室电解池中以恒电流模式电解, 以较好 的产率获得了吲哚双官能团化产物 40-2. 以 5-氟尿嘧啶 作为阳性对照药物, 采用噻唑蓝(MTT)法对产物 40-3 进 行体外抗肿瘤活性研究, 部分化合物对肿瘤细胞表现出 较强的抑制作用.

当向反应体系中加入 4 equiv. 的自由基捕捉剂 TEMPO 时，该反应被彻底抑制，使用 HRMS 去分析该 反应液, 观察到 TEMPO 与磺酰肼自由基的加成产物. 亚磷酸三乙酯也捕捉到自由基中间体，且获得吲哚磷酸 化产物. 这些结果表明反应过程中涉及自由基中间体. 结合循环伏安实验，作者认为溴离子首先在阳极被氧化 成溴自由基，磺酰肼被溴自由基氧化生成自由基中间体 40-4. 溴基自由基进一步氧化 40-4, 然后消去一分子 $\mathrm{N}_{2}$, 生成磺酰基自由基 40-7. 类似地，吲哚 40-1 可被溴自由 基氧化以产生吲哚自由基阳离子中间体 40-8, 其与磺酰 自由基 40-7 进行自由基偶联反应产生磺化吲哚中间体 40-9. 另外一分子的磺酰肼 40-2 加成到阳离子中间体 40-9 上得到二氢吲哚中间体 40-10, 其在阳极上再经历 氧化芳构化生成 2,3-二取代的吲哚衍生物 40-3.
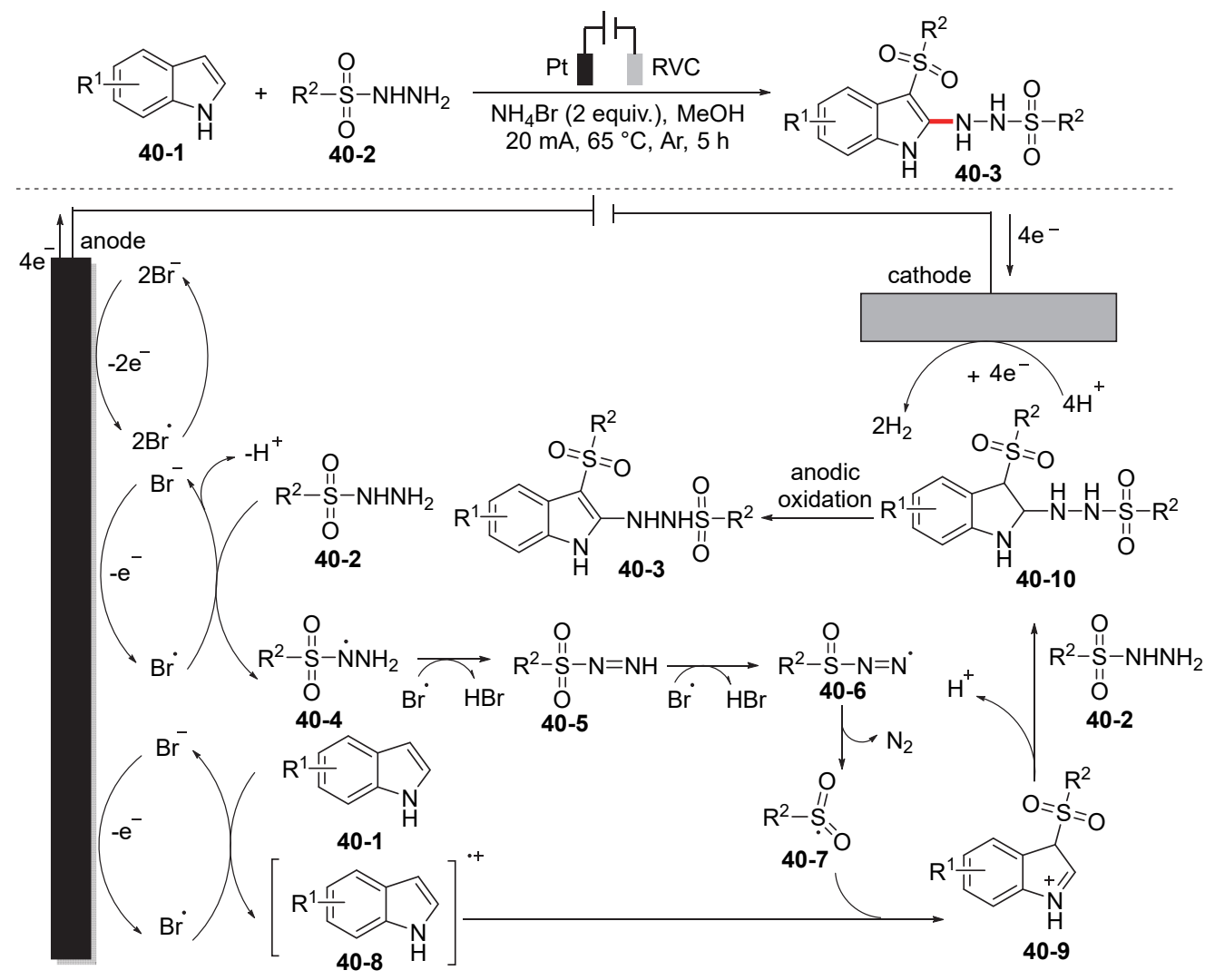

图式 40 吲哚的电化学区域选择性磺酰化和肼化反应

Scheme 40 Electrochemically enabled chemoselective sulfonylation and hydrazination of indoles 
2019 年, 吴骊珠课题组 ${ }^{[53]}$ 报道了电化学条件下无 强导向基团的烷氧基芳烃邻位胺化反应，利用该方法能 够获得不同取代基类型的芳香胺和杂芳胺(Scheme 41). 该反应以 $\mathrm{RVC}$ 为阳极, $\mathrm{Pt}$ 片为阴极, ${ }^{n} \mathrm{Bu}_{4} \mathrm{NOAc}$ 为电解 质, TFE 为溶剂, 茴香醚 41-1 和吡唑 41-2 在单室电解池
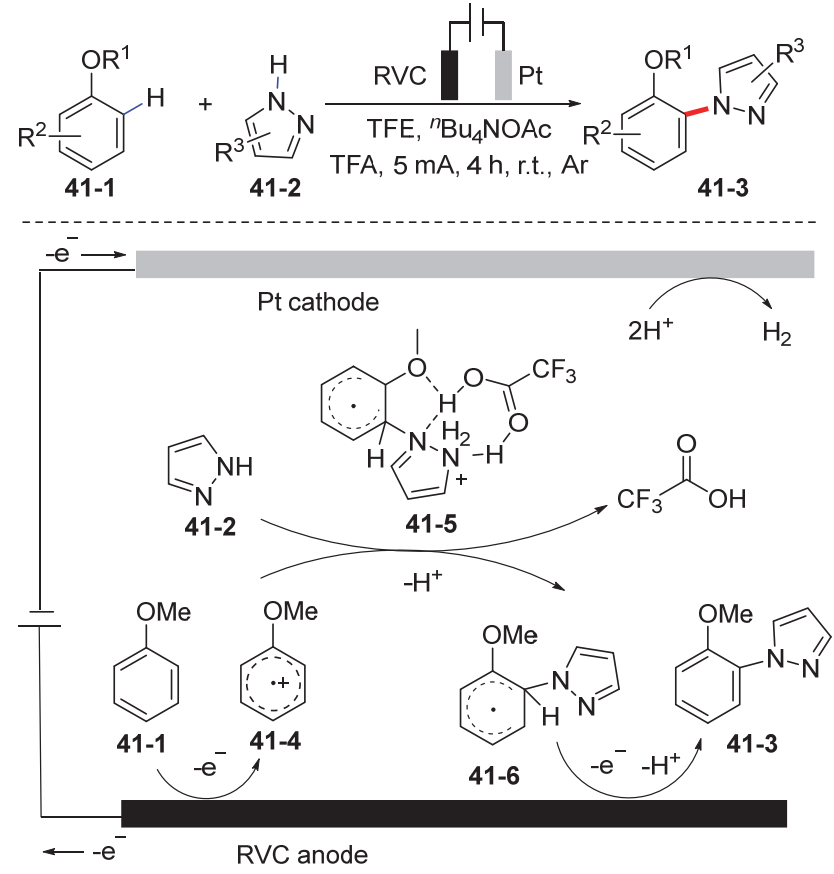

图式 41 芳香醚的电化学邻位胺化反应

Scheme 41 Electrochemical ortho-selective amination of aromatic ethers
中以恒电流模式电解时, 能够获得邻位与对位胺化产物 混合物. 但是当向反应体系中添加 TFA 时, 能选择性的 生成邻位胺化产物 41-3.

为了验证反应机理，作者进行了控制实验和循环伏 安实验. 当向反应中加入 TEMPO 或 BHT 时, 未获得目 标产物，这证实了在该反应可能涉及自由基路径. 循环 伏安实验发现茴香醚 41-1 的氧化电势低于吡唑 41-2, 表 明茴香醚先被氧化. 基于上述实验，作者提出了如下的 反应机理：首先，茴香醚 41-1 在阳极表面上通过单电子 转移氧化成相应的自由基阳离子中间体 41-4. 氟化溶剂 具有稳定自由基阳离子的作用. 随后，通过 TFA 辅助的 氢键相互作用, 吡唑作为亲核试剂进攻自由基阳离子 41-4 生成中间体 41-5, 其随后脱去一个质子生成中间体 41-6. 最后，中间体 41-6 经历阳极氧化和脱质子过程, 得到芳构化生成产物 41-3.

与电化学 $\mathrm{C}-\mathrm{H}$ 键胺化方面取得的进展相比, 电化 学条件下通过 $\mathrm{C}-\mathrm{C}$ 键断裂形成 $\mathrm{C}-\mathrm{N}$ 键的研究却很少. 最近，通过直接电化学阳极氧化产生芳基自由基阳离子 途径，焦宁课题组和曾程初课题组 ${ }^{[54]}$ 联合报道了烷基 芳烃的电化学氧化 $\mathrm{C}-\mathrm{C}$ 键胺化反应，可用于合成多样 性取代的苯胺和醛(Scheme 42). 室温下, 氩气氛围中, 以 $\mathrm{Me}_{4} \mathrm{NBF}_{4}$ 为电解质, DCE/TFA 为溶剂, 配有石墨电极 的单室电解池中, 以恒电流模式电解，一系列烷基取代 的芳烃 42-1 和烷基叠氮化物 42-2 发生基于选择性 C- $\mathrm{C}$ 键断裂的 $\mathrm{C}-\mathrm{N}$ 键形成反应。该方法避免使用过渡金属

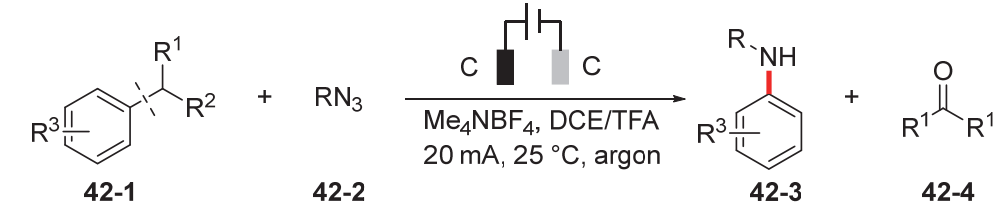

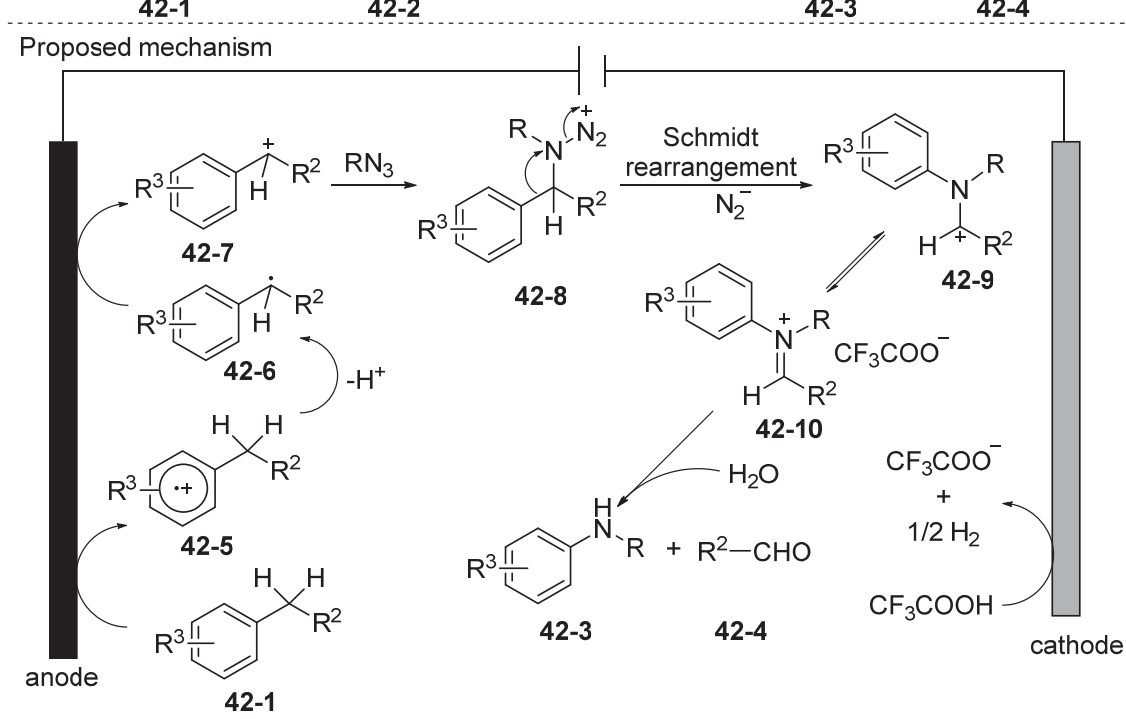

图式 42 电化学条件下通过 $\mathrm{C}-\mathrm{C}$ 键断裂形成 $\mathrm{C}-\mathrm{N}$ 键

Scheme 42 Electrochemical $\mathrm{C}-\mathrm{N}$ bond formation through $\mathrm{C}-\mathrm{C}$ bond cleavage 
催化剂和外源性化学氧化剂, 反应条件温和, 是一种新 型的电化学 $\mathrm{C}-\mathrm{N}$ 键形成方法.

循环伏安实验表明烷基芳烃比烷基叠氮化合物更 容易氧化. 基于循环伏安实验和相关文献的报道, 作者 提出了该 $\mathrm{C}-\mathrm{C}$ 键胺化反应可能的反应机理. 首先, 42-1 在阳极上被氧化, 产生芳基自由基阳离子 42-5; 中间体 42-5 脱去一个氢正离子生成茮基 C-自由基 42-6, 进一步 氧化形成苄基碳正离子中间体 42-7; 然后, 有机叠氮化 合物亲核攻击碳正离子中间体 42-7 产生中间体 42-8. 以 $\mathrm{N}_{2}$ 的释放为驱动力, 通过 Schmidt-type 重排反应生成中 间体 42-9. 最后, 中间体 42-9 发生异构化和水解反应产 生 $\mathrm{N}$-烷基苯胺 42-3 和醛 42-4.

相对于通过电化学阳极氧化产生芳基自由基阳离 子来介导 $\mathrm{C}-\mathrm{N}$ 键的形成, 通过电化学阳极氧化产生烯 基自由基阳离子来介导 $\mathrm{C}-\mathrm{N}$ 键的形成也是一种有效的 策略. 2018 年, 以氨基磺酸酯为氮源, 经由烯基自由基 阳离子途径, 程旭课题组 ${ }^{[55]}$ 报道了三芳基取代烯烃的 氮杂环丙烷化反应 (Scheme 43). 室温下, 氩气气氛中, 以石墨毡为电极, $\mathrm{LiClO}_{4}$ 为电解质, $\mathrm{MeCN}$ 为溶剂, 2,6二甲基吡啶为碱, 在单室电解池中以恒电位模式电解, 三芳基取代烯烃 43-1 与氨基磺酸六氟异丙醇酯(Hfs$\mathrm{NH}_{2}$, 43-2) 反应，得到一系列氮杂环丙烷 43-3.

机理实验表明, 该反应涉及氨基磺酸酯和电化学阳 极氧化产生的碳阳离子物种之间分步形成两个 $\mathrm{C}-\mathrm{N}$ 键. 首先, 烯烃 43-1 经过直接的阳极氧化形成自由基阳 离子中间体 43-4; 氨基磺酸酯亲核进攻中间体 43-4 形 成第一个 $\mathrm{C}-\mathrm{N}$ 键, 再在碱的作用下脱质子产生 $\mathrm{C}$-自由 基中间体 43-5; 随后, C-自由基中间体 43-5 在阳极上被 氧化成碳正离子中间体 43-6; 最后, 分子内的氮原子和 碳正离子形成 $\mathrm{C}-\mathrm{N}$ 键关环得到氮杂环丙烷产物 43-3.

经由间接电解产生的烯基自由基阳离子途径, 2019 年, 徐海超课题组 ${ }^{[5]}$ 报道了电化学条件下烯烃 44-1 与

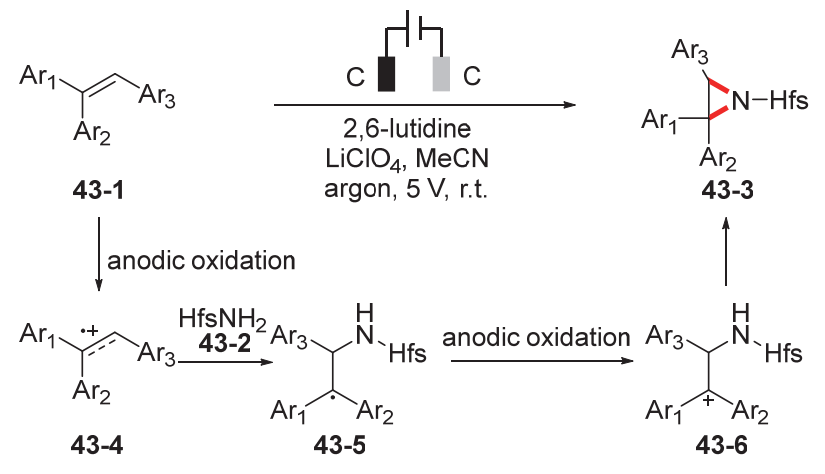

图式 43 三芳基乙烯的电化学氮杂环丙烷化反应 Scheme 43 Electrochemical aziridination of triaryl ethylenes

磺酰胺 44-2 的脱氢环化反应(Scheme 44). 室温下, 以三 芳胺为催化剂, $\mathrm{Et}_{4} \mathrm{NPF}_{6}$ 为电解质, ${ }^{i} \mathrm{PrCO}_{2} \mathrm{H}$ 和 $\mathrm{BF}_{3} \cdot \mathrm{Et}_{2} \mathrm{O}$ 为添加剂, $\mathrm{MeCN} / \mathrm{CH}_{2} \mathrm{Cl}_{2}$ 为溶剂, 以 $\mathrm{RVC}$ 为阳极, $\mathrm{Pt}$ 片 电极为阴极, 在单室电解池中恒电流模式电解, 烯烃和 磺酰胺反应生成五元环状磺酰二胺 44-3. 非电化学条件 下进一步脱除磺酰基得到 1,2-二胺类化合物 44-4. 使用 单取代的磺酰胺为原料，通过该策略可制备出具有两个 不同胺基的 1,2-二胺化合物. 该方法通过有机电子转移 催化剂与电的结合避免了过渡金属催化剂和外源性化 学氧化剂的使用, 且增强了底物和官能团的兼容性.

该反应利用三芳基胺介导的间接电解过程, 将烯基 转化为烯基自由基阳离子中间体 44-5; 磺胺 44-2 捕获 烯烃自由基阳离子 44-5, 生成 C-自由基中间体 44-6; 中 间体 44-6 经历三芳基胺介导的单电子转移过程转化为 碳正离子中间体 44-7, 随后氮原子亲核进攻碳正离子形 成第二个 $\mathrm{C}-\mathrm{N}$ 键, 最终得到环状磺酰二胺产物 44-3.

以上方法主要涉及阳极氧化一个底物产生活性物 种, 再与另外一个底物反应形成 $\mathrm{C}-\mathrm{N}$ 键. 两个底物同 时在阳极氧化产生活性中间体, 然后两个活性中间体之 间发生偶联也可用于形成 $\mathrm{C}-\mathrm{N}$ 键. 咪唑并 $[1,2-a]$ 吡啶

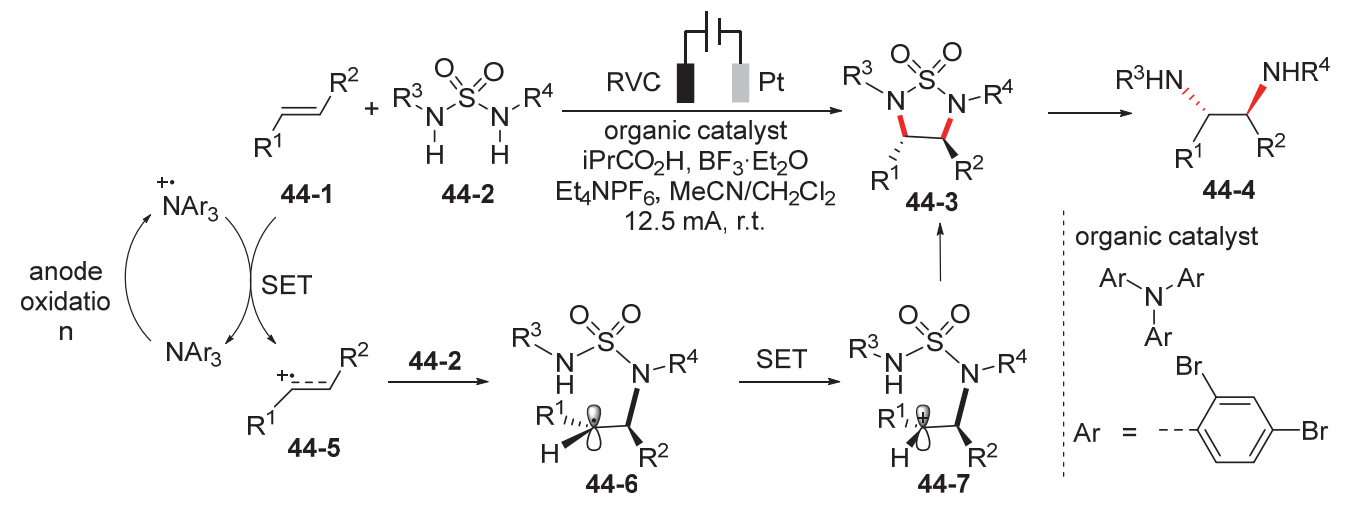

图式 44 基于烯烃活化实现烯烃的 1,2-二胺基化反应

Scheme 44 1,2-Diamination of alkenes via activation of alkenes 
也是一类重要的含氮杂环, 在材料和医药领域有着重要 应用, 已有多个上市药物含有该结构骨架, 对咪唑并 [1,2- $a$ ]吡啶进行修饰或官能团化是有机合成领域的研究 热点之一. 2019 年, 雷爱文课题组 ${ }^{[57]}$ 基于电化学氧化 $\mathrm{C}-\mathrm{H} / \mathrm{N}-\mathrm{H}$ 交叉偶联策略, 实现了对咪唑并 $[1,2-a$ 吡啶 的 C(3)氨基化修饰(Scheme 45). 在单室电解池中, 使用 石墨棒为阳极, 镍板为阴极, $\mathrm{NaNO}_{3}$ 为电解质, $\mathrm{MeCN} /$ $\mathrm{H}_{2} \mathrm{O} / \mathrm{EtOH}$ 为混合溶剂, 2-苯基咪唑[1,2- $a$ ] 吡啶 45-1 与咪 唑 45-2 在 $50{ }^{\circ} \mathrm{C}$ 下以恒电流模式电解 $5 \mathrm{~h}$, 以中等收率 获得目标产物 45-3. 不同的咪唑[1,2- $a$ 吡啶及唑类亲核 试剂都能兼容此反应. 然而, 当使用长链脂肪胺作为反 应底物时, 没有检测到目标产物.

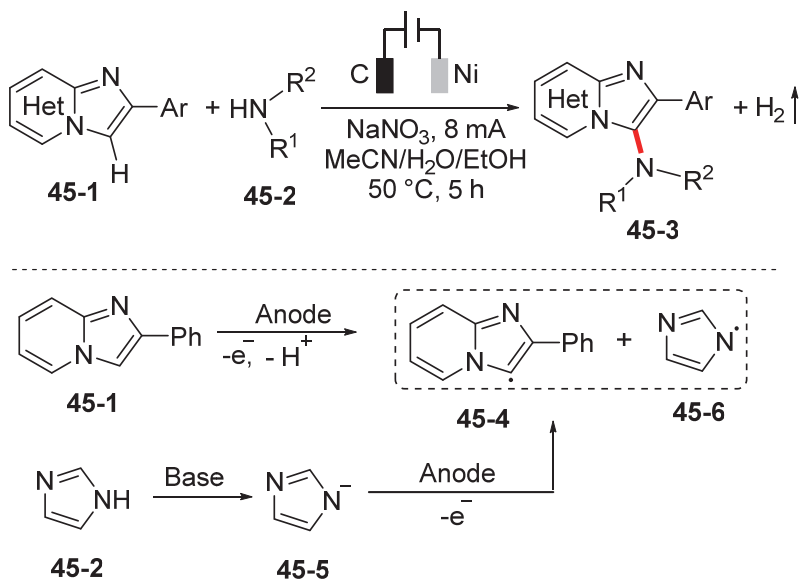

图式 45 电化学分子间 $\mathrm{C}-\mathrm{H} / \mathrm{N}-\mathrm{H}$ 氧化交叉偶联反应

Scheme 45 Electrochemical intermolecular oxidative $\mathrm{C}-\mathrm{H} /$ $\mathrm{N}-\mathrm{H}$ cross-coupling reaction

循环伏安实验表明, 在此电化学条件下, 45-1 和 45-2 在阳极上可能同时被氧化. 在标准条件下, 当不添 加 45-2 时, 反应体系可检测到 45-1 的自偶联产物, 该控 制实验表明, 在电解条件下 45-1 可以转化为相应的自 由基. 在上述实验的基础上, 作者给出了该反应的可能 机理: 45-1 的阳极氧化和去质子化过程生成自由基 45-4; 同时，阴极还原生成的 $\mathrm{HO}^{-}$或者 $\mathrm{EtO}^{-}$使底物 45-2 脱质 子, 得到其共轭碱 45-5, 其在阳极上进一步氧化形成 N自由基 45-6; 最后，自由基/自由基交叉偶联生成 $\mathrm{C}$ $\mathrm{H} / \mathrm{N}-\mathrm{H}$ 交叉偶联产物. 但作者不能完全排除 $\mathrm{N}$-自由基 45-6 对 45-1 的自由基加成途径.

随后, 作者利用上述电化学分子内 $\mathrm{C}-\mathrm{H} / \mathrm{N}-\mathrm{H}$ 氧 化交叉偶联策略, 合成了 $10 H$-苯并 [4,5]咪唑并 $[1,2-a]$ 吲 哚衍生物(Scheme 46). 但在之前的直接电解条件下, 不 能获得目标产物. 当使用二茂铁作为催化剂, 石墨棒为 阳极, 镍片为阴极, ${ }^{n} \mathrm{Bu}_{4} \mathrm{NBF}_{4}$ 为电解质, $\mathrm{MeCN} / \mathrm{EtOH}$ 为 溶剂, 在 $70{ }^{\circ} \mathrm{C}$ 下, 46-1 在单室电解池中以恒电流模式 电解 $4 \mathrm{~h}$, 能以优良的分离产率获得 $10 H$-苯并[4,5]咪唑
[1,2- $a]$ 吲哚衍生物 46-2. 该反应历程如下：首先, $\mathrm{Cp}_{2} \mathrm{Fe}$ 在阳极氧化得到 $\mathrm{Cp}_{2} \mathrm{Fe}^{+} ; \mathrm{Cp}_{2} \mathrm{Fe}^{+}$然后氧化氮负离子 $46-3$ 生成 $\mathrm{N}$-自由基中间体 46-4, 同时 $\mathrm{Cp}_{2} \mathrm{Fe}$ 得到再生. 随后, $\mathrm{N}$-自由基对芳环加成，并伴随进一步的单电子氧化和去 质子化过程最终得到 $\mathrm{C}-\mathrm{H} / \mathrm{N}-\mathrm{H}$ 交叉偶联产物 46-2.

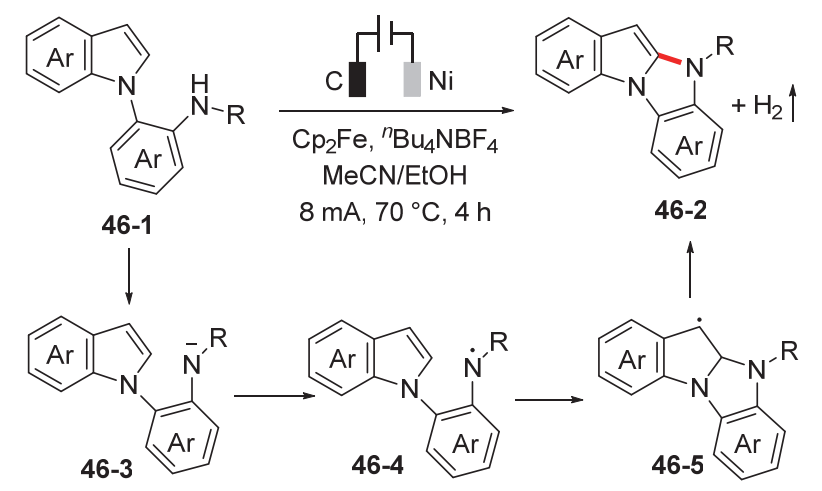

图式 46 电化学分子内 $\mathrm{C}-\mathrm{H} / \mathrm{N}-\mathrm{H}$ 氧化交叉偶联反应 Scheme 46 Electrochemical intramolecular oxidative $\mathrm{C}-\mathrm{H} /$ $\mathrm{N}-\mathrm{H}$ cross-couplings

利用 $\mathrm{N}$-自由基/C-自由基偶联策略合成 C-3 氨基咪 唑并 $\left[1,2-a\right.$ 吡啶后, 雷爱文课题组 ${ }^{[58]}$ 于同年报道了富电 子芳烃与二芳胺衍生物之间的电氧化 $\mathrm{C}-\mathrm{H} / \mathrm{N}-\mathrm{H}$ 交叉 偶联反应，合成了一系列三芳胺衍生物(Scheme 47). 该 反应在氮气氛围中, 无需外加化学氧化剂, 以碳棒为阳 极, $\mathrm{Pt}$ 片为阴极, ${ }^{n} \mathrm{Bu}_{4} \mathrm{NBF}_{4}$ 为电解质, $\mathrm{MeCN} / \mathrm{MeOH}$ 为溶 剂, $N, N$-二甲基苯胺 47-1 与吩噻嗪 47-2 在单室电解池中 以恒电流模式电解 $2 \mathrm{~h}$, 以中等收率获得对位选择性的 $\mathrm{C}\left(\mathrm{sp}^{2}\right)-\mathrm{H} / \mathrm{N}-\mathrm{H}$ 偶联产物. 该合成方法具有很好的区 域选择性和官能团耐受性.

恒电位电解实验指出，当两种底物都被氧化时可以 得到最好的结果. 通过测量发现标准反应条件下的阳极 电位高于两种底物的氧化电位，因此芳烃自由基阳离子 与 $\mathrm{N}$-自由基的交叉偶联可能是主要的反应途径. 同时 EPR 实验表明二烷基胺、吩噻嗪和二芳胺在电解条件下 均能通过阳极的单电子氧化生成相应的自由基. 基于上 述实验，作者提出了如下反应机理：首先，47-1 在阳极 上氧化生成自由基阳离子 47-4; 同时, 47-2 也可以在阳 极氧化并脱去质子生成 N-自由基 47-5; 随后，自由基阳 离子 47-4 与 $\mathrm{N}$-自由基 47-5 之间的交叉偶联形成中间体 47-6; 最后, 47-6 去质子化得到对位胺化产物 47-3. 在反 应过程中，氢离子在阴极被还原释放出 $\mathrm{H}_{2}$.

邻二胺是一种重要的结构单元, 广泛存在于天然产 物、药物以及催化剂分子结构中. 烯烃的氧化双胺化是 最直接构建邻二胺结构的方法，但是胺基化产物和对应 底物的氧化电位相近，常常会出现胺基化产物的过度氧 化，导致反应产率低下. 2017 年，林松课题组 ${ }^{[59]}$ 结合过 


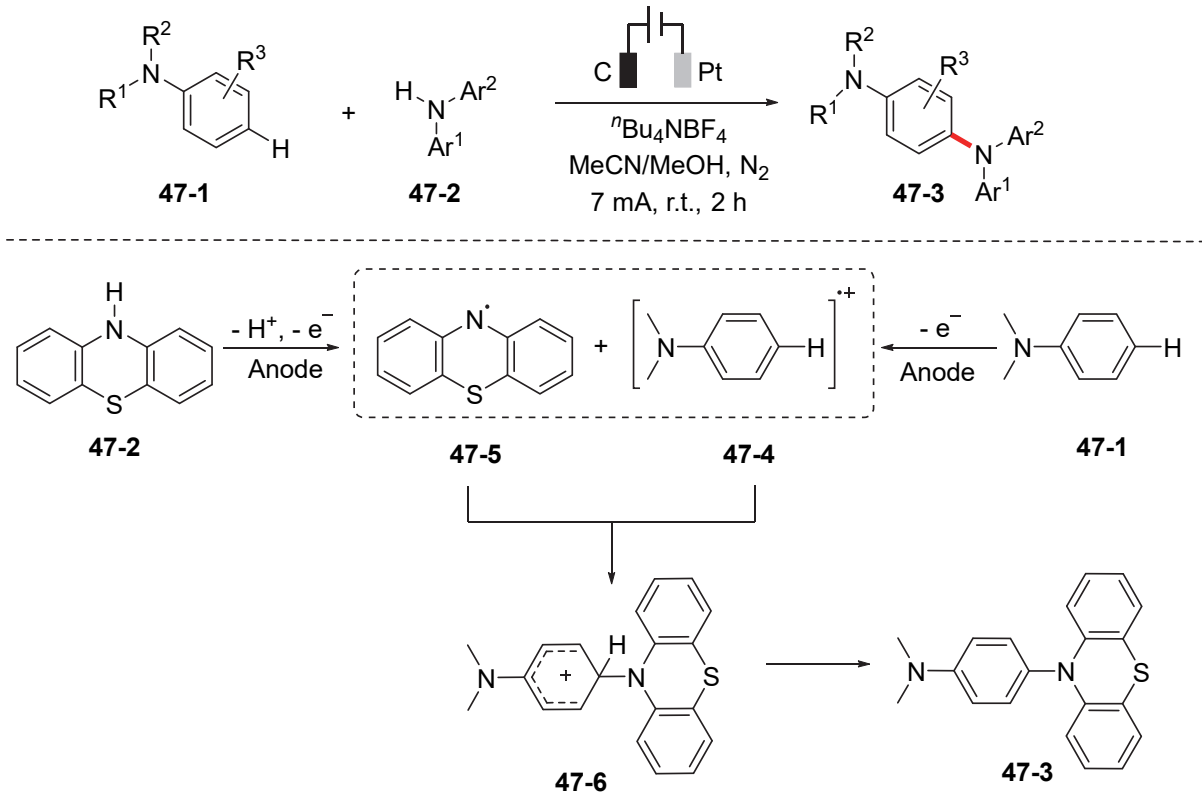

图式 47 芳胺的对位选择性电化学胺化反应

Scheme 47 Electrochemical amination of aromatic amines with high para-selectivity

渡金属催化体系与电化学过程, 以叠氮基作为氨基前 体, 首先将烯烃转化为邻二叠氮化物 48-3, 该中间体在 非电解条件下经过简单的还原操作得到含邻二胺结构 单元的产物 48-4 (Scheme 48). 在氮气氛中, 使用 $\mathrm{MnBr}_{2} \bullet 4 \mathrm{H}_{2} \mathrm{O}$ 为催化剂, $\mathrm{LiClO}_{4}$ 为电解质, $\mathrm{HOAc}$ 为质子 源, $\mathrm{MeCN}$ 为溶液, $\mathrm{RVC}$ 为阳极, $\mathrm{Pt}$ 片电极为阴极, 室温 下, 在单室电解池中以恒电位模式电解, $\mathrm{NaN}_{3}$ 48-2 与含 烯基的底物 48-1 反应生成一系列含邻二叠氮基的产物.

自由基钟实验表明该反应涉及自由基中间体，结合 循环伏安与紫外-可见分光光度实验, 作者提出了两种 烯烃双叠氮化可能的反应机理. 第一种路径, 叠氮负离 子在阳极直接氧化为叠氮自由基, 然后加成到烯基上得 到 C-自由基中间体 48-5; 接着, 从 $\mathrm{Mn}^{\mathrm{III}}-\mathrm{N}_{3}$ 物种转移叠 氮基到中间体 48-5 上得到最终产物 48-3. 第二种路径, 首先 $\mathrm{Mn}(\mathrm{II})$ 盐发生配体交换生成 $\mathrm{Mn}(\mathrm{II})-\mathrm{N}_{3}$, 接着在 RVC 阳极氧化为 $\mathrm{Mn}(\mathrm{III})-\mathrm{N}_{3}$ 物种, 进而对烯基发生自由 基加成得到 C-自由基中间体 48-5; 随后, $\mathrm{Mn}(\mathrm{III})-\mathrm{N}_{3}$ 物 种对 C-自由基中间体 48-5 发生进一步加成得到最终的 双叠氮化产物 48-3.

2018 年, 雷爱文课题组 ${ }^{[00]}$ 利用间接电化学氧化策 略, 实现了 $\mathrm{Co}$ 催化的芳烃 $\mathrm{C}-\mathrm{H}$ 胺化反应, 为合成芳胺 提供了一种绿色便捷的途径(Scheme 49). 该反应在隔 膜型双室电解池中进行, 以碳纤维布作为阳极、镍片作 为阴极, 在阳极电解池中放入含有 $20 \mathrm{~mol} \% \mathrm{Co}(\mathrm{OAc})_{2}$ ・ $4 \mathrm{H}_{2} \mathrm{O}$ 、 1 equiv. $\mathrm{NaOPiv} \cdot \mathrm{H}_{2} \mathrm{O}$ 及 2 equiv. ${ }^{n} \mathrm{Bu}_{4} \mathrm{NBF}_{4}$ 的 $\mathrm{MeCN}$ 溶液, 在阴极电解池中放入含有 2 equiv. $\mathrm{NaO}-$ Piv $\mathrm{H}_{2} \mathrm{O}$ 和 8 equiv. HOPiv 的 $\mathrm{MeOH}$ 溶液. $N$-(喹啉-8-基)
噻吩-2-甲酰胺(49-1)及吗啉 49-2 作为模型底物，在氮气 氛围中, $65{ }^{\circ} \mathrm{C}$ 恒电流模式电解 $3 \mathrm{~h}$, 以 $74 \%$ 的产率获得 目标产物. 值得注意的是, 该反应在单室池电解池中不 能发生.

为了深入了解反应机理, 作者进行了动力学同位素 实验、循环伏安实验. 动力学同位素实验表明, $\mathrm{C}-\mathrm{H}$ 键 断裂不是反应的决速步骤. 根据上述实验和先前文献报 道, 作者给出了两种机理. 途径 I: 首先, 钴(II)在阳极 上氧化成钴(III); 然后, 钴(III)与 $N$-(喹啉-8-基)苯基-2甲酰胺(49-1)配位得到钴(III)-配合物 49-5. 途径 II: 首 先, 在碱存在下, 钴(II)与 49-1 配位得到钴(II)-络合物 49-4; 随后, 钴(II)配合物 49-4 在阳极氧化得到钴(III)配合物 49-5. 在碱存在下, 三价钴发生 $\mathrm{C}-\mathrm{H}$ 活化, 随 后与吗啉 49-2 配位形成钴(III)-络合物 49-6. 49-6 发生后 续的还原消除生成产物 49-3 并释放钴(I)物种. 钴(I)物 种在阳极上被氧化为钴(II), 进而完成钴的催化循环.

同年, Ackermann 课题组 ${ }^{[61]}$ 也利用 8-氨基喹啉为导 向基团, 使用镍催化剂实现了电化学条件下芳烃 $\mathrm{C}-\mathrm{H}$ 胺化反应(Scheme 50). 与雷爱文课题组的方法不同, 该 反应避免使用双室电解池, 但反应温度需加热到 $120{ }^{\circ} \mathrm{C}$. 该反应以 $\mathrm{Ni}(\mathrm{DME}) \mathrm{Cl}_{2}$ 为催化剂, $\mathrm{NaOPiv}$ 为添 加剂, $\mathrm{RVC}$ 为阳极, 泡沫 $\mathrm{Ni}$ 电极为阴极, ${ }^{n} \mathrm{Bu}_{4} \mathrm{NBF}_{4} / \mathrm{DMA}$ 为电解质溶液, 50-1 与仲胺 50-2 在氮气环境中以恒电流 模式电解 $10 \mathrm{~h}$, 以良好的分离收率得到胺化产物 50-3.

为了深入了解反应机理，作者进行了一系列控制实 验. 分子间竞争实验表明, 在 $\mathrm{C}-\mathrm{H}$ 金属化反应中发生 了一个协同的金属化脱质子过程. 当使用 $\mathrm{D}_{3} \mathrm{COD}$ 作为 

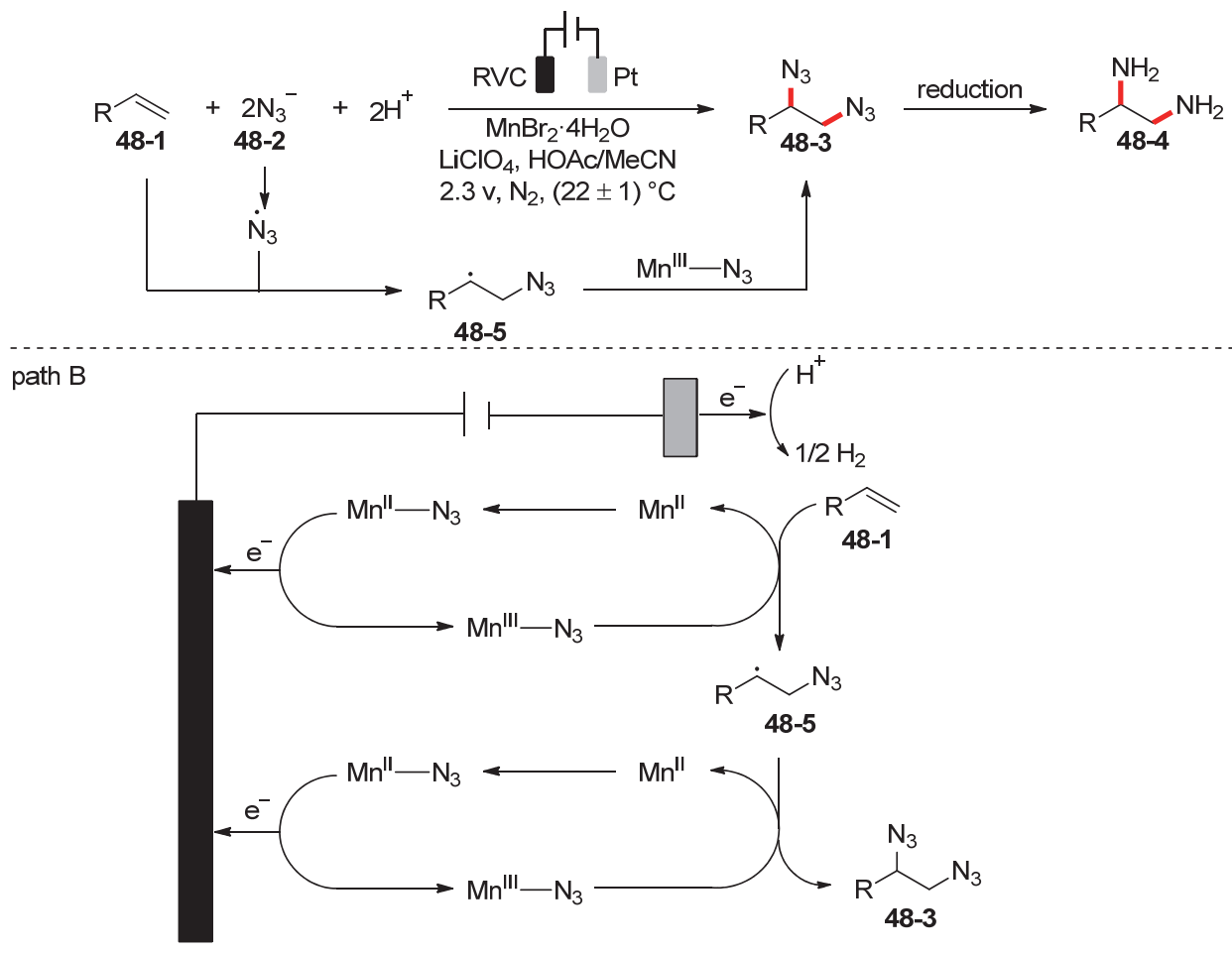

图式 48 金属催化烯烃的电化学双叠氮化反应

Scheme 48 Metal-catalyzed electrochemical alkene diazidation
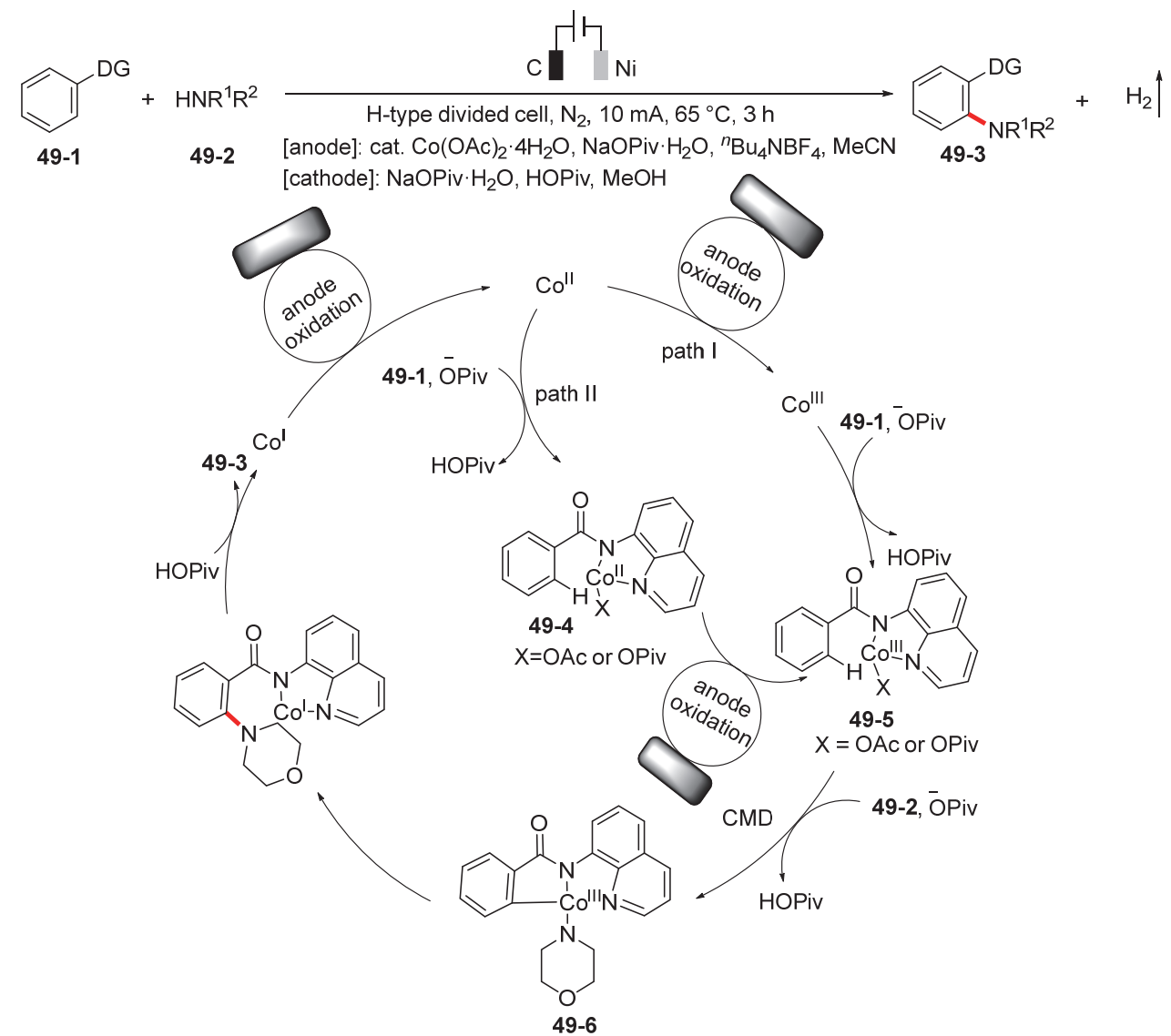

图式 49 钴(II)催化的电化学氧化芳烃 $\mathrm{C}-\mathrm{H}$ 胺化反应

Scheme 49 Cobalt(II)-catalyzed electrooxidative $\mathrm{C}-\mathrm{H}$ amination of arenes 


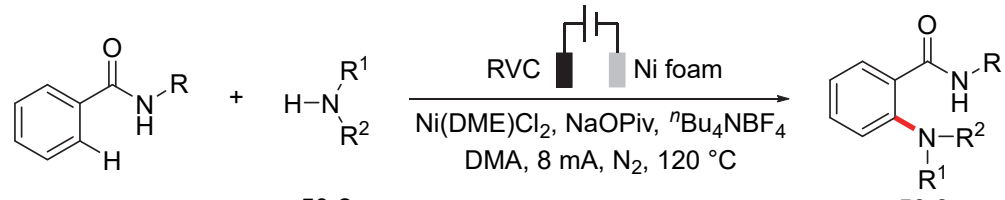

$50-1$

$50-2$

50-3

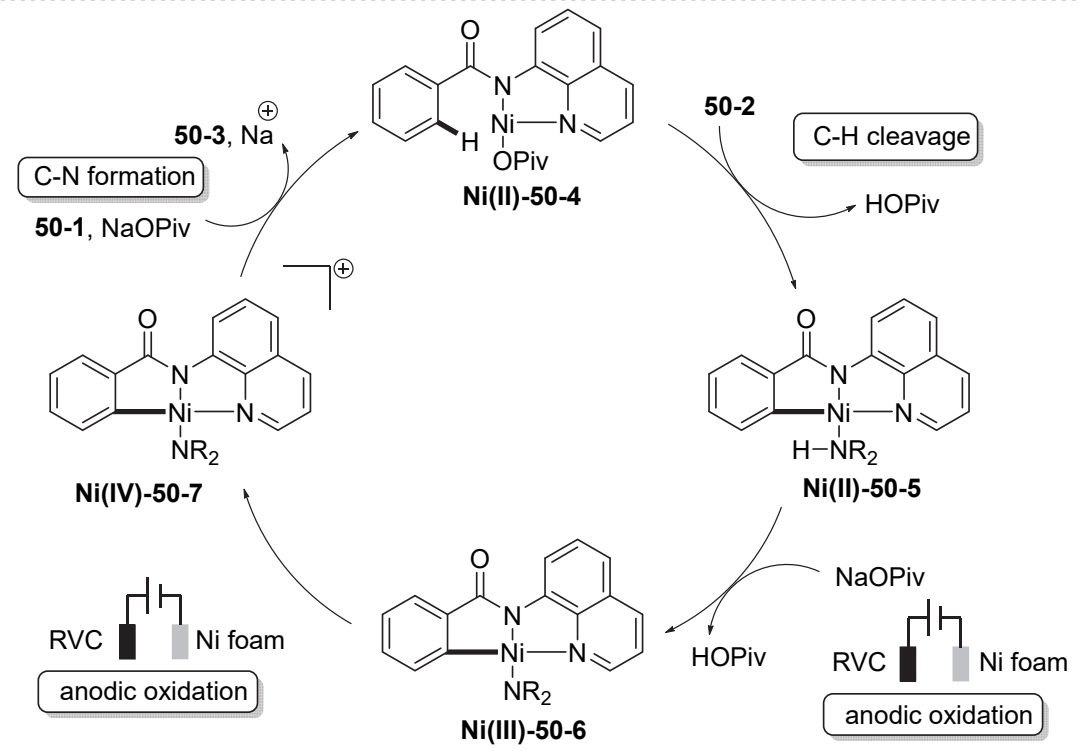

图式 50 镍催化的电氧化芳烃 $\mathrm{C}-\mathrm{H}$ 胺化反应

Scheme 50 Nickel-catalyzed electrooxidative $\mathrm{C}-\mathrm{H}$ amination of arenes

共溶剂时, 没有发现 $\mathrm{H} / \mathrm{D}$ 竞争过程. $k_{\mathrm{H}} / k_{\mathrm{D}}=1.1$ 的动力学 同位素效应实验说明 $\mathrm{C}-\mathrm{H}$ 断裂过程不是反应的决速步 骤。循环伏安实验发现底物和 NaOPiv 的加入对 $\mathrm{Ni}$ (II/III)的电极电位有很大的影响. 基于机理研究, 作 者提出通过 8-氨基喹啉导向苯甲酰胺的 $\mathrm{C}-\mathrm{H}$ 镍化反应 给出中间体 $\mathrm{Ni}^{\mathrm{II}}-\mathbf{5 0}-4$. 随后, 胺的脱质子化和阳极氧化 生成镍(II)络合物 $\mathrm{Ni}^{\mathrm{II}}-\mathbf{5 0 - 5}$. 进一步阳极氧化依次生成 高价金属络合物 $\mathrm{Ni}^{\mathrm{III}}-50-6$ 和 $\mathrm{Ni}^{\mathrm{IV}}-50-7$, 其发生还原消 除生成目标产物 50-3, 同时再生催化活性的络合物

\section{$\mathrm{Ni}^{\mathrm{II}} \mathbf{- 5 0}-\mathbf{4}$.}

将导向基团由 8 -氨基喹啉换为 2-氨基吡啶氮氧, Ackermann 课题组 ${ }^{[2]}$ 利用钴催化剂实现了电化学条件 下芳基(杂芳基)甲酰胺邻位 $\mathrm{C}-\mathrm{H}$ 的选择性胺化反应 (Scheme 51). 该反应可在空气环境中进行, 且使用可再 生的 $\gamma$-戊内酯 $(\mathrm{GVL})$ 作为溶剂. 以 $\mathrm{Co}(\mathrm{OAc})_{2} \bullet 4 \mathrm{H}_{2} \mathrm{O}$ 为催 化剂, ${ }^{n} \mathrm{Bu}_{4} \mathrm{NPF}_{6}$ 为电解质, $\mathrm{KOAc}$ 为添加剂, $\mathrm{RVC}$ 为阳极, Pt 片为阴极, 苯甲酰胺 51-1 与六元环状仲胺 51-2 在单 室电解池中以恒电流模式电解 $24 \mathrm{~h}$, 能以中等以上产率 获得胺化产物. 在此条件下, 导向基团为 $\mathrm{N}, \mathrm{N}$-双齿配位 或 $\mathrm{N}$-单齿配位基团，均不能得到目标产物.

作者提出了如下的反应机理: 首先, 二价钴在阳极 氧化形成的催化活性钴(III)羧酸盐物种 51-4; 随后, 羧 酸盐辅助的 $\mathrm{C}-\mathrm{H}$ 活化生成中间体 51-5; 在胺的作用下,
51-5 离去羧酸负离子生成钴酰胺物种 51-6, 其发生后续 的还原消除生成目标产物 51-3 并释放一价钴物种. 一 价钴物种通过阳极氧化再生为 51-4, 实现催化循环.

2019 年, Kathiravan 课题组 ${ }^{[63]}$ 报道了铜催化的电化 学芳基酰胺的 $\mathrm{C}\left(\mathrm{sp}^{2}\right)-\mathrm{H}$ 胺化反应, 使用电子作为唯一 的氧化剂, $\mathrm{H}_{2}$ 作为唯一的副产物(Scheme 52). 该电解反 应以 $\mathrm{RVC}$ 作为阳极, $\mathrm{Pt}$ 片作为阴极, $\mathrm{NaOAc}$ 作为碱, $\mathrm{Cu}(\mathrm{OAc})_{2}$ 作为催化剂, $\mathrm{MeCN}$ 作为溶剂, 利用 8-氨基喹 啉作为导向基团, 芳基甲酰胺 52-1 与仲胺 52-2 在单室 电解池中以恒电流模式电解, 能以良好的分离产率获得 邻位胺化产物 52-3. 作者发现一系列含有活性药物成分 (API)或相关结构的衍生物胺，都可有效地用于该反应， 突出该方法在药物后期结构修饰应用中的潜力.

基于机理研究实验，作者提出了两种可能的反应路 径: 对于路径 $\mathrm{a}, \mathrm{Cu}(\mathrm{II})$ 在阳极上氧化成 $\mathrm{Cu}(\mathrm{III})$, 然后在 $\mathrm{NaOAc}$ 的存在下与酰胺 52-1 反应形成中间体 52-5; 对 于路径 $\mathrm{b}, \mathrm{Cu}(\mathrm{II})$ 先与 52-1 配位, 然后被阳极氧化为 52-5. 发生还原消除生成最终产物 52-3 并释放出一价铜. 最 后，一价铜被阳极氧化生成二价铜完成催化循环.

过渡金属催化的电化学有机合成多采用直接的阳 极氧化来实现过渡金属催化剂的循环，由于阳极氧化形 成的高价态金属离子容易在阴极被还原，反应通常需要 在隔膜电解池中进行. 2018 年, 利用间接阳极氧化来实 


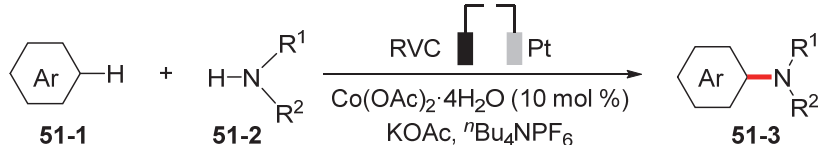

$$
\begin{aligned}
& \text { GVL, } 2.5 \mathrm{~mA}, 24 \mathrm{~h} 40^{\circ} \mathrm{C}
\end{aligned}
$$

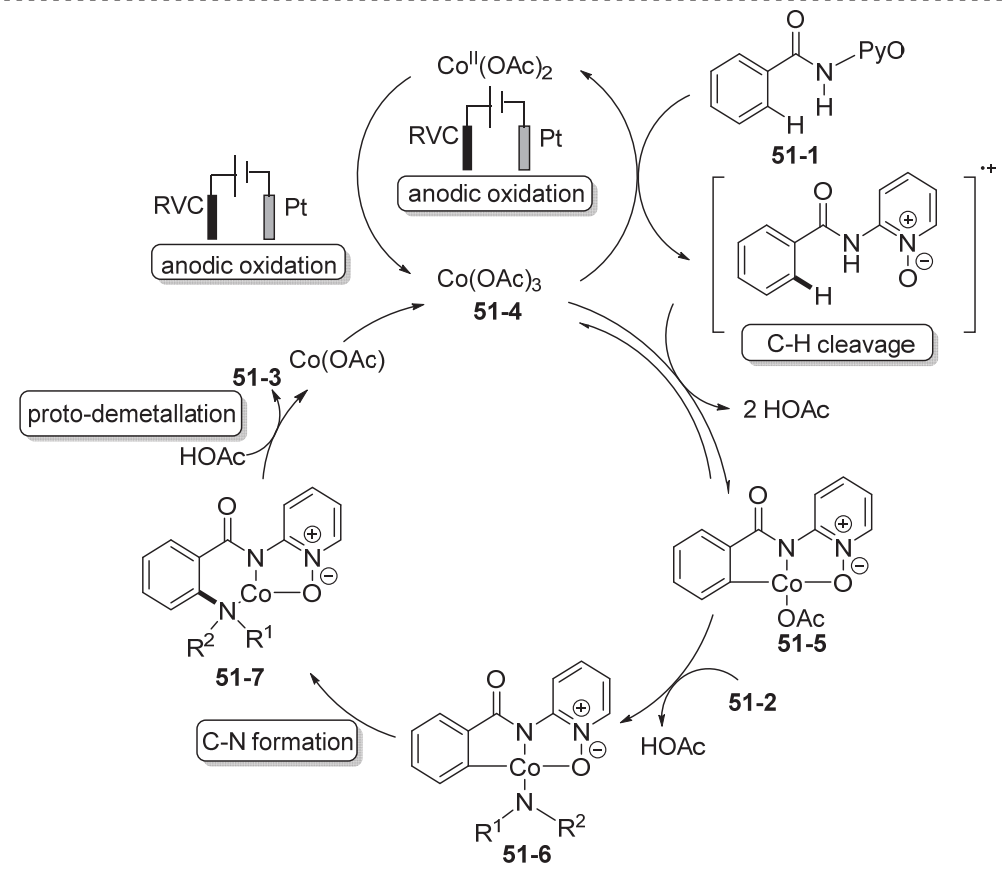

图式 51 钴催化的电化学 $\mathrm{C}-\mathrm{H}$ 胺化反应

Scheme 51 Cobalt-catalyzed electrochemical $\mathrm{C}-\mathrm{H}$ amination

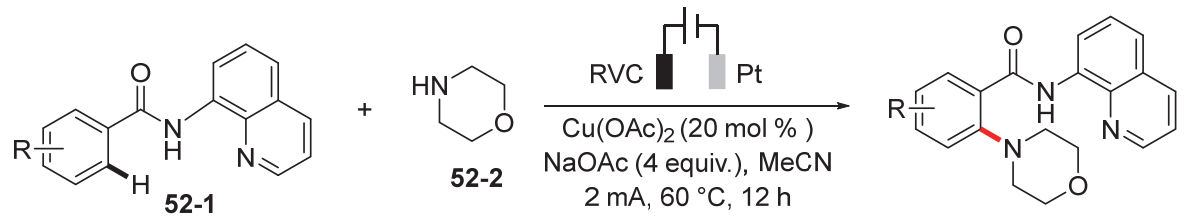

52-1 $2 \mathrm{~mA}, 60^{\circ} \mathrm{C}, 12 \mathrm{~h}$

52-3

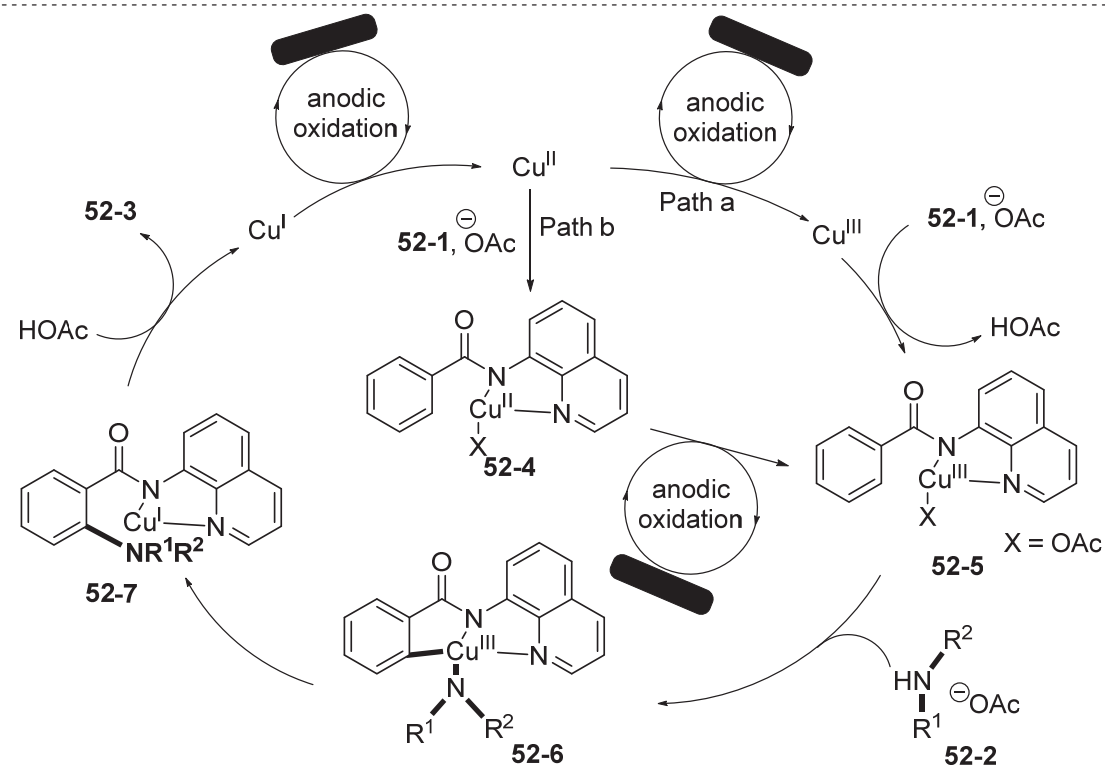

图式 52 铜催化与电氧化协同作用的芳烃 $\mathrm{C}\left(\mathrm{sp}^{2}\right)-\mathrm{H}$ 胺化反应

Scheme 52 Synergistic combination of copper catalysis and electrooxidation for $\mathrm{C}\left(\mathrm{sp}^{2}\right)-\mathrm{H}$ amination 
现金属催化剂的再生, 梅天胜课题组 ${ }^{[64]}$ 实现了铜催化 的 2-吡啶甲酰(杂)芳胺与仲胺的电化学 $\mathrm{C}(\mathrm{sp} 2)-\mathrm{H}$ 胺化 反应 $(\mathrm{Scheme} 53)$. 以 $\mathrm{Cu}(\mathrm{OTf})_{2}$ 为催化剂, ${ }^{n} \mathrm{Bu}_{4} \mathrm{NI}$ 为电化 学媒质, $\mathrm{KOPiv}$ 为碱, $\mathrm{MeCN}$ 为溶剂, 阴阳极均为 $\mathrm{Pt}$ 片电 极, 室温下在单室电解池中恒电流模式电解, 2-吡啶甲 酰(杂)芳胺 53-1 与环状仲胺 53-2 发生 $\mathrm{C}-\mathrm{H} / \mathrm{N}-\mathrm{H}$ 键的 氧化交叉脱氢偶联, 得到邻位胺基化的产物 53-3.

机理实验表明该反应可能经历单电子转移过程, 铜 离子与底物分子配位后可降低 $\mathrm{Cu}(\mathrm{II})$ 的氧化电位, $\mathrm{Cu}(\mathrm{III})$ 物种为催化活性物种, 碘离子可以作为电化学媒 质实现 $\mathrm{Cu}(\mathrm{III})$ 的再生, 间接电解可以在更低的电位下驱 动反应的进行, 从而避免高电位导致的产物过度氧化. 作者提出了一个可能的反应机理. 首先, $\mathrm{Cu}(\mathrm{II})$ 催化剂与 胺 53-2 和底物 53-1 配位生成铜(II)复合物 53-4, 其被碘 自由基氧化生成铜(III)物种 53-5. Cu(III)物种的生成是 催化循环中的决速步骤. 接着, 复合物 53-5 经历单电子 转移(SET)生成自由基阳离子中间体 53-6. 胺转移到自 由基阳离子中间体后, 再经历第二次 SET 过程产生物种 53-7, 其释放出胺化产物 53-3 并生成 $\mathrm{Cu}(\mathrm{I})$ 物种. 最后,
$\mathrm{Cu}(\mathrm{I})$ 物种经历碘离子介导的阳极氧化后, $\mathrm{Cu}(\mathrm{II})$ 催化剂 再生而完成催化循环.

\section{$3 \mathrm{C}(\mathrm{sp})$ - $\mathrm{N}$ 键偶联反应}

\section{1 分子内 $\mathrm{C}(\mathrm{sp})-\mathrm{N}$ 键偶联反应}

$\mathrm{N}$-自由基中间体除了对烯烃或芳烃进行加成以外， 还可对炔烃进行加成, 进而构建 $\mathrm{C}(\mathrm{sp})-\mathrm{N}$ 键. 基于电化 学引发 N-自由基的策略, 2016 年, 徐海超课题组 ${ }^{[65]}$ 报道 了基于 $\mathrm{N}$-自由基的分子内串联反应, 实现了功能化吲 哚和氮杂吲哚的电化学合成(Scheme 54). 该反应以 $\mathrm{RVC}$ 为阳极, $\mathrm{Pt}$ 片为阴极, $\mathrm{Cp}_{2} \mathrm{Fe}$ 为电催化剂, $\mathrm{Na}_{2} \mathrm{CO}_{3}$ 为 碱, ${ }^{n} \mathrm{Bu}_{4} \mathrm{NBF}_{4}$ 为电解质, $\mathrm{MeOH} / \mathrm{THF}$ 为溶剂, 反应温度 为 $80{ }^{\circ} \mathrm{C}$. 该合成方法与多种敏感官能团具有较好的相 容性, 各种给电子基团和吸电子基团都能表现出较好的 反应活性. 4-和 3-氨基吡啶衍生底物在标准反应条件下 有效反应, 从而为 5-氮杂吲哚、4-氮杂吲哚和 6-氮杂吲 哚提供了有效地合成途径.

基于机理研究, 作者认为该反应经历了 $\mathrm{N}$-自由基 中间体历程. 首先, $\left[\mathrm{Cp}_{2} \mathrm{Fe}\right]$ 在阳极氧化到 $\left[\mathrm{Cp}_{2} \mathrm{Fe}\right]^{+}$; 同
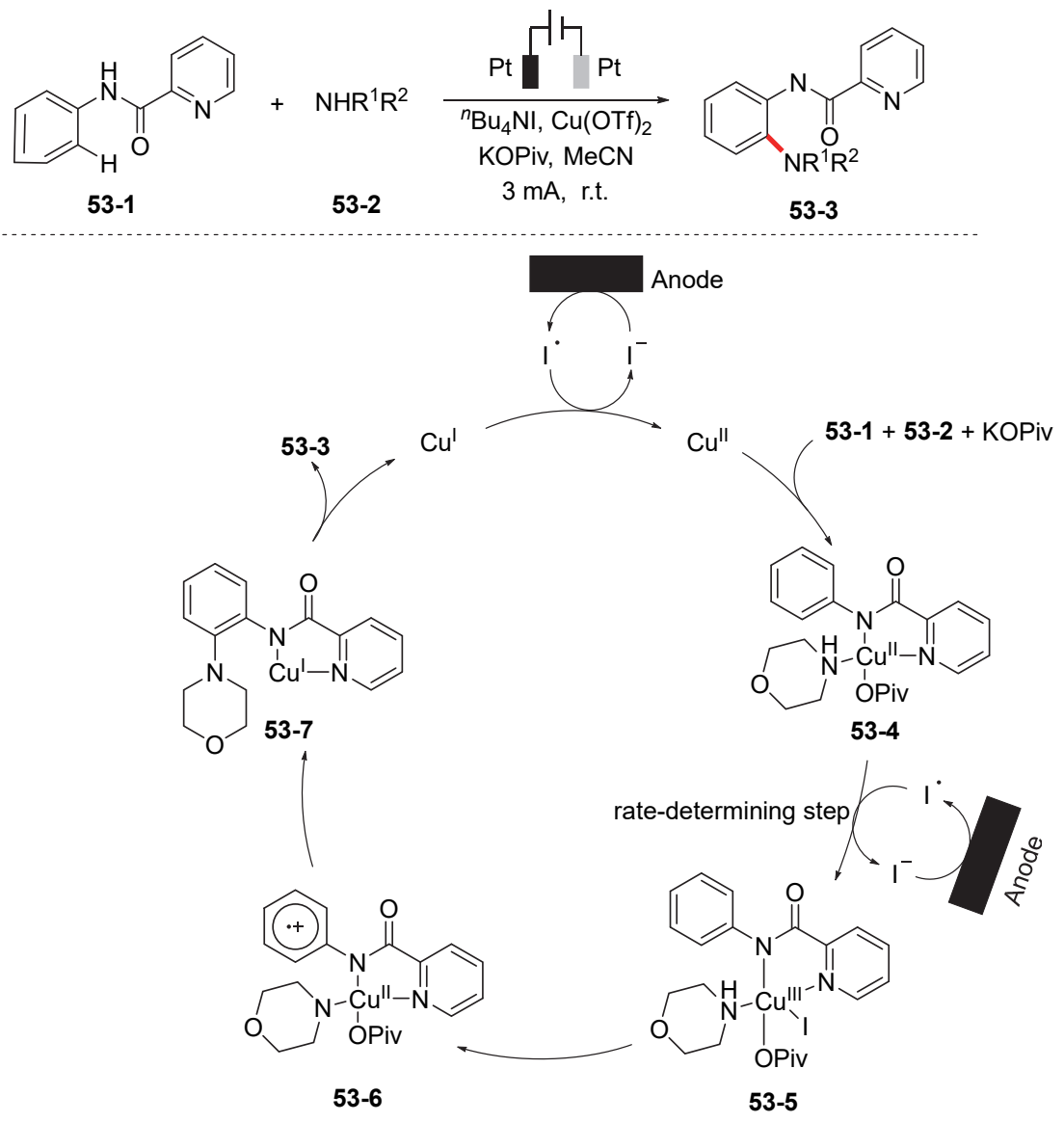

图式 53 铜催化的芳烃与仲胺的电化学 $\mathrm{C}-\mathrm{H}$ 胺化反应

Scheme 53 Copper-catalyzed electrochemical $\mathrm{C}-\mathrm{H}$ amination of arenes with secondary amines 


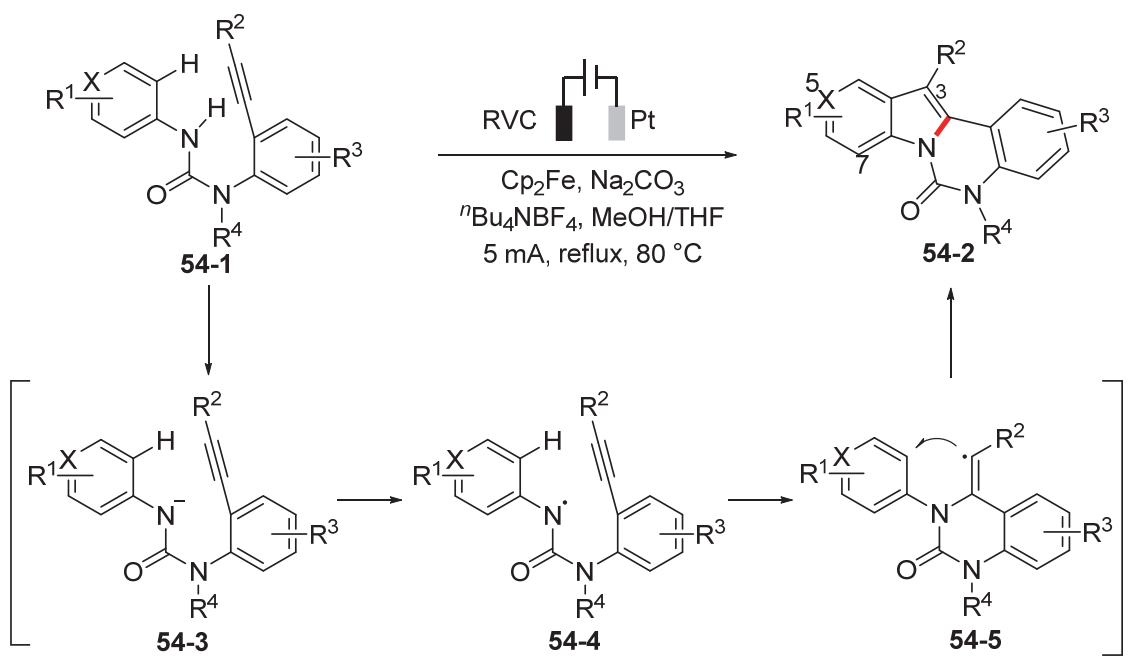

图式 54 电化学合成高功能化(氮杂)吲哚

Scheme 54 Electrochemical synthesis of highly functionalized (aza)indoles

时, $\mathrm{MeOH}$ 在阴极还原生成甲氧基负离子和 $\mathrm{H}_{2}$. 然后, 甲氧基负离子㩲取底物 54-1 中的质子, 生成氮负离子 54-3. 随后, 54-3 和 $\left[\mathrm{Cp}_{2} \mathrm{Fe}\right]^{+}$之间的单电子转移作用生成 $\mathrm{N}$-自由基 54-4 并实现 $\left[\mathrm{Cp}_{2} \mathrm{Fe}\right]$ 再生. 最后, 54-4 对炔烃进 行自由基加成、环化得到乙烯基自由基 54-5. 乙烯基自 由基与芳环进行第二次环化反应，然后发生后续的氧化 和脱质子化、再芳构化过程生成最终产物 54-2.

随后，将底物换为更具挑战性的二芳炔基豚类化合 物 55-1, 基于电化学引发 $\mathrm{N}$-自由基的策略, 徐海超课题 组 ${ }^{[66]}$ 实现了电化学自由基串联环化反应，一锅构建三 个环，可用于制备多环含氮杂环化合物 55-2 (Scheme 55). 采用配有 RVC 阳极和 Pt 片阴极的单室电解池, 以 $\mathrm{Cp}_{2} \mathrm{Fe}$ 为氧化还原催化剂, ${ }^{n} \mathrm{Bu}_{4} \mathrm{NBF}_{4}$ 为电解质, $\mathrm{Na}_{2} \mathrm{CO}_{3}$ 为添加剂, $\mathrm{THF} / \mathrm{MeOH}$ 的混合液为溶剂, 回流下以恒电 流模式下电解, 得到了最佳反应结果. 使用 $\mathrm{Cp}_{2} \mathrm{Fe}$ 作为 催化剂使反应高效进行, 同时避免多环含氮芳烃产物的 过度氧化.

采用同时含炔基和氮杂芳环取代的氨基甲酸酯类 化合物为底物 56-1, 基于电化学条件下产生酰胺 N-自 由基策略, 通过分子内 $[3+2]$ 环化反应, 徐海超课题 组 ${ }^{[67]}$ 以间接电解方式实现了多种重要咪唑并芳杂环化 合物 56-2 的高效合成(Scheme 56). 在配备 RVC 阳极和 $\mathrm{Pt}$ 片阴极的单室电解池中, 以 $\mathrm{MeCN} / \mathrm{H}_{2} \mathrm{O}$ 为溶剂, 四芳 基肼为催化剂, 以 $\mathrm{Et}_{4} \mathrm{NBF}_{4}$ 为电解质, $\mathrm{NaHCO}_{3}$ 为添加 剂, 在恒电流模式下回流 $\left(80{ }^{\circ} \mathrm{C}\right)$ 得到最佳反应结果. 该 有机电合成方法机理新颖, 通过自由基串联环化反应实 现两个 $\mathrm{C}-\mathrm{N}$ 键的构建, 并伴随 $\mathrm{CO}_{2}$ 和 $\mathrm{H}_{2}$ 的产生. 此外, 该方法使用四芳基肼为催化剂, 无需使用氧化剂和过渡 金属催化剂, 且底物范围广.

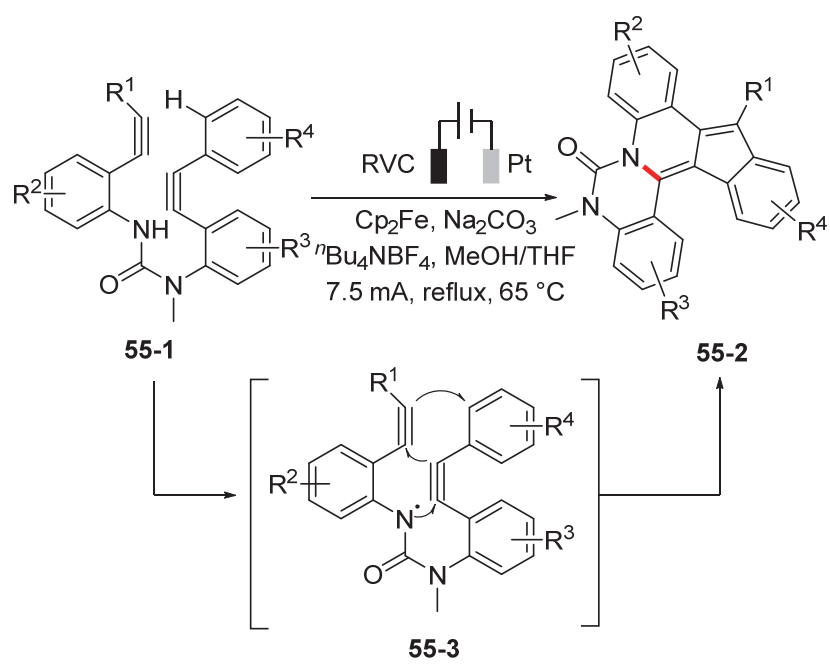

图式 55 电化学促进环化反应制备含氮多环芳烃

Scheme 55 Electrolytic cyclization leading to $N$-doped polycyclic aromatic hydrocarbons

苯并咪唑酮和苯并噁唑酮是许多生物活性分子的 核心骨架，通常从苯的衍生物出发(如邻苯二胺、邻氨基 苯酚衍生物), 经过羰基化来合成. 由于起始原料较难 制备，限制了该方法制备产物结构的多样性. 2019 年, 徐海超课题组 ${ }^{[68]}$ 从开链化合物出发, 通过阳极氧化促 进的自由基串联环化反应，一步构建五元杂环和苯环， 实现了多取代苯并咪唑酮和苯并噁唑酮的合成(Scheme 57). 以 $\mathrm{RVC}$ 为阳极, $\mathrm{Pt}$ 片为阴极, $\mathrm{Et}_{4} \mathrm{NPF}_{6}$ 为电解质, $\mathrm{TFA}$ 为添加剂, $\mathrm{DMF}$ 为溶剂, $110{ }^{\circ} \mathrm{C}$ 下在单室电解池中 恒电流模式电解，单侧氮原子上含炔基和烯基的脲 57-1 发生分子内串联环化反应，生成苯并咪唑酮类产物 57-2. 标准条件下将添加剂换为 $\mathrm{AcOH}$, 溶剂换为 TFE, 


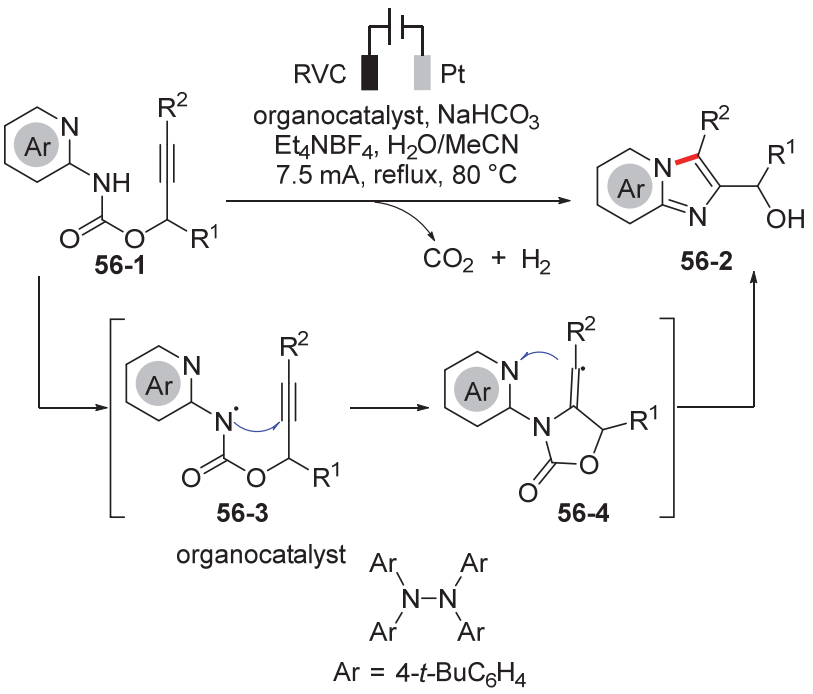

图式 56 电化学合成咪唑稠合氮杂环化合物

Scheme 56 Electrochemical synthesis of imidazo-fused Nheteroaromatic compounds

于 $80{ }^{\circ} \mathrm{C}$ 下氨基甲酸酯类底物可以转化为苯并噁唑酮类 产物. 与该课题组开发的碱为添加剂, 二茂铁或四芳基 肼介导的间接阳极氧化产生酰胺 N-自由基不同; 该方 法需要用酸性添加剂, 通过直接的阳极氧化产生酰胺 $\mathrm{N}$-自由基活性中间体 57-3 促进反应进行, 氧化过程中 产生的氢正离子扩散到阴极发生还原反应析氢, 无需使 用化学计量的氧化试剂及质子受体, 为苯并咪唑酮和苯 并噁唑酮的合成提供了简便、高效、绿色的合成新方法.

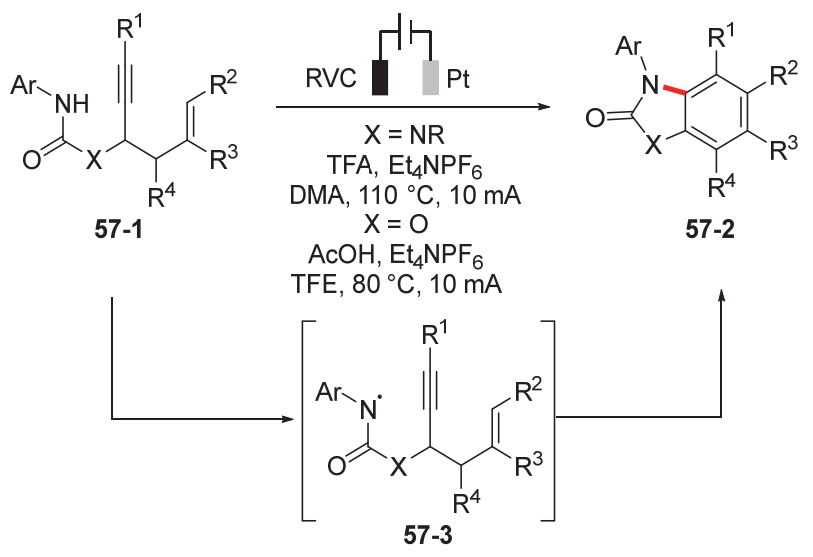

图式 57 电化学合成苯并咪唑酮和苯并恶唑酮

Scheme 57 Electrosynthesis of benzimidazolones and benzoxazolones

\section{2 分子间 $\mathrm{C}(\mathrm{sp})-\mathrm{N}$ 键偶联反应}

电化学诱导的分子间 $\mathrm{C}(\mathrm{sp})-\mathrm{N}$ 键偶联反应往往需 要过渡金属催化剂的参与. 2018 年, Ackermann 课题 组 ${ }^{[69]}$ 利用钴催化与电氧化的组合, 以 2-氨基吡啶氮氧为 导向基团, 实现了分子间的 $\mathrm{C}(\mathrm{sp})-\mathrm{N}$ 键偶联反应, 进而 获得了多种取代基类型的异喹啉酮化合物(Scheme 58).
该反应以 $\mathrm{RVC}$ 为阳极, $\mathrm{Pt}$ 片为阴极, $\mathrm{Co}(\mathrm{OAc})_{2} \bullet 4 \mathrm{H}_{2} \mathrm{O}$ 为 催化剂, $\mathrm{NaOPiv}$ 为碱, $\mathrm{H}_{2} \mathrm{O} / \mathrm{MeOH}$ 为混合溶剂, 苯甲酰 胺 58-1 与苯乙炔 58-2 在单室电解池中以 $4 \mathrm{~mA}$ 恒电流 电解 $16 \mathrm{~h}$, 能够以良好的分离产率获得异喹啉酮 58-3. 该方法具有很好的化学选择性及区域选择性，且具有较 好的底物适用范围.

基于竞争实验、同位素实验以及循环伏安实验等机 理研究，作者认为该反应是通过阳极氧化生成羧酸 钴(III) 58-5 开始的. 此后, 羧酸钴辅助的 $\mathrm{C}-\mathrm{H}$ 活化生 成中间体 58-6, 进而与炔的加成反应得到环状钴(III)中 间体 58-7. 随后，还原消除生成目标产物 58-3 并伴随着 钴(I)物种 58-4 的生成. 最后, 通过阳极氧化再生具有催 化活性的羧酸钴(III)复合物 58-5 完成催化循环.

随后, Ackermann 课题组 ${ }^{[70]}$ 将 N,O-配位模式导向策 略拓展到联烯化合物的反应(Scheme 59). 该反应以 $\mathrm{Co}(\mathrm{OAc})_{2} \bullet 4 \mathrm{H}_{2} \mathrm{O}$ 为催化剂, $\mathrm{NaOPiv}$ 为添加剂, $\mathrm{MeOH}$ 为 溶剂, RVC 为阳极, Pt 片为阴极, 在单室电解池中以恒 电流模式电解, N-取代苯甲酰胺 59-1 与丙二烯类化合物 59-2 发生 $[4+2]$ 环化反应得到异喹啉酮类化合物 59-3. 在确定了最佳反应条件后，作者探讨了苯甲酰胺的 N取代模式，实验结果发现吡啶基 $\mathrm{N}$-氧化物作为导向基 才时与联烯 59-2 的反应效果最好. 该合成方法具有较 好的官能团耐受性，包括碘代、硫醚和酯取代的底物都 能很好地进行反应. 与 Scheme 58 所示的反应机理类似, 作者该电化学反应是由阳极氧化钴物种启动的, 环状 Co(III)化合物 59-4 是反应的关键中间体.

紧接着, Ackermann 课题组 ${ }^{[71]}$ 将吡啶氮氧导向基团 换为吡啶肼基，仍旧以钴盐作为催化剂，通过电化学氧 化的 $\mathrm{C}-\mathrm{H} / \mathrm{N}-\mathrm{H}$ 键活化实现了芳基甲酰肼对内炔的 $[4+2]$ 环化反应 $(\mathrm{Scheme} 60)$. 以 $\mathrm{Co}(\mathrm{OAc})_{2}$ 为催化剂, $\mathrm{PivOH}$ 为添加剂, $\mathrm{TFE}$ 为溶剂, $\mathrm{RVC}$ 为阳极, $\mathrm{Pt}$ 片为阴极, $N$-吡啶基苯甲酰肼 60-1 与二苯乙炔 60-2 在单室电解池 中以 $5 \mathrm{~mA}$ 恒流模式电解 $16 \mathrm{~h}$, 以优良的分离收率得到 目标环化产物 60-3. 在 $[4+2]$ 炔烃环化体系中, 含给电 子或吸电子二取代炔烃均能顺利转化. 对于不对称的二 芳基炔烃, 反应具有较好的区域选择性，优先将缺电子 的芳基部分置于氮的远端. 在最优的反应条件下，各种 末端炔烃也被证明是可行的反应底物.

与 Scheme 58 所示的反应机理类似, 作者认为该反 应也是由阳极氧化生成 $\operatorname{Co}(\mathrm{III})$ 引发的. 羧酸钴盐辅助的 $\mathrm{C}$ - $\mathrm{H}$ 活化提供 $\mathrm{Co}$-酰胺络合物中间体，随后的烷基苯 基内炔的迁移插入生成七元 $\operatorname{Co}(\mathrm{III})$ 化合物 60-4. 随后还 原消除得到目标产物 60-3 并形成 $\operatorname{Co}(\mathrm{I})$ 物种. 其在阳极 上被氧化再生 $\mathrm{Co}(\mathrm{III})$. 

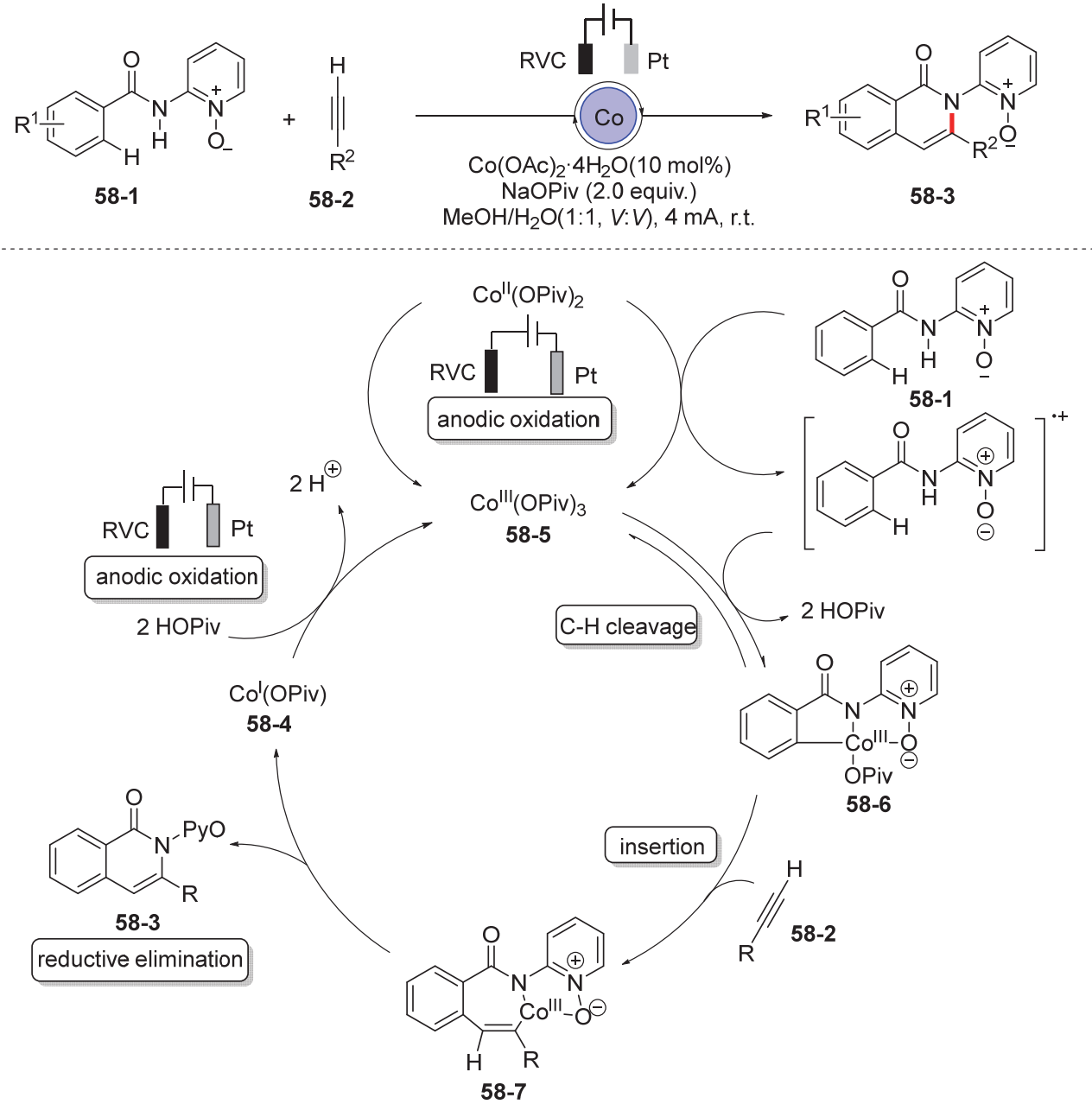

图式 58 钴催化的电化学 $\mathrm{C}-\mathrm{H} / \mathrm{N}-\mathrm{H}$ 活化

Scheme 58 Electrochemical $\mathrm{C}-\mathrm{H} / \mathrm{N}-\mathrm{H}$ activation by cobalt catalysis

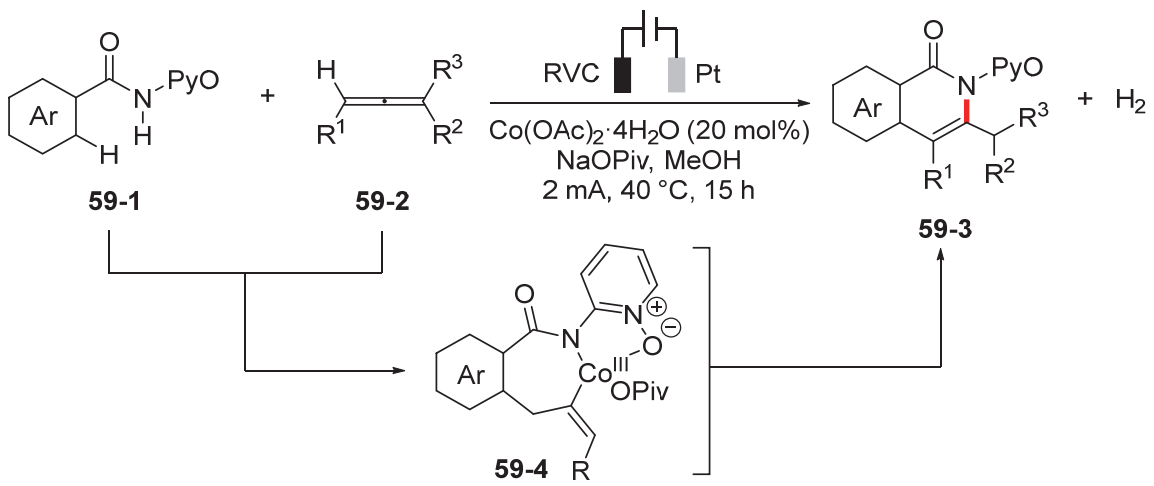

图式 59 钴催化的 C-H 活化实现联烯化合物的电化学氧化环化反应

Scheme 59 Cobalt-catalyzed electrooxidative $\mathrm{C}-\mathrm{H}$ activation for the allene annulations

在实现了吡啶肼基导向的电化学 $\mathrm{C}-\mathrm{H} / \mathrm{Het}-\mathrm{H}$ 官 能团化之后, 采用相似的电化学条件, 梅汝槐、 Ackermann 等[72]将单内炔拓展到更具有挑战性的 $1,3-二$ 炔(Scheme 61). 在 $60{ }^{\circ} \mathrm{C}$ 下, 使用配备有 RVC 阳极和铂 䇴阴极的单室电解池, 以 $\mathrm{Co}(\mathrm{OAc})_{2}$ 为催化剂, $\mathrm{TFE}$ 为溶 剂, $\mathrm{PivOH}$ 为添加剂, 在恒电流模式下电解, 苯甲酰肼
61-1 与 1,3-二炔 61-2 发生 $[4+2]$ 环化反应, 生成炔基取 代的异喹啉酮 61-3. 该反应具有优异的区域选择性，对 于两端为烷基和芳基取代的不对称 1,3-二炔底物, 烷基 端的炔发生环加成反应. 基于机理研究结果和先前相关 的报道，该反应也经历七元 $\mathrm{Co}(\mathrm{III})$ 物种 61-4. 


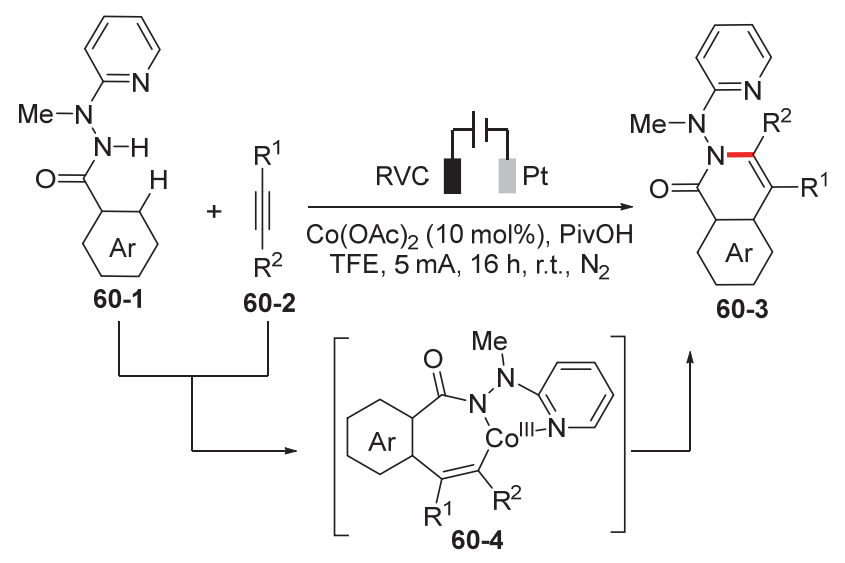

图式 60 钴催化内炔的电化学 $[4+2]$ 环化反应

Scheme 60 Electrochemically cobalt-catalyzed [4+2] annulations of internal alkynes

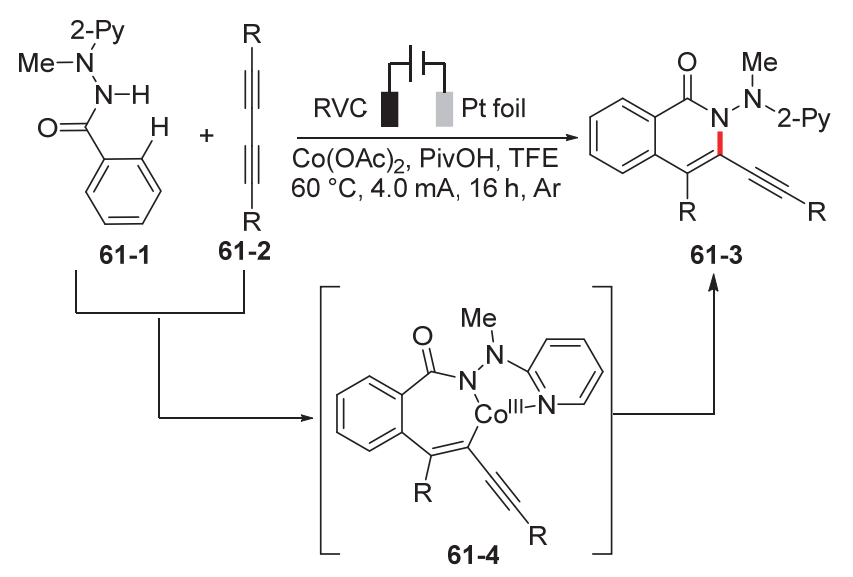

图式 61 钴-电催化 1,3-二炔的氧化 $\mathrm{C}-\mathrm{H}$ 环化反应

Scheme 61 Cobalt-catalyzed electrooxidative $\mathrm{C}-\mathrm{H}$ annulation with 1,3-diynes

流动电解池通过电解液的流动提升传质和传热速 率，配以高电极表面一反应容量比、电极间距较小的电解 池体系，具有减少电解质的使用、缩短反应时间、增加 工艺安全性、便于放大等优点. 采用流动电合成技术, 基于铑催化的 $\mathrm{C}-\mathrm{H}$ 活化策略, Ackermann 课题组 ${ }^{[73]}$ 实 现了亚氨酸酯与炔烃的 $[4+2]$ 环化反应(Scheme 62). 室 温下, $1 \mathrm{kPa} \mathrm{O}$ 氛围中, $\left(\mathrm{Cp}^{*} \mathrm{RhCl}_{2}\right)_{2}$ 为催化剂, $\mathrm{NaOPiv}$ 和 HOPiv 为添加剂, $\mathrm{MeOH}$ 为溶剂, 石墨毡为阳极, 泡沫 $\mathrm{Ni}$ 电极为阴极, 恒电位模式电解, 亚氨酸酯 62-1 与内炔 烃 62-2 在模块化流动电解池中反应, 得到一系列含吡 啶结构单元的稠环化合物 62-3. 分子氧可以促进催化活 性物种的再生，防止高活性铑中间体在阴极还原. 电化 学条件下, 以弱配位方式进行亚氨酸酯 $\mathrm{C}-\mathrm{H} / \mathrm{N}-\mathrm{H}$ 官 能团化, 反应具有较好的化学选择性. 机理研究表明反 应经历了一个快速的 $\mathrm{C}-\mathrm{H}$ 活化过程, 随后形成铑(III) 七元环状中间体 62-4、62-5; 铑(III) 七元环状中间体除 了可直接经历还原消除产生目标产物外，电化学氧化诱
导的还原消除途径也起着重要作用，铑(III)氧化到铑 (IV)时，还原消除更容易发生; 最后，通过阳极氧化来 实现具有催化活性羧酸铑(III)物种的再生.

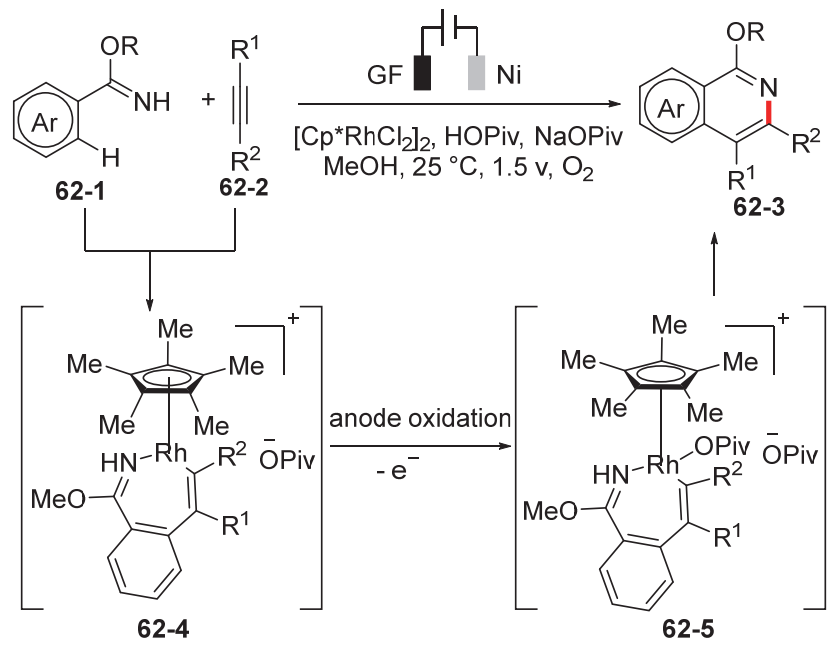

图式 62 流动电化学化学技术协同金属铑催化的 $\mathrm{C}-\mathrm{H}$ 环化 反应

Scheme 62 Rh-catalyzed $\mathrm{C}-\mathrm{H}$ annulation under electroflow conditions

过渡金属催化的氧化 $\mathrm{C}-\mathrm{H}$ 键活化/环化已经被证 明是合成多环芳烃的有效手段. 然而, 传统的 $\mathrm{C}-\mathrm{H}$ 键 活化方法通常需要使用化学计量的氧化剂(如铜盐或银 盐), 限制了该方法的应用. 采用金属催化和电化学合 成的组合策略, 可以避免化学氧化剂的使用. 最近, Ackermann 课题组和徐海超课题组发现一种新的催化机 制一阳极氧化诱导的还原消除，在铑催化的 $\mathrm{C}-\mathrm{N}$ 键 ${ }^{[73]}$ 和 $\mathrm{C}-\mathrm{P}$ 键 ${ }^{[74]}$ 形成过程中, 电流不仅起着末端氧化剂的 作用, 而且还表现出独特的阳极氧化诱导的还原消除作 用. 基于这个发现, 2020 年, Ackermann 课题组 ${ }^{[75]}$ 实现了 $O$-甲基偕胺肜与炔的多米诺环化反应 (Scheme 63). $35{ }^{\circ} \mathrm{C}$ 下, 以 $\left[\mathrm{Cp} * \mathrm{Rh}\left(\mathrm{CH}_{3} \mathrm{CN}\right)_{3}\right]\left(\mathrm{SbF}_{6}\right)_{2}$ 为催化剂, $\mathrm{KOAc}$ 为碱, 1 -金刚烷甲酸 $(\mathrm{AdOH})$ 为添加剂, 以石墨毡为阳极, Pt 为阴极, 在单室电解池中以恒电流模式电解, 一分子 芳基偕胺肜 63-1 与三分子二芳基炔 63-2 反应，一步构 建包含三个 $\mathrm{C}-\mathrm{N}$ 键在内的六个化学键, 得到氮杂多环 芳烃 63-3.

同年，徐海超课题组 ${ }^{[76]}$ 使用苯胺衍生物作为偶联 试剂, 开发了电化学条件下钉催化的苯胺衍生物与炔烃 的脱氢环化反应，并用于吲哚类化合物的合成(Scheme 64). 该方法使用 $\mathrm{RVC}$ 为阳极, $\mathrm{Pt}$ 片为阴极, 含 $20 \mathrm{~mol} \%$ $\mathrm{KPF}_{6}$ 和 $20 \mathrm{~mol} \% \mathrm{NaOAc}$ 的 $\mathrm{H}_{2} \mathrm{O} / \mathrm{PrOH}$ 为电解质溶液, $\left[\mathrm{RuCl}_{2} \text { (p-cymene) }\right]_{2}$ 为催化剂. 在单室电解池中, 以恒电 流模式电解 $N-2$-嘧啶取代苯胺 64-1 与二苯乙炔 64-2, 能 以优异的分离产率获得吲哚产物. 除了吲哚合成外，该 电化学条件下的 $\mathrm{Ru}$ 催化方法学也可用于苄胺与炔烃的 


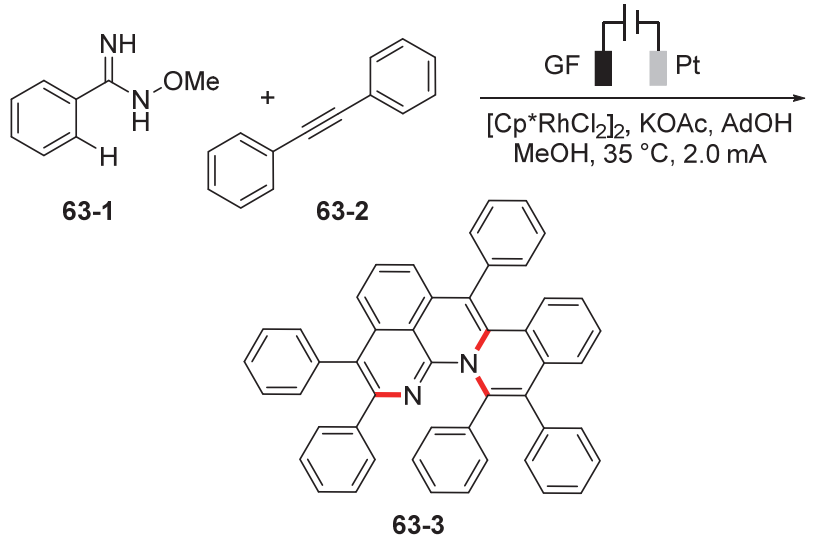

图式 63 电化学协同金属铑催化的多米诺 C-H 环化反应合 成氮杂多环芳烃

Scheme 63 Rh-catalyzed electrochemical synthesis of azananographene

[4+2]环化反应制备异喹啉化合物 64-3.

$\mathrm{H} / \mathrm{D}$ 交换实验表明苯胺衍生物中芳基 $\mathrm{C}-\mathrm{H}$ 键的活 化是可逆的. 在没有通电的情况下, 增加 $\mathrm{Ru}$ 催化剂的 量至 1 equiv., 也可获得目标产物. 机理实验结果表明电 流有助于再生活性钉催化剂, 而不影响催化循环的其他 步骤. 结合机理实验和相关报道, 作者提出了 $\mathrm{Ru}$ 催化
的电解环化反应机理. 首先, 在 $\mathrm{NaOAc}$ 存在下，催化剂 前体 $\mathrm{RuCl}_{2}(p$-cymene $\left.)\right]_{2}$ 转化为二醋酸钉配合物 64-4. 64-4 首先与 64-1 络合, 然后发生可逆的芳基 $\mathrm{C}-\mathrm{H}$ 键活 化生成六元钓环 64-6, 其乙酸配体随后被炔基 64-2 取代 得到中间体 64-7. 随后, $\mathrm{Ru}-\mathrm{C}$ 键对炔烃的加成生成六 元钕环中间体 64-8. 最后, 64-8 的还原消除生成吲哚产 物 64-3 和 $\mathrm{Ru}^{0}$ 物种, 后者在阳极上被氧化, 再生催化活 性的 $\mathrm{Ru}$ 络合物. 相应地, 质子在阴极上被还原产生 $\mathrm{H}_{2}$.

2019 年, 潘英明与唐海涛课题组 ${ }^{[77]}$ 利用双 $\mathrm{C}-\mathrm{H}$ 活 化策略, 开发了一种钉催化的无保护基团的苯甲酰胺与 炔烃电化学脱氢环化反应，并用于多环异喹啉酮的合成 中 (Scheme 65). 该合成策略使用电子作为氧化剂来循 环钉催化剂，有效避免了化学氧化剂的使用。该反应以 $\left[\mathrm{RuCl}_{2} \text { (p-cymene) }\right]_{2}$ 为催化剂, $\mathrm{NaOPiv}$ 为碱, $\mathrm{RVC}$ 为阳 极, $\mathrm{Pt}$ 片为阴极, ${ }^{n} \mathrm{Bu}_{4} \mathrm{NClO}_{4}$ 为电解质, ${ }^{i} \mathrm{PrOH} / \mathrm{H}_{2} \mathrm{O}$ 为溶 剂, 反应温度为 $100{ }^{\circ} \mathrm{C}$, 苯甲酰胺 65-1 与两分子的炔 65-2 在单室电解池中以恒电流模式电解, 能以优良的分 离产率获得多环异喹啉酮化合物 65-3. 与已报道的使用 强氧化剂的反应方法学相比，该方法的优势是能够在温 和的电解条件下进行，能显著提高反应的区域选择性.

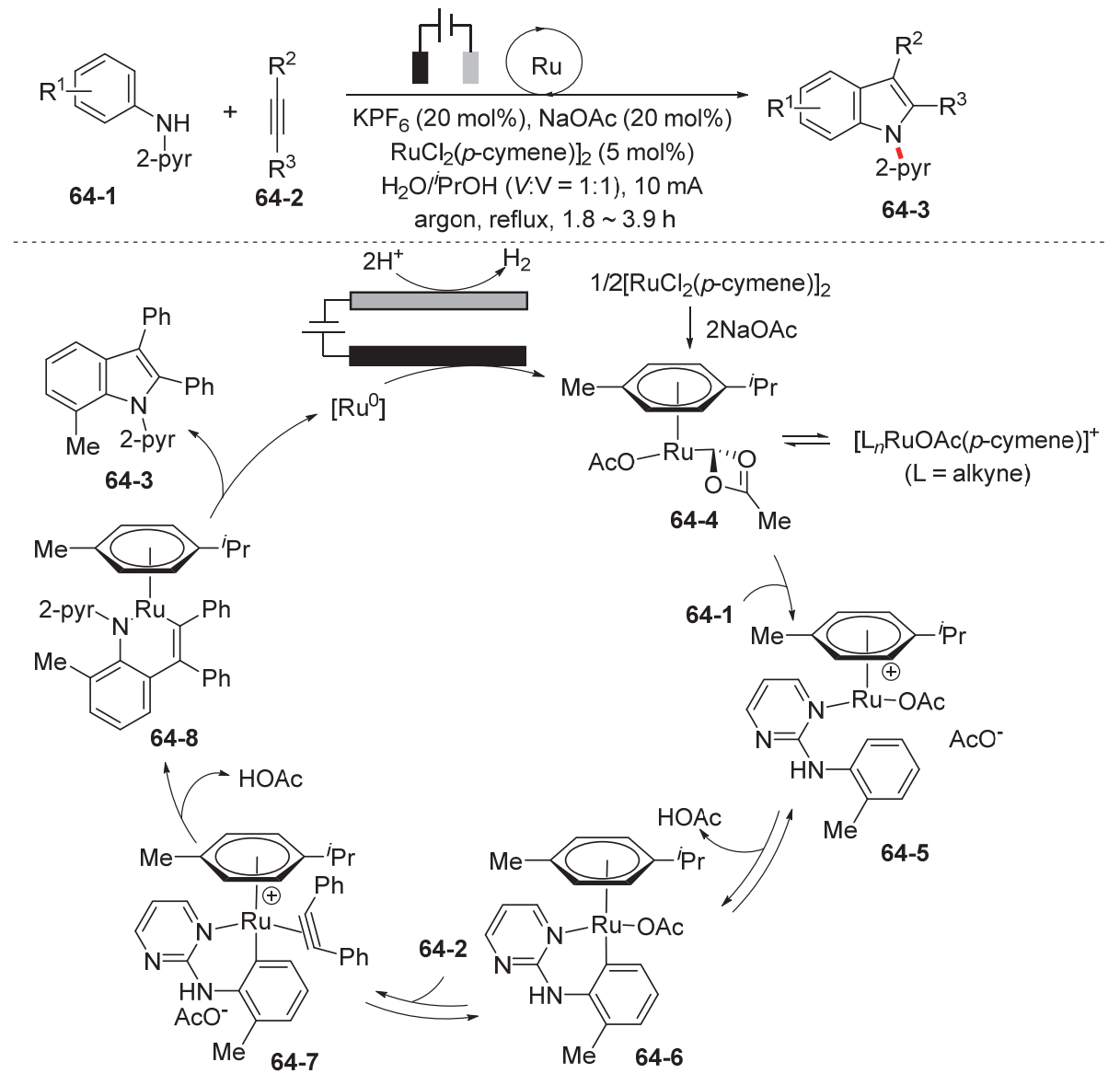

图式 64 钉催化的苯胺衍生物与炔烃的电化学脱氢环化反应

Scheme 64 Ruthenium-catalyzed electrochemical dehydrogenative annulation of anilines with alkynes 
作者进一步考察了异喹啉酮产物的抗肿瘤活性, 发现 65-5 的抗肿瘤活性优于 65-6. 基于控制实验结果、DFT 计算以及先前的研究报道, 作者提出了 $\mathrm{Ru}$ 催化的电化 学环化反应机理, 其与徐海超课题组提出的机理类 似 ${ }^{[76]}$.

内磺酰胺不仅是重要的合成子, 还是许多药物、和 生物活性分子的基本骨架. 近期, 以 8-氨基喹啉为导向 基团，雷爱文课题组 ${ }^{[78]}$ 报道了钴催化的磺胺类化合物 与炔烃的 $[4+2]$ 电化学环化反应, 为合成结构多样的内 磺酰胺化合物提供了一种绿色的方法, 且该方法可放大 至克级规模(Scheme 66). 该反应以 4-甲基- $N$-(喹啉-8基)苯磺酰胺 66-1 与苯乙炔 66-2 作为模型底物, 以 $\mathrm{Co}(\mathrm{OAc})_{2} \cdot 4 \mathrm{H}_{2} \mathrm{O}$ 作为催化剂, $\mathrm{NaOAc}$ 作为碱, $\mathrm{EtOH} /$ $\mathrm{HOAc}$ 的混合液作为溶剂, 在单室电解池中以 $4 \mathrm{~mA}$ 恒 流电解, 能够以 $80 \%$ 的收率获得目标产物 66-3. 当溶剂 换为 TFE/HOAc 时, 能够以 $85 \%$ 的收率获得目标产物. 考虑到 TFE 的价格比较昂贵, 作者最终选择 $\mathrm{EtOH} /$ HOAc 作为反应溶剂. 在最优的条件下, 作者进行了底 物拓展，发现不同取代基的苯乙炔和脂肪炔烃都可与 66-1 进行较好的电环化反应. 此外, 内炔(1-苯基丙炔) 也可兼容该反应条件. 作者接着探索了磺胺的适用范 围, 实验发现大多数的富电子及缺电子取代的磺胺化合 物的产率较低. 但是将工作电流减小到 $3 \mathrm{~mA}$ 或增大到 $5 \mathrm{~mA}$, 富电子和缺电子底物都可以较好地参与反应. 基 于循环伏安实验、控制实验及 EPR 实验结果, 作者认为
在 $\mathrm{C}-\mathrm{N}$ 键形成过程中可能经历了 $\mathrm{Co}(\mathrm{II}) / \mathrm{Co}(\mathrm{III}) / \mathrm{Co}(\mathrm{I})$ 催化循环, 66-4 为关键中间体.

$\mathrm{CO}$ 参与的氧化羰基化反应是制备羰基衍生物最具 原子经济性的方法之一, 然而以 $\mathrm{CO}$ 和 $\mathrm{O}_{2}$ 的混合气体作 为反应气面临爆炸极限范围广的问题，限制了该类反应 的工业应用. 2020 年, 雷爱文课题组 ${ }^{[79]}$ 开发了一种电化 学辅助下钯催化末端炔烃的氧化氨基羰基化反应 (Scheme 67). 室温下, 在 $101 \mathrm{kPa} \mathrm{CO}$ 氛围中, 以 $\mathrm{Et}_{4} \mathrm{~N}-$ $\mathrm{BF}_{4}$ 为电解质, $\mathrm{PdCl}_{2}$ 为催化剂, $\mathrm{P}(p \text {-tol })_{3}$ 为配体, $\mathrm{NEt}_{3}$ 为 碱, $\mathrm{MeCN} /{ }^{n} \mathrm{BuOH}$ 为溶剂, 碳纤维布为阳极, 铁片为阴 极, 在单室电解池中以恒电位模式电解, 苯乙炔 67-1、 环庚胺 67-2 与 CO 发生三组分偶联反应, 生成 $N$-环庚 基-3-苯基丙炔酰胺 67-3. 该反应具有反应条件温和、底 物适用性好、安全可靠、容易规模放大等优点.

循环伏安实验表明, $\mathrm{CO}$ 、正丁醇及膦配体均能影响 钯催化剂的氧化还原电位, 所有底物的氧化电位均高于 标准反应条件的电解电位，正丁醇及膦配体对抑制 $\operatorname{Pd}(\mathrm{II})$ 物种的过度还原起着重要作用. 在线红外(In-situ IR)实验表明 $\mathrm{C}-\mathrm{H}$ 键断裂过程并非反应的决速步骤，而 钯催化剂的浓度及阳极的表面积对反应的速率有影响, 显示阳极氧化的速率与反应的决速步骤存在相关性. 快 速扫描 X 射线吸收精细结构谱分析(QXAFS)实验表明 炔或胺的加入均会使钯催化剂的配位结构发生明显的 改变, 而在不电解的条件下, 钯催化剂可发生部分还原, 形成钯金属族或者钯纳米颗粒.
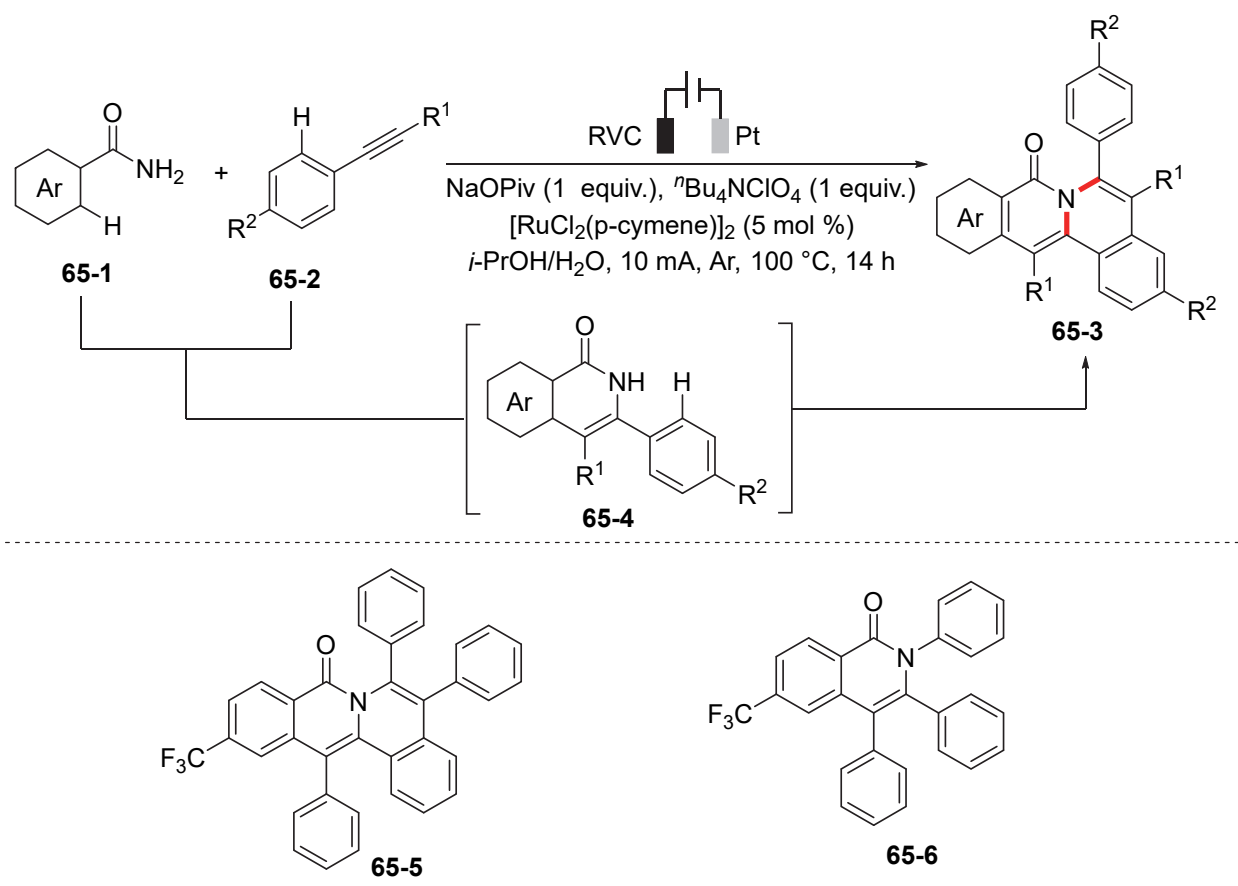

图式 65 酰胺和炔烃的电化学脱氢环化反应

Scheme 65 Electrochemically dehydrogenative annulation of amides with alkynes 


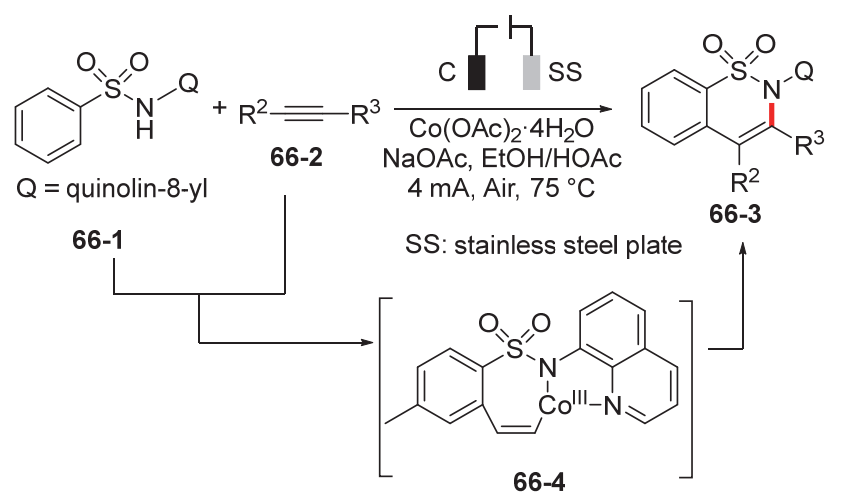

图式 66 钴催化的电化学 $[4+2]$ 环化反应

Scheme 66 Cobalt-catalyzed electrochemical $[4+2]$ annulation reaction
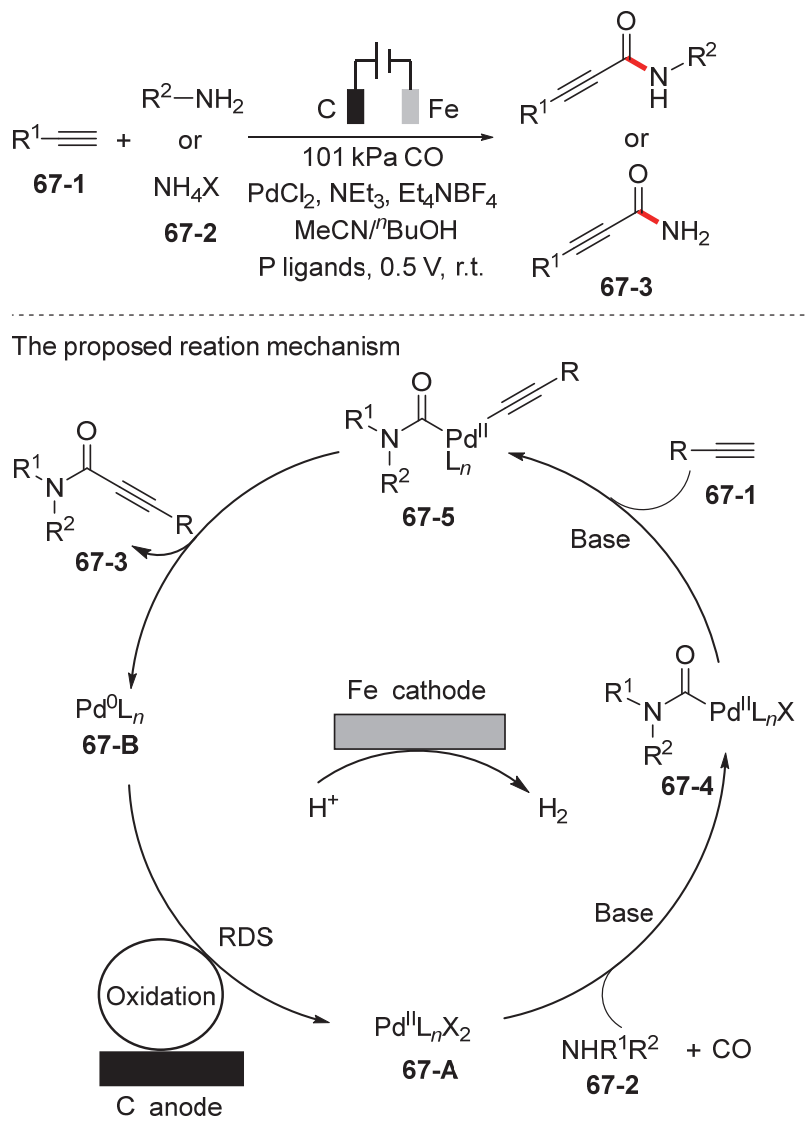

图式 67 末端炔烃的电化学氧化氨基羰基化反应

Scheme 67 Electrochemical oxidative aminocarbonylation of terminal alkynes

根据以上实验结果，作者提出了可能的反应机理. 在碱的作用下, 底物胺 67-2 与 $\operatorname{Pd}(\mathrm{II})$ 物种 67-A 中的过渡 金属中心配位，发生 CO 插入形成氨甲酰钯中间体 67-4; 末端炔烃 67-1 脱氢后与 67-4 中 Pd 过渡金属中心配位得 到 67-5; 67-5 发生还原消除后得到目标产物 67-3; 与此 同时生成 $\operatorname{Pd}(0)$ 物种 $67-\mathrm{B}$, 其经过电化学阳极氧化实现 $\operatorname{Pd}(\mathrm{II})$ 催化剂 67-A 的再生.

\section{4 结论与展望}

综上所述，电化学合成用于 $\mathrm{C}-\mathrm{N}$ 键的构建已得到 广泛的关注, 反应类型涵盖 $\mathrm{C}\left(\mathrm{sp}^{3}\right)-\mathrm{N}$ 键偶联, $\mathrm{C}\left(\mathrm{sp}^{2}\right)-$ $\mathrm{N}$ 键偶联以及 $\mathrm{C}(\mathrm{sp})-\mathrm{N}$ 键偶联反应. 和以往的合成方法 学相比, 电化学合成作为一种绿色合成手段在 $\mathrm{C}-\mathrm{N}$ 键 的合成中展示出其独特的优势: 反应条件温和、官能团 兼容性强, 无需外加氧化还原试剂、具有较好的原子经 济性. 尽管电化学合成 $\mathrm{C}-\mathrm{N}$ 键已获得较大的进展, 但 是该方面的研究依然存在一些局限性：首先, 电解反应 往往需要使用过量的支持电解质; 其次, 阴极往往使用 昂贵的铂电极利于析氢. 近年来一些研究表明, 流动化 学与有机电化学的组合能够有效降低电解质的用量. 因 此, 将流动化学与电化学合成相结合, 并用于 $\mathrm{C}-\mathrm{N}$ 键 的高效绿色合成是重要研究方向之一. 此外, 发展易于 析氢的电极材料也是电化学 $\mathrm{C}-\mathrm{N}$ 键合成的研究方向之

\section{References}

[1] Pozharskiı̆, A. F.; Katritzky, A. R., Heterocycles in Life and Society: An Introduction to Heterocyclic Chemistry, Biochemistry and Applications, 2nd ed., Wiley, United Kingdom, 2011.

[2] Novel Drug Approvals for 2019. Retrieved December 15, 2019 , from https://www.fda.gov/drugs/newdrugs-fda-cders-new-molecular-entities-and-new-therapeutic-biological-products/novel-drugapprovals-2019.

[3] Wermuth, C. The Practice of Medicinal Chemistry, Academic Press, USA, 2003.

[4] Hao, Z.; Iqbal, A. Chem. Soc. Rev. 1997, 26, p. 203.

[5] (a) Hartwig, J. F. Handbook of Organopalladium Chemistry for Organic Synthesis, John Wiley \& Sons Inc., USA, 2002, 1051.

(b) Sambiagio, C.; Marsden, S. P.; Blacker, A. J.; McGowan, P. C. Chem. Soc. Rev. 2014, 43, 3525.

(c) Ruiz-Castillo, P.; Buchwald, S. L. Chem. Rev. 2016, 116, 12564.

(d) Duan, X.; Liu, N.; Wang, J.; Ma, J. Chin. J. Org. Chem. 2019, 39, 661 (in Chinese).

(段希炎, 刘宁, 王佳, 马军营, 有机化学, 2019, 39, 661.)

[6] (a) Zhao, J.; Zhang, Q. Acta Chim. Sinica 2015, 73, 1235 (in Chinese).

(赵金钵, 张前, 王佳, 化学学报, 2015, 73, 1235.)

(b) Europe, P. Chem. Rev. 2016, 116, 12564.

(c) Baeten, M.; Maes, B. U. W. Adv. Organomet. Chem. 2017, 67, 401.

(d) Luo, J.; Wei, W. T. Adv. Synth. Catal. 2018, 360, 2076

(e) Wang, P.; Deng, L. Chin. J. Chem. 2018, 36, 1222.

(f) Liu, Q.; Lv, Y.; Bao, P.; Yue, H.; Wei, W. Chin. J. Org. Chem. 2020, 40, 4015 (in Chinese).

(刘启顺, 吕玉芬, 鲍鹏丽, 岳会兰, 魏伟, 有机化学, 2020, 40, 4015.)

(g) Hua, B.; Yang, Q.; Xiao, W. Chin. J. Org. Chem. 2020, 40, 3559 (in Chinese).

(华庭碧, 阳青青, 肖文精, 有机化学, 2020, 40, 3559.)

(h) Dong, K.; Liu, Q.; Wu, L.-Z. Acta Chim. Sinica 2020, 78, 299 (in Chinese).

(董奎, 刘强, 吴骊珠, 化学学报, 2020, 78, 299.)

[7] McElroy, C. R.; Constantinou, A.; Jones, L. C.; Summerton, L.; Clark, J. H. Green Chem. 2015, 17, 3111.

[8] Francke, R.; Little, R. D. Chem. Soc. Rev. 2014, 43, 2492. 
[9] (a) O'Brien, A. G.; Maruyama, A.; Inokuma, Y.; Fujita, M.; Baran, P. S.; Blackmond, D. G. Angew. Chem., Int. Ed. 2014, 53, 11868. (b) Horn, E. J.; Rosen, B. R.; Baran, P. S. ACS Cent. Sci. 2016, 2, 302.

(c) Dou, G. Y.; Jiang, Y. Y.; Xu, K.; Zeng, C. C. Org. Chem. Front. 2019, 6, 2392

(d) Jiang, Y.; Xu, K.; Zeng, C. C. CCS Chem. 2021, 3, 1911.

[10] (a) Yang, Q.-L.; Fang, P.; Mei, T.-S. Chin. J. Chem. 2018, 36, 338.

(b) Yuan, Y.; Lei, A. W. Acc. Chem. Res. 2019, 52, 3309.

(c) Ackermann, L. Acc. Chem. Res. 2020, 53, 84.

(d) Jiao, K.-J.; Xing, Y.-K.; Yang, Q.-L.; Qiu, H.; Mei, T.-S. Acc. Chem. Res. 2020, 53, 300

[11] (a) Jiang, Y. Y.; Xu, K.; Zeng, C. C. Chem. Rev. 2018, 118, 4485. (b) Ye, Z.; Zhang, F. Chin. J. Org. Chem. 2020, 40, 241 (in Chinese).

(叶增辉, 张逢质, 有机化学, 2020, 40, 241.)

(c) Lian, F.; Xu, K. Chin. J. Org. Chem. 2020, 40, 3490 (in Chinese).

(廉菲, 徐坤, 有机化学, 2020, 40, 3490.)

(d) Wang, X.; Xu, X.; Wang, Z.; Fang, P.; Mei, T. Chin. J. Org. Chem. 2020, 40, 3738 (in Chinese).

(王向阳, 徐学涛, 王振华, 方萍, 梅天胜, 有机化学, 2020, 40, 3738.)

(e) Cheng, X. Chin. J. Org. Chem. 2020, 40, 2600 (in Chinese). (程旭, 有机化学, 2020, 40, 2600.)

(f) Ma, H.; Mei, T. Chin. J. Org. Chem. 2020, 40, 3982 (in Chinese).

(马红星, 梅天胜, 有机化学, 2020, 40, 3982.)

(g) Hu, X.; Lei, A. Chin. J. Org. Chem. 2020, 40, 3471 (in Chinese)

(胡霞, 雷爱文, 有机化学, 2020, 40, 3471.)

[12] Qian, P.; Su, J.-H.; Wang, Y.; Bi, M.; Zha, Z.; Wang, Z. J. Org. Chem. 2017, 82, 6434.

[13] Herold, S.; Bafaluy, D.; Muñiz, K. Green Chem. 2018, 20, 3191.

[14] Hu, X.; Zhang, G.; Bu, F.; Nie, L.; Lei, A. ACS Catal. 2018, 8, 9370.

[15] Wang, H.; Shi, J.; Tan, J.; Xu, W.; Zhang, S.; Xu, K. Org. Lett. 2019, 21, 9430 .

[16] Xu, K.; Zhang, Z.; Qian, P.; Zha, Z.; Wang, Z. Chem. Commun. 2015, 51, 11108 .

[17] Li, Y.; Gao, H.; Zhang, Z.; Qian, P.; Bi, M.; Zha, Z.; Wang, Z. Chem. Commun. 2016, 52, 8600.

[18] Wu, J.; Zhou, Y.; Zhou, Y.; Chiang, C.-W.; Lei, A. ACS Catal. 2017, 7,8320 .

[19] Wan, Z.; Wang, D.; Yang, Z.; Zhang, H.; Wang, S.; Lei, A. Green Chem. 2020, 22, 3742.

[20] Lin, M.-Y.; Xu, K.; Jiang, Y.-Y.; Liu, Y.-G.; Sun, B.-G.; Zeng, C.-C. Adv. Synth. Catal. 2018, 360, 1665.

[21] Qian, P.; Yan, Z.; Zhou, Z.; Hu, K.; Wang, J.; Li, Z.; Zha, Z.; Wang, Z. Org. Lett. 2018, 20, 6359.

[22] Lian, F.; Sun, C.; Xu, K.; Zeng, C. Org. Lett. 2019, 21, 156.

[23] Wu, Z.-J.; Li, S.-R.; Xu, H.-C. Angew. Chem., Int. Ed. 2018, 57, 14070.

[24] Hu, K.; Qian, P.; Su, J.-H.; Li, Z.; Wang, J.; Zha, Z.; Wang, Z. J. Org. Chem. 2019, 84, 1647.

[25] Liu, K.; Song, C.; Wu, J.; Deng, Y.; Tang, S.; Lei, A. Green Chem. 2019, 21,765

[26] Feng, M.-L.; Li, S.-Q.; He, H.-Z.; Xi, L.-Y.; Chen, S.-Y.; Yu, X.-Q. Green Chem. 2019, 21, 1619.

[27] Sun, C. C.; Lian, F.; Xu, K.; Zeng, C. C.; Sun, B. G. Adv. Synth. Catal. 2019, 361, 4041.

[28] Hayashi, R.; Shimizu, A.; Song, Y.; Ashikari, Y.; Nokami, T.; Yoshida, J.-I. Chem.-Eur. J. 2017, 23, 61.

[29] Hou, Z.-W.; Liu, D.-J.; Xiong, P.; Lai, X.-L.; Song, J.; Xu, H.-C. Angew. Chem., Int. Ed. 2021, 60, 2943.
[30] Niu, L.; Jiang, C.; Liang, Y.; Liu, D.; Bu, F.; Shi, R.; Chen, H.; Chowdhury, A. D.; Lei, A. J. Am. Chem. Soc. 2020, 142, 17693.

[31] Zhu, L.; Xiong, P.; Mao, Z.-Y.; Wang, Y.-H.; Yan, X.; Lu, X.; Xu, H.-C. Angew. Chem., Int. Ed. 2016, 55, 2226.

[32] Folgueiras-Amador, A. A.; Philipps, K.; Guilbaud, S.; Poelakker, J.; Wirth, T. Angew. Chem., Int. Ed. 2017, 56, 15446.

[33] Xiong, P.; Xu, H.-H.; Xu, H.-C. J. Am. Chem. Soc. 2017, 139, 2956.

[34] Hou, Z. W.; Yan, H.; Song, J. S.; Xu, H. C. Chin. J. Chem. 2018, 36,909 .

[35] Long, H.; Song, J.; Xu, H.-C. Org. Chem. Front. 2018, 5, 3129.

[36] Zhao, H. B.; Hou, Z. W.; Liu, Z. J.; Zhou, Z. F.; Song, J.; Xu, H. C. Angew. Chem., Int. Ed. 2017, 56, 587.

[37] Zhao, H. B.; Xu, P.; Song, J.; Xu, H. C. Angew. Chem., Int. Ed. 2018, 57, 15153.

[38] Zhang, S.; Li, L.; Xue, M.; Zhang, R.; Xu, K.; Zeng, C. Org. Lett. 2018, 20, 3443.

[39] Liu, C.; Jiang, Q.; Lin, Y.; Fang, Z.; Guo, K. Org. Lett. 2020, 22, 795.

[40] Morofuji, T.; Shimizu, A.; Yoshida, J.-I. Chem.-Eur. J. 2015, 21, 3211.

[41] Zhao, H. B.; Liu, Z. J.; Song, J.; Xu, H. C. Angew. Chem., Int. Ed. 2017, 56, 12732

[42] Hu, K.; Zhang, Y.; Zhou, Z.; Yang, Y.; Zha, Z.; Wang, Z. Org. Lett. 2020, 22, 5773.

[43] Guo, S.; Liu, L.; Hu, K.; Sun, Q.; Zha, Z.; Yang, Y.; Wang, Z. Chin. Chem. Lett. 2021, 32, 1033.

[44] Chen, J.; Yan, W.-Q.; Lam, C. M.; Zeng, C.-C.; Hu, L.-M.; Little, R. D. Org. Lett. 2015, 17, 986.

[45] Li, K. J.; Xu, K.; Liu, Y. G.; Zeng, C. C.; Sun, B. G. Adv. Synth. Catal. 2019, 361, 1033.

[46] Hu, X.; Zhang, G.; Nie, L.; Kong, T.; Lei, A. Nat. Commun. 2019, 10, 5467.

[47] Wang, Q.; Wang, P.; Gao, X.; Wang, D.; Wang, S.; Liang, X.-A.; Wang, L.; Zhang, H.; Lei, A. Chem. Sci. 2020, 11, 2181.

[48] Ye, Z. H.; Ding, M. R.; Wu, Y. Q.; Li, Y.; Hua, W. K.; Zhang, F. Z. Green Chem. 2018, 20, 1732.

[49] Tang, S.; Wang, S.; Liu, Y.; Cong, H.; Lei, A. Angew. Chem., Int. Ed. 2018, 57, 4737.

[50] Song, C.; Liu, K.; Wang, Z.; Ding, B.; Wang, S.; Weng, Y.; Chiang, C.-W.; Lei, A. Chem. Sci. 2019, 10, 7982.

[51] Wesenberg, L. J.; Herold, S.; Shimizu, A.; Yoshida, J.-I.; Waldvogel, S. R. Chem.-Eur. J. 2017, 23, 12096.

[52] Zhang, Y.-Z.; Mo, Z.-Y.; Wang, H.-S.; Wen, X.-A.; Tang, H.-T.; Pan, Y.-M. Green Chem. 2019, 21, 3807.

[53] Wang, J.-H.; Lei, T.; Nan, X.-L.; Wu, H.-L.; Li, X.-B.; Chen, B.; Tung, C.-H.; Wu, L.-Z. Org. Lett. 2019, 21, 5581.

[54] Adeli, Y.; Huang, K.; Liang, Y.; Jiang, Y.; Liu, J.; Song, S.; Zeng, C.-C.; Jiao, N. ACS Catal. 2019, 9, 2063.

[55] Li, J.; Huang, W.; Chen, J.; He, L.; Cheng, X.; Li, G. Angew. Chem., Int. Ed. 2018, 57, 5695

[56] Cai, C.-Y.; Shu, X.-M.; Xu, H.-C. Nat. Commun. 2019, 10, 4953.

[57] Yu, Y.; Yuan, Y.; Liu, H.; He, M.; Yang, M.; Liu, P.; Yu, B.; Dong, X.; Lei, A. Chem. Commun. 2019, 55, 1809.

[58] Liu, K.; Tang, S.; Wu, T.; Wang, S.; Zou, M.; Cong, H.; Lei, A. Nat. Commun. 2019, 10, 639.

[59] Fu, N.; Sauer, G. S.; Saha, A.; Loo, A.; Lin, S. Science 2017, 357, 575.

[60] Gao, X.; Wang, P.; Zeng, L.; Tang, S.; Lei, A. J. Am. Chem. Soc. 2018, $140,4195$.

[61] Zhang, S.-K.; Samanta, R. C.; Sauermann, N.; Ackermann, L. Chem.-Eur. J. 2018, 24, 19166.

[62] Sauermann, N.; Mei, R.; Ackermann, L. Angew. Chem., Int. Ed. 
2018, 57, 5090.

[63] Kathiravan, S.; Suriyanarayanan, S.; Nicholls, I. A. Org. Lett. 2019, 21, 1968.

[64] Yang, Q.-L.; Wang, X.-Y.; Lu, J.-Y.; Zhang, L.-P.; Fang, P.; Mei, T.-S. J. Am. Chem. Soc. 2018, 140, 11487.

[65] Hou, Z. W.; Mao, Z. Y.; Zhao, H. B.; Melcamu, Y. Y.; Lu, X.; Song, J.; Xu, H. C. Angew. Chem., Int. Ed. 2016, 55, 9168.

[66] Hou, Z.-W.; Mao, Z.-Y.; Song, J.; Xu, H.-C. ACS Catal. 2017, 7, 5810 .

[67] Hou, Z.-W.; Mao, Z.-Y.; Melcamu, Y. Y.; Lu, X.; Xu, H.-C. Angew. Chem., Int. Ed. 2018, 57, 1636.

[68] Xu, F.; Long, H.; Song, J.; Xu, H.-C. Angew. Chem., Int. Ed. 2019, $58,9017$.

[69] Tian, C.; Massignan, L.; Meyer, T. H.; Ackermann, L. Angew. Chem., Int. Ed. 2018, 57, 2383.

[70] Meyer, T. H.; Oliveira, J. o. C.; Sau, S. C.; Ang, N. W.; Ackermann, L. ACS Catal. 2018, $8,9140$.

[71] Mei, R.; Sauermann, N.; Oliveira, J. O. C.; Ackermann, L. J. Am.
Chem. Soc. 2018, 140, 7913.

[72] Mei, R.; Ma, W.; Zhang, Y.; Guo, X.; Ackermann, L. Org. Lett. 2019, 21, 6534.

[73] Kong, W.-J.; Finger, L. H.; Messinis, A. M.; Kuniyil, R.; Oliveira, J. C. A.; Ackermann, L. J. Am. Chem. Soc. 2019, 141, 17198.

[74] Wu, Z.-J.; Su, F.; Lin, W.; Song, J.; Wen, T.-B.; Zhang, H.-J.; Xu, H.-C. Angew. Chem., Int. Ed. 2019, 58, 16770.

[75] Kong, W.-J.; Shen, Z.; Finger, L. H.; Ackermann, L. Angew. Chem., Int. Ed. 2020, 59, 5551.

[76] Xu, F.; Li, Y.-J.; Huang, C.; Xu, H.-C. ACS Catal. 2018, 8, 3820.

[77] Wang, Z.-Q.; Hou, C.; Zhong, Y.-F.; Lu, Y.-X.; Mo, Z.-Y.; Pan, Y.-M.; Tang, H.-T. Org. Lett. 2019, 21, 9841.

[78] Cao, Y.; Yuan, Y.; Lin, Y.; Jiang, X.; Weng, Y.; Wang, T.; Bu, F.; Zeng, L.; Lei, A. Green Chem. 2020, 22, 1548.

[79] Zeng, L.; Li, H.; Hu, J.; Zhang, D.; Hu, J.; Peng, P.; Wang, S.; Shi, R.; Peng, J.; Pao, C.-W.; Chen, J.-L.; Lee, J.-F.; Zhang, H.; Chen, Y.-H.; Lei, A. Nat. Catal. 2020, 3, 438. 